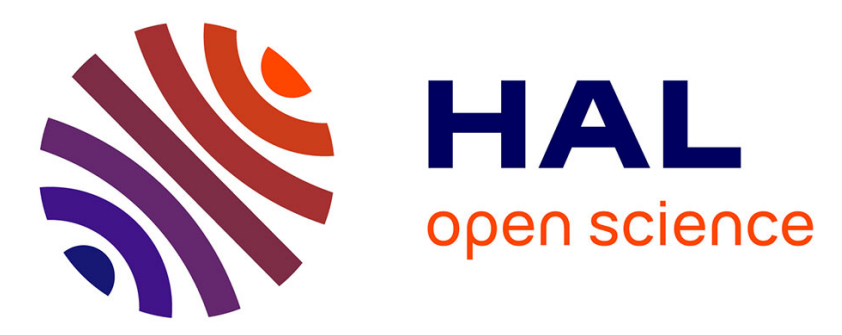

\title{
Sequence of infilling events in Gale Crater, Mars: Results from morphology, stratigraphy, and mineralogy
}

\author{
L. Le Deit, E. Hauber, F. Fueten, M Pondrelli, A. P Rossi, R. Jaumann
}

\section{To cite this version:}

L. Le Deit, E. Hauber, F. Fueten, M Pondrelli, A. P Rossi, et al.. Sequence of infilling events in Gale Crater, Mars: Results from morphology, stratigraphy, and mineralogy. Journal of Geophysical Research. Planets, 2013, 118, 10.1002/2012JE004322 . hal-02359919

\section{HAL Id: hal-02359919 https://hal.science/hal-02359919}

Submitted on 12 Nov 2019

HAL is a multi-disciplinary open access archive for the deposit and dissemination of scientific research documents, whether they are published or not. The documents may come from teaching and research institutions in France or abroad, or from public or private research centers.
L'archive ouverte pluridisciplinaire HAL, est destinée au dépôt et à la diffusion de documents scientifiques de niveau recherche, publiés ou non, émanant des établissements d'enseignement et de recherche français ou étrangers, des laboratoires publics ou privés. 


\title{
Sequence of infilling events in Gale Crater, Mars: Results from morphology, stratigraphy, and mineralogy
}

\author{
Laetitia Le Deit, ${ }^{1,2}$ Ernst Hauber, ${ }^{1}$ Frank Fueten, ${ }^{3}$ Monica Pondrelli, ${ }^{4}$ \\ Angelo Pio Rossi, ${ }^{5}$ and Ralf Jaumann ${ }^{1}$ \\ Received 20 December 2012; revised 24 October 2013; accepted 31 October 2013.
}

[1] Gale Crater is filled by sedimentary deposits including a mound of layered deposits, Aeolis Mons. Using orbital data, we mapped the crater infillings and measured their geometry to determine their origin. The sediment of Aeolis Mons is interpreted to be primarily air fall material such as dust, volcanic ash, fine-grained impact products, and possibly snow deposited by settling from the atmosphere, as well as wind-blown sands cemented in the crater center. Unconformity surfaces between the geological units are evidence for depositional hiatuses. Crater floor material deposited around Aeolis Mons and on the crater wall is interpreted to be alluvial and colluvial deposits. Morphologic evidence suggests that a shallow lake existed after the formation of the lowermost part of Aeolis Mons (the Small yardangs unit and the mass-wasting deposits). A suite of several features including patterned ground and possible rock glaciers are suggestive of periglacial processes with a permafrost environment after the first hundreds of thousands of years following its formation, dated to $\sim 3.61 \mathrm{Ga}$, in the Late Noachian/Early Hesperian.

Episodic melting of snow in the crater could have caused the formation of sulfates and clays in Aeolis Mons, the formation of rock glaciers and the incision of deep canyons and valleys along its flanks as well as on the crater wall and rim, and the formation of a lake in the deepest portions of Gale.

Citation: Le Deit, L., E. Hauber, F. Fueten, M. Pondrelli, A. P. Rossi, and R. Jaumann (2013), Sequence of infilling events in Gale Crater, Mars: Results from morphology, stratigraphy, and mineralogy, J. Geophys. Res. Planets, 118, doi:10.1002/ 2012JE004322.

\section{Introduction}

[2] Constraining the evolution of water reservoirs through time is crucial to understand the geological and climatic history of Mars. Many studies suggest that the surface water reservoir has been affected by a major change in the Late Noachian/Early Hesperian Epoch [e.g., Bibring et al., 2006]. Since then, surface water appears to have been limited with decreasing pluvial and fluvial activity [Fassett and Head, 2008] and a corresponding retreat of groundwater to greater depths [Andrews-Hanna and Lewis, 2011]. This hypothesis is supported by the evolution of the mineral species visible

\footnotetext{
${ }^{1}$ Institute of Planetary Research, German Aerospace Center, Berlin, Germany.

${ }^{2}$ Laboratoire de Planétologie et Géodynamique, LPG Nantes, CNRS UMR 6112, Université de Nantes, Nantes, France.

${ }^{3}$ Department of Earth Sciences, Brock University, St. Catharines, Ontario, Canada.

${ }^{4}$ International Research School of Planetary Sciences, Università d'Annunzio, Pescara, Italy.

${ }^{5}$ Department of Earth and Space Sciences, Jacobs University Bremen, Bremen, Germany.

Corresponding author: L. Le Deit, Laboratoire de Planétologie et Géodynamique, LPG Nantes, CNRS UMR 6112, Université de Nantes, 2 rue de la Houssinière, 44322 Nantes cedex 3, France.

(Laetitia.Ledeit@univ-nantes.fr)

(C)2013. American Geophysical Union. All Rights Reserved. 2169-9097/13/10.1002/2012JE004322
}

at the surface. The occurrence of thousands of phyllosilicaterich and chloride-rich outcrops attests to surface and nearsurface aqueous activity during early Mars [Poulet et al., 2005; Osterloo et al., 2010; Le Deit et al., 2012]. Sulfates are the dominant hydrated minerals from the Hesperian to the Amazonian epochs, from the equatorial latitudes [Gendrin et al., 2005] to the northern pole [Langevin et al., 2005; Massé et al., 2012]. Recently, the observation of seasonal recurrent slope lineae along steep equator-facing slopes at midlatitudes [McEwen et al., 2011] suggests that current aqueous activity is very limited at the surface. Hence, sedimentary formations and associated hydrated minerals contain a record of the environmental conditions prevailing during their formation. Understanding the geological environments existing during this Late Noachian/Early Hesperian transition will enable us to constrain this fundamental period of the Martian history.

[3] Gale Crater is a $150 \mathrm{~km}$ diameter impact crater filled by sedimentary deposits including a crescent-shaped mound of layered deposits, Aeolis Mons (informally also named Mount Sharp), up to $5 \mathrm{~km}$ high and $6000 \mathrm{~km}^{2}$ in area (Figures 1 and 2b-2d; Malin and Edgett, 2000], for which several origins have been proposed [e.g., Wray, 2012]. The past presence of water is indicated by the occurrence of many channels carved into the deposits and the crater rim, and by both phyllosilicates and sulfates detected at the base of the mound [Milliken et al., 2010; Thomson et al., 2011]. These characteristics suggest that Gale may have experienced favorable conditions to support 


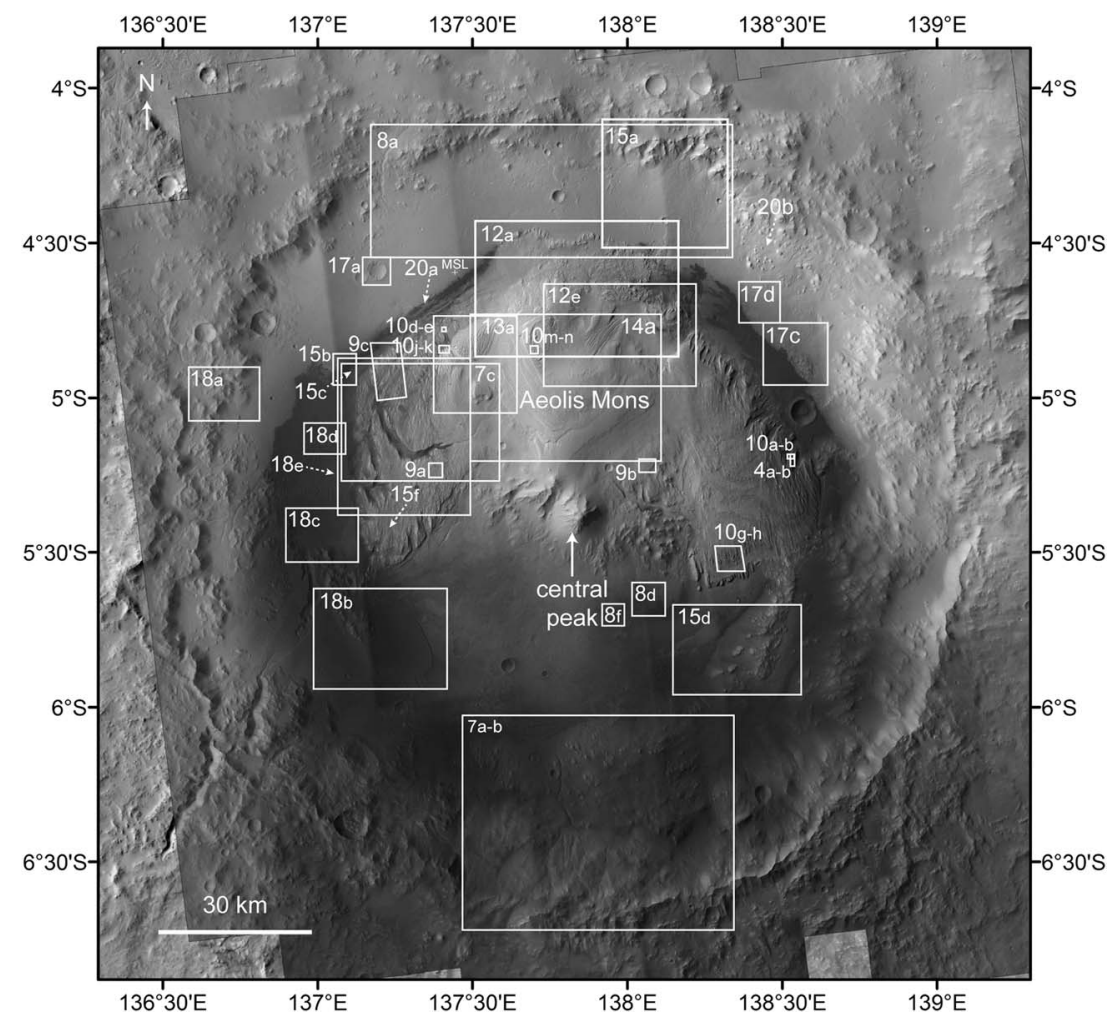

Figure 1. Mosaic of CTX images overlapping a mosaic of HRSC nadir panchromatic images of Gale Crater. Locations of other figures in the paper are indicated. The MSL landing site, "Bradbury Landing" is also reported.

life. All estimates of the age of Gale are consistent with a formation before the mid-Hesperian Epoch [Greeley and Guest, 1987]. Hence, Gale Crater is a site of high interest to understand the regional geological and climatic environment around the Late Noachian/Early Hesperian transition.

[4] The Mars Science Laboratory (MSL), Curiosity, has been investigating the crater on the ground since August 2012. Gale Crater was selected from a short list of four candidate landing sites, which remained after a comprehensive search for the scientifically most interesting and yet safe site to investigate the potential habitability of Mars [Grant et al., 2011]. While all the final four landing sites display layered sediments and alteration minerals (phyllosilicates), Gale was selected because of its geologic diversity, both in terms of morphology and mineralogy [Golombek et al., 2012]. The main target of MSL, which has a complex payload that includes a gas chromatograph-mass spectrometer and gas analyzer that will search for organic carbon, is Aeolis Mons [Grotzinger et al., 2012]. MSL will also investigate scientifically interesting targets along its traverse toward Aeolis Mons, and at the time of writing, the first results from the examination of rocks and soils are becoming available.

[5] Our objective is to reconstruct the paleoenvironments that existed within Gale and their evolution throughout time by determining the origin of the infilling materials using the available orbital data. First, we present the geological context of Gale and background from previous studies. Second, we provide age estimates of the crater formation and of the crater floor and produce a geologic map of Gale in order to characterize the distribution, the morphology, and the stratigraphy of its infill. We also measure the geometry of the layered deposits and discuss their possible origins. We investigate the possibility that a shallow lake existed in Gale at a time when at least some of the layered deposits had already formed. We also propose a geological scenario in which the region has been subject to a periglacial environment. Finally, a geological history of Gale is described.

\section{Geologic Context and Background}

[6] Gale Crater $\left(-5.4^{\circ} \mathrm{N}, 137.9^{\circ} \mathrm{E}\right)$ is located at the dichotomy boundary, with Terra Cimmeria to the south and Elysium Planitia to the north (Figures 1 and 2a). Gale is bordered to the east by outcrops of the lower member of the Medusae Fossae Formation (MFF) in Aeolis Mensae, Aeolis Planum, and Zephyria Planum [e.g., Greeley and Guest, 1987; Zimbelman, 2008; Zimbelman and Griffin, 2010]. The MFF corresponds to extensive light-toned and friable layered deposits that have been formed during the Amazonian Epoch [e.g., Scott and Tanaka, 1986; Malin and Edgett, 2000; Hynek et al., 2003]. Parts of the MFF may already have been present during the Hesperian Epoch [Kerber and Head, 2010; Zimbelman and Scheidt, 2012].

[7] Knowing the age of Gale is critical to determining a time constraint on the aqueous processes that existed after its formation. Using Mariner 9 and Viking data, Gale was mapped as a Noachian crater [Scott and Carr, 1978; Greeley and Guest, 1987]. Malin and Edgett [2000] also suggested that Gale Crater and other filled craters were formed during the Noachian because of their widespread exhumation. Because few valley networks dissected the crater rim, and based on stratigraphic relationships with fretted terrains to the north of 

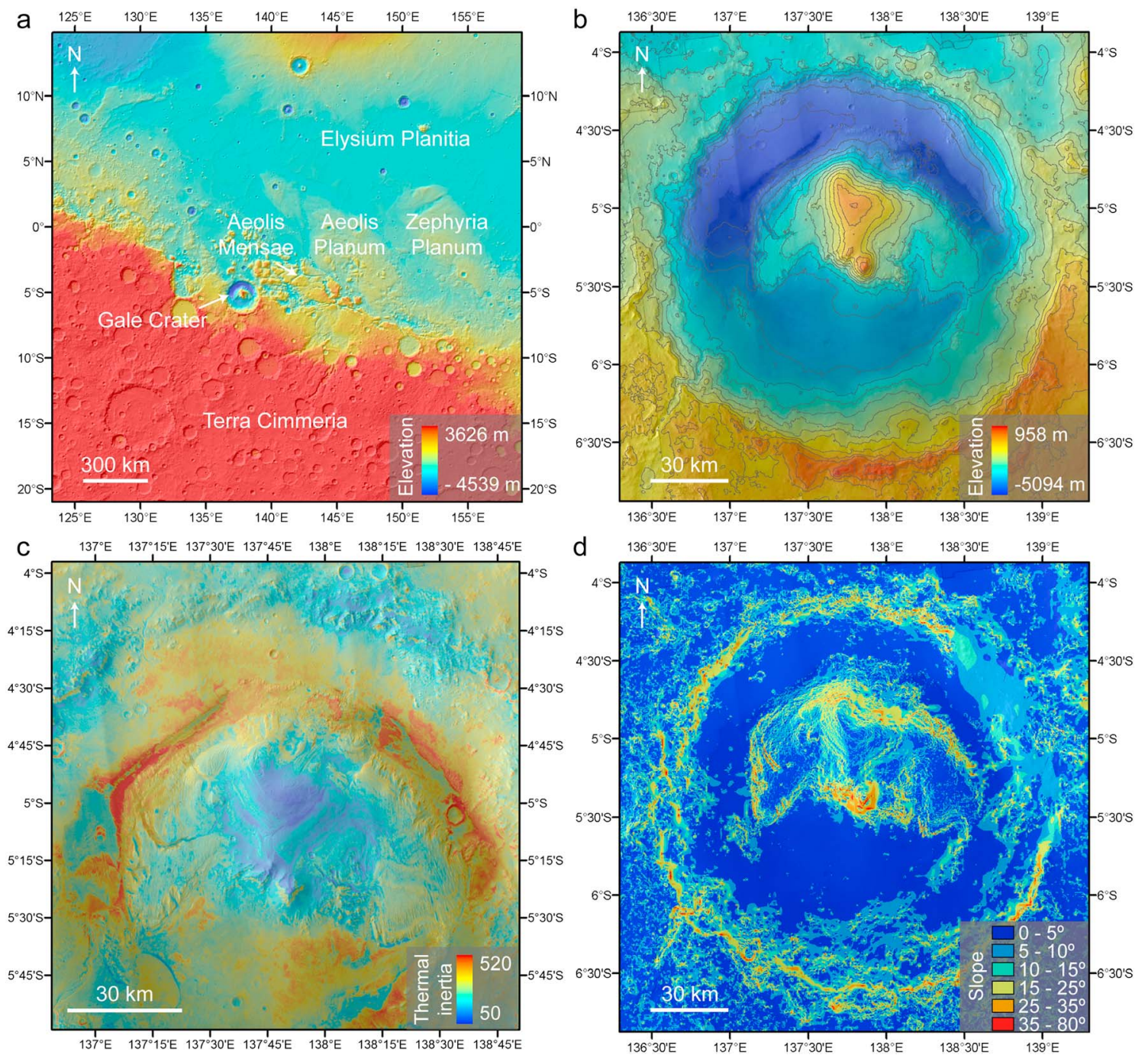

Figure 2. Location and physiography of Gale Crater. (a) MOLA digital elevation model at 128 pixels/deg overlapping a MOLA hillshade map (32 pixels/deg). (b) HRSC DEM at $50 \mathrm{~m} /$ pixel of Gale (elevation contours: $400 \mathrm{~m}$ ). (c) THEMIS qualitative thermal inertia map (in J.m ${ }^{-2} \cdot \mathrm{K}^{-1} \cdot \mathrm{s}^{-1 / 2}$, Fergason et al. [2006]) overlapping a mosaic of CTX images. (d) Slope map performed from the HRSC digital elevation model displayed in Figure 2b.

Gale, Irwin et al. [2005] suggested that the Gale impact occurred near the Noachian/Hesperian boundary after the Late Noachian decline of highland valley network activity and before the formation of the fretted terrains. Scott and Chapman [1995] estimated that Gale formed much later during the Amazonian. The most recent age determinations by crater counting based on Context Camera (CTX) and High Resolution Imaging Science Experiment (HiRISE) data suggest a formation age of Late Noachian/Early Hesperian [Thomson et al., 2011].

[8] The age of the central mound has been inferred to be Noachian to Amazonian [Greeley and Guest, 1987; Cabrol et al., 1999; Malin and Edgett, 2000; Thomson et al., 2011]. Using crater counts on the crater floor that postdates the base of the mound, Thomson et al. [2011] suggested that the basal layering of the mound can be no younger than Early Hesperian.

[9] Many possible origins have previously been proposed for the layered deposits of Aeolis Mons and its surrounding plains. In the context of regional mapping, the latter have been interpreted to be smooth-floor material of possibly aeolian, volcanic (lava flow), fluvial, or mass-wasting origin [Greeley and Guest, 1987; Scott and Chapman, 1995]. The layered deposits of Aeolis Mons were interpreted to be interbedded lava flows or sedimentary deposits of aeolian or fluvial origin by Greeley and Guest [1987], and probably ash-flow tuffs, largely unwelded, possibly pyroclastic, paleopolar, or aeolian material by Scott and Chapman [1995]. These layered deposits have also been interpreted to be lacustrine deposits [Cabrol et al., 1999; Malin and Edgett, 2000], spring deposits [Rossi et al., 2008], and ancient polar deposits made of aeolian dust plus ice [Schultz and Lutz, 1988]. This latest model has recently been reassessed by Niles and Michalski [2009], who suggested that the sedimentary deposits in Meridiani Planum and other sulfate-rich deposits on Mars would be the sublimation residue from large-scale deposits consisting of aeolian dust and ice. Sulfates would have been formed by acid weathering inside the ice when thin films of water, formed through radiant 

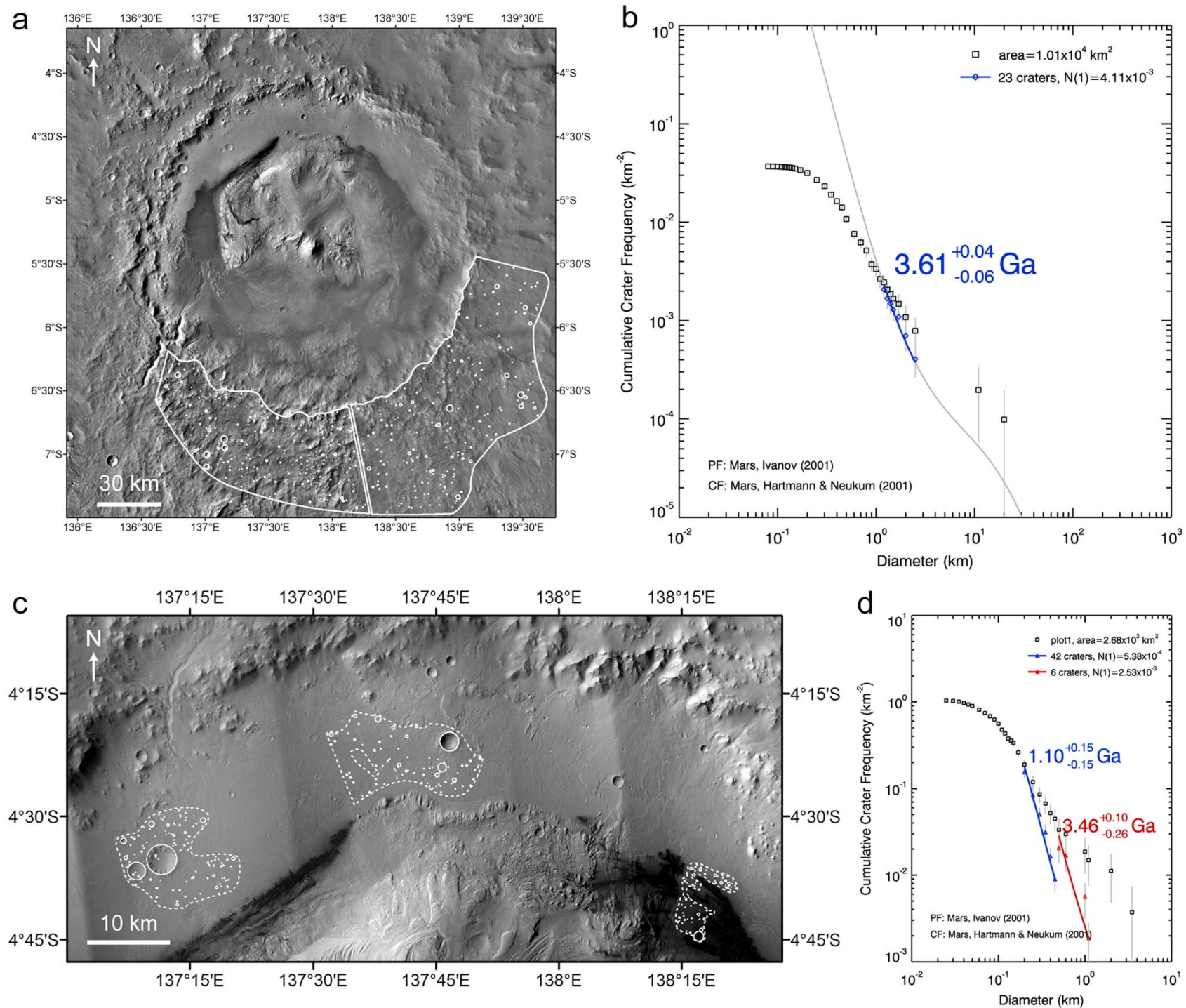

Figure 3. Age determination of Gale Crater and of the Cf1 units by crater counts. (a) Crater counted and the counting areas (in white) on the ejecta of the crater on a mosaic of HRSC nadir panchromatic images. (b) Crater size-frequency distribution including an inferred model age of the crater (in blue). The blue points are the cumulative crater frequencies excluding the two largest points, which correspond to craters that are older than the Gale ejecta. Only craters with more than $70 \mathrm{~m}$ were used for isochron fitting to avoid counting secondary craters [McEwen et al., 2005] and the possible physical effects of target material [Dundas et al., 2010]. (c) Crater counted and the counting areas (in white) on the Cf1 unit on a mosaic of CTX images. (d) Crater size-frequency distribution including inferred model ages of the base (red) and of the top of the Cfl unit (blue). The blue and red points are the cumulative crater frequencies excluding the three largest points, which correspond to craters that are older than the Cf1 unit. Similarly as for Figure $3 \mathrm{~d}$, craters $<70 \mathrm{~m}$ diameter were not used for data fitting.

heating, would have enabled the reaction between silicate material and sulfur-rich aerosols deposited from the atmosphere [Niles and Michalski, 2009]. This formation process of sulfates has been proposed to occur today in the northern Martian polar cap [Massé et al., 2012]. Andrews-Hanna et al. [2007, 2010] proposed a global groundwater model in which groundwater evaporation results in evaporite precipitation and cementation of aeolian sediments in regional topographic lows including Meridiani Planum, the northern lowlands, and large impact basins resulting in the formation of the layered sedimentary deposits observed in these locations. Recently, Andrews-
Hanna et al. [2012] also proposed that the sulfate-rich lower unit of Aeolis Mons in Gale corresponds to sulfate-cemented sedimentary deposits whose formation has been driven by groundwater flow sourced from a precipitation belt east of the Isidis basin. Thomson et al. [2011] concluded that the material of the mound (at least the lowest part) may have been deposited in a lacustrine environment (sourced from either groundwater or overland flow) or resulted from an aeolian deposition in a paleopolar or high obliquity environment. Kite et al. [2012] proposed a model in which aqueous cements are precipitated in sedimentary rocks on Mars and in Gale Crater via snowmelt 
Table 1. Names of the Geological Units Mapped in This Study Related to Those Mapped in Previous Studies According to Their Location in Gale ${ }^{\mathrm{a}}$

\begin{tabular}{|c|c|c|c|}
\hline This Study & Anderson and Bell [2010] & Thomson et al. [2011] & Milliken et al. [2010] \\
\hline \multicolumn{4}{|c|}{ Crater floor units } \\
\hline Fan-shaped deposits & - & - & - \\
\hline Crater floor units $2-4$ & Undivided material & - & - \\
\hline Crater floor unit 1 & $\begin{array}{l}\text { Mound skirting unit, Undivided } \\
\text { material }\end{array}$ & Lower mound marginal $1-2$ units & - \\
\hline Layered deposits & - & - & - \\
\hline \multicolumn{4}{|c|}{ Aeolis Mons units } \\
\hline Caprock unit & - & $\begin{array}{l}\text { Upper mound subdued layered } 2 \text { unit, } \\
\text { Upper mound mantled } 2 \text { unit }\end{array}$ & - \\
\hline Benched unit & Upper mound & Upper mound layered 1-2 units & Upper formation \\
\hline Small yardangs unit 2 & $\begin{array}{l}\text { Dark-toned layered yardangs, } \\
\text { Upper mound }\end{array}$ & $\begin{array}{l}\text { Upper mound subdued layered } 3 \text { unit, } \\
\text { Upper mound layered } 3 \text { unit, } \\
\text { Upper mound smooth plains } 1 \text { unit, } \\
\text { Lower mound eastern layered unit }\end{array}$ & Upper formation \\
\hline Coarse yardangs unit & Light-toned yardangs & Upper mound etched $1-3$ units & Upper formation \\
\hline Mass-wasting deposits & $\begin{array}{l}\text { Lobate features, Undivided } \\
\text { material }\end{array}$ & $\begin{array}{l}\text { Lower mound subdued knobby unit, } \\
\text { Upper mound subdued layered } 1 \text { unit, } \\
\text { Lower mound knobby unit, Lower mound mantled unit }\end{array}$ & - \\
\hline Small yardangs unit 1 & Dark-toned layered yardangs & $\begin{array}{c}\text { Lower mound 1-3 units, Lower mound subdued } 3 \text { unit, } \\
\text { Lower mound eastern layered unit, } \\
\text { Lower mound embayed unit, Upper mound layered etched unit, } \\
\text { Upper mound etched unit 4, Upper mound layered } 4 \text { unit }\end{array}$ & Lower formation \\
\hline Basement and slope deposits & - & $\begin{array}{l}\text { Upper mound mountainous unit, Upper mound chaotic unit, } \\
\text { Lower mound marginal } 3 \text { unit }\end{array}$ & - \\
\hline
\end{tabular}

${ }^{a}$ Major differences in unit boundaries and description often exist.

water. Schwenzer et al. [2012] suggested that Gale is partially filled by impact melt that would have pooled in an annular depression surrounding the central uplift. They also suggested that phyllosilicates, quartz, sulfates, and sulfides may have been formed by alteration and precipitation of sulfur-rich host rocks in a hydrothermal system that would have been active after the impact for several hundred thousands of years. Many authors noted the morphologic similarities between the MFF and the layered deposits of Aeolis Mons [Schultz and Lutz, 1988; Scott and Chapman, 1995; Zimbelman, 2008; Thomson et al., 2011]. Scott and Chapman [1995] mapped the latter as a part of the medium member of the MFF. Since the layered deposits of Gale display alternating resistant (cliff-forming) and friable (slope-forming) layers like the lower member formation of the MFF, Zimbelman and Griffin [2010] suggested that Gale layers may be the westernmost remnants of a previously more extended MFF. Many formation hypotheses have been suggested for the MFF including aeolian dust deposits, volcanic ash deposits possibly emplaced as multiple ignimbrite events, or paleopolar deposits [e.g., Scott and Tanaka, 1982; Schultz and Lutz, 1988; Bradley et al., 2002; Watters et al., 2007; Mandt et al., 2008].

\section{Methodology}

\subsection{Age Determination}

[10] We estimated model ages of the formation of Gale and of a crater floor unit by performing crater counts on High Resolution Stereo Camera (HRSC, 16-20 m/pixel) [Jaumann et al., 2007] and CTX ( 6 m/pixel) [Malin et al., 2007] images. Counting areas were mapped and craters were counted using the CraterTools extension for ArcGIS software [Kneissl et al., 2011] (Figure 3). Absolute model ages were determined using the software Craterstats [Michael and Neukum, 2010] applying the Mars production function of Ivanov [2001] and the chronology function of Hartmann and Neukum [2001].

[11] The formation age of Gale Crater has been estimated on the basis of crater counts on the ejecta of the crater. In contrast to Thomson et al. [2011], we determined the extent of the ejecta blanket by textural analysis of the crater surroundings instead of using a mathematical relation which estimates the extent of the ejecta from the size of the impact crater. Our approach aims to avoid counting craters which are actually not on the ejecta but on the basement. Thus, the area of the ejecta blanket appears smaller than determined in the previous study of Thomson et al. [2011]. We made crater counts on the ejecta located to the southeast of the crater (Figure 3a), which are best preserved from fluvial and aeolian degradation.

\subsection{Geologic Mapping}

[12] We based our geologic mapping on the analysis of visible and near-infrared images of the CTX and the HiRISE (25-32 cm/pixel, McEwen et al., 2007) instruments onboard the Mars Reconnaissance Orbiter. Topographic data were obtained from a HRSC gridded Digital Elevation Model (DEM) with a cell size of $50 \mathrm{~m}$ [Gwinner et al., 2010]. We processed a slope map using this HRSC DEM in ArcGIS (Figure 2d). The geological units and landforms have been defined according to their location, physical characteristics (i.e., elevation, slope, tone, stratification, and sedimentary structures), erosion patterns (i.e., yardangs, channels, and dunes), and mineralogical composition inferred from recent studies [i.e., Milliken et al., 2010; Thomson et al., 2011]. Gale Crater has been mapped in previous studies in which the geological units have also been distinguished primarily on the bases of their geomorphologic characteristics and/or mineralogical composition [Anderson and Bell, 2010; Milliken et al., 2010; Thomson et al., 2011]. Our approach 
Table 2. Layer Attitude and Thickness of Aeolis Mons ${ }^{\mathrm{a}}$

\begin{tabular}{lccrc}
\hline Unit/Site & Location & Mean Dip Value $( \pm \sigma)$ & Range of Layer Thickness & HiRISE Stereo Pair \\
\hline Small yardangs unit (eastern site) & $138.5^{\circ} \mathrm{E}, 5.2^{\circ} \mathrm{S}$ & $2.75^{\circ} \mathrm{N} \pm 0.89^{\circ}$ & $1.1-31 \mathrm{~m}$ & ESP_016375_1750 ESP_016520_1750 \\
Small yardangs unit (western site) & $137.4^{\circ} \mathrm{E},-4.8^{\circ} \mathrm{S}$ & $2.71^{\circ} \mathrm{NW} \pm 1.11^{\circ}$ & $0.4-17.3 \mathrm{~m}$ & PSP_009149_1750 PSP_009294_1750 \\
Small yardangs unit (southern site) & $138.3^{\circ} \mathrm{E}, 5.5^{\circ} \mathrm{S}$ & $3.1^{\circ} \mathrm{SE} \pm 1.20^{\circ}$ & $1.2-26.3 \mathrm{~m}$ & ESP_014186_1745 ESP_020410_1745 \\
Coarse yardangs unit & $137.4^{\circ} \mathrm{E}, 4.9^{\circ} \mathrm{S}$ & $8.5^{\circ} \mathrm{SW} \pm 0.71^{\circ}$ & $0.02-8.1 \mathrm{~m}$ & PSP_009149_1750 PSP_009294_1750 \\
Benched unit & $137.7^{\circ} \mathrm{E}, 4.9^{\circ} \mathrm{S}$ & $6.83^{\circ} \mathrm{NW} \pm 1.94^{\circ}$ & $0.01-5.8 \mathrm{~m}$ & PSP_008002_1750 PSP_009927_1750 $^{\circ}$ \\
\hline
\end{tabular}

${ }^{\mathrm{a}}$ The HiRISE stereo pair images used for processing the DEMs are indicated.

differs from the earlier work in that the stratigraphic consistency in space and time between these geological units has been checked by constructing interpretative cross sections through Gale based on topographic profiles drawn from the HRSC DEM. Also, our mapping has been made on the entire crater and is not limited to Aeolis Mons and the MSL landing site only.

[13] Based on this mapping, we distinguish geological units which differ from those of previous studies in terms of boundaries and description. Table 1 provides the names of the geological units described in this study as compared to those defined in previous studies.

\subsection{Geometric Measurements}

[14] Geometric measurements were based on HiRISE DEMs, which were derived from HiRISE stereo pair images using the NASA Ames Stereo Pipeline [Moratto et al., 2010; Broxton and Edwards, 2008]. HiRISE DEMs, which
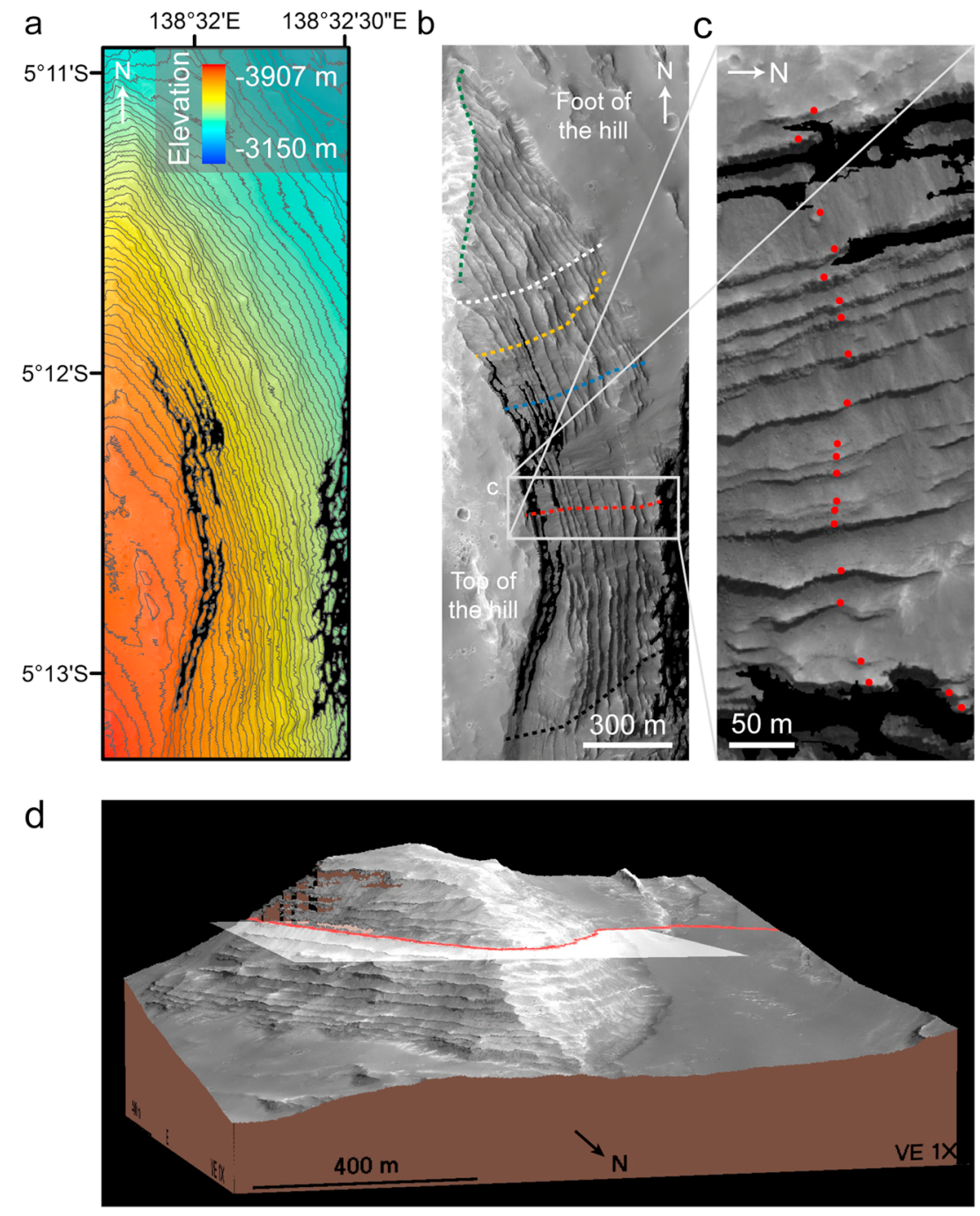

Figure 4. Example of geometric measurements of layer thickness and attitude of the Small yardangs unit 1 (eastern site). (a) Orthorectified HiRISE image (ESP_016375_1750) and its close-up view (Figure 4b) showing one of the six transects across the DEM for which we plotted each visible layer in order to measure its apparent thickness. Locations of Figures $4 \mathrm{a}$ and $4 \mathrm{~b}$ are indicated in Figure 1. (c) 3-D perspective view of the Small yardangs unit 1 outcrop shown in Figure 4a showing a plane fitting a layer used to measure of its attitude. 

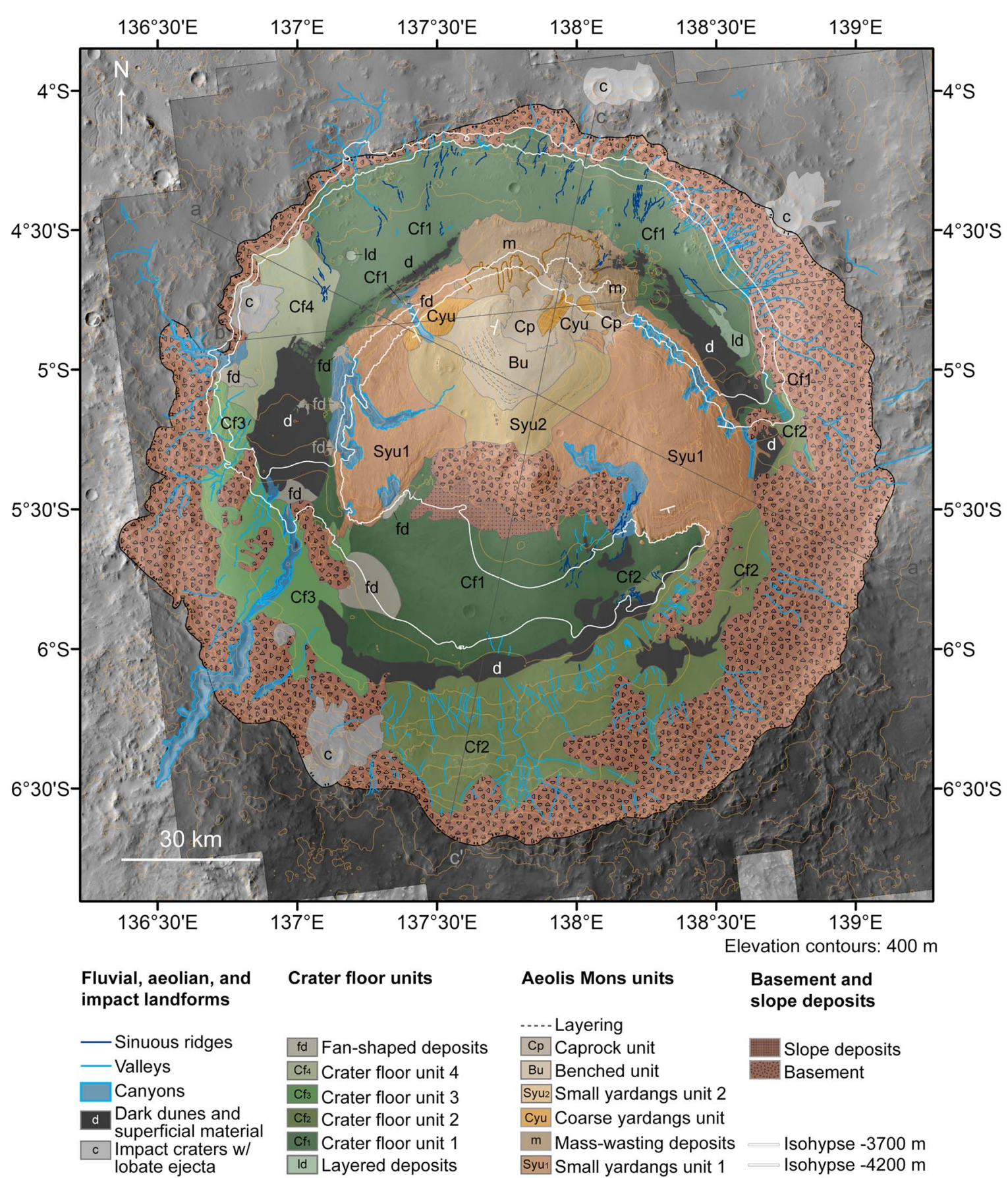

Aeolis Mons units

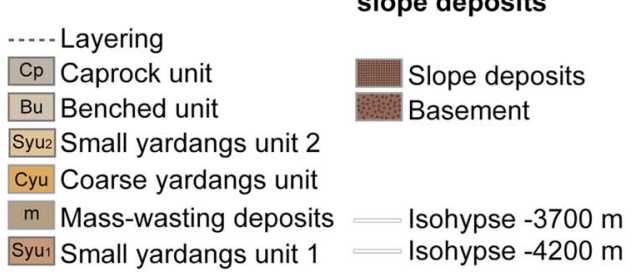

Figure 5. Geologic map of Gale Crater displayed on a mosaic of CTX images overlapping a mosaic of HRSC nadir panchromatic images. Locations of cross sections shown in Figure 12 are indicated.

can reach a spatial resolution of $\sim 1 \mathrm{~m} / \mathrm{pixel}$, have been subsampled (two cells, i.e., $\sim 50 \mathrm{~cm} / \mathrm{pixel}$ ) in order to optimize processing time versus desired resolution. The actual error in elevation from pixel to pixel, relevant for the thickness measurements, is estimated to be approximately $1 \mathrm{dm}$. The DEMs have been compared to HRSC and adjusted for constant offset. The locations of HiRISE subsampled DEMs and their corresponding stereo pair images are reported in Table 2.

[15] Layer thicknesses were calculated by plotting each visible layer on orthorectified HiRISE images along transects in the correspondent HiRISE DEMs using the software ArcGIS (Figures 4a-4c). As a result, we obtained the apparent thickness of layers or bundle of layers by calculating the difference in elevation between two data points. We considered that the apparent thickness of layers is roughly equivalent to the true thickness of layers since their dip is generally low $\left(<\sim 10^{\circ}\right)$.

[16] Layering attitudes were measured using the Orion software ( Pangaea Scientific) by fitting a plane to sample points individually placed along the exposed layering (Figure 4d). The methodology is discussed in detail by Fueten et al. 


\section{LE DEIT ET AL.: SEDIMENTARY INFILLING IN GALE CRATER}
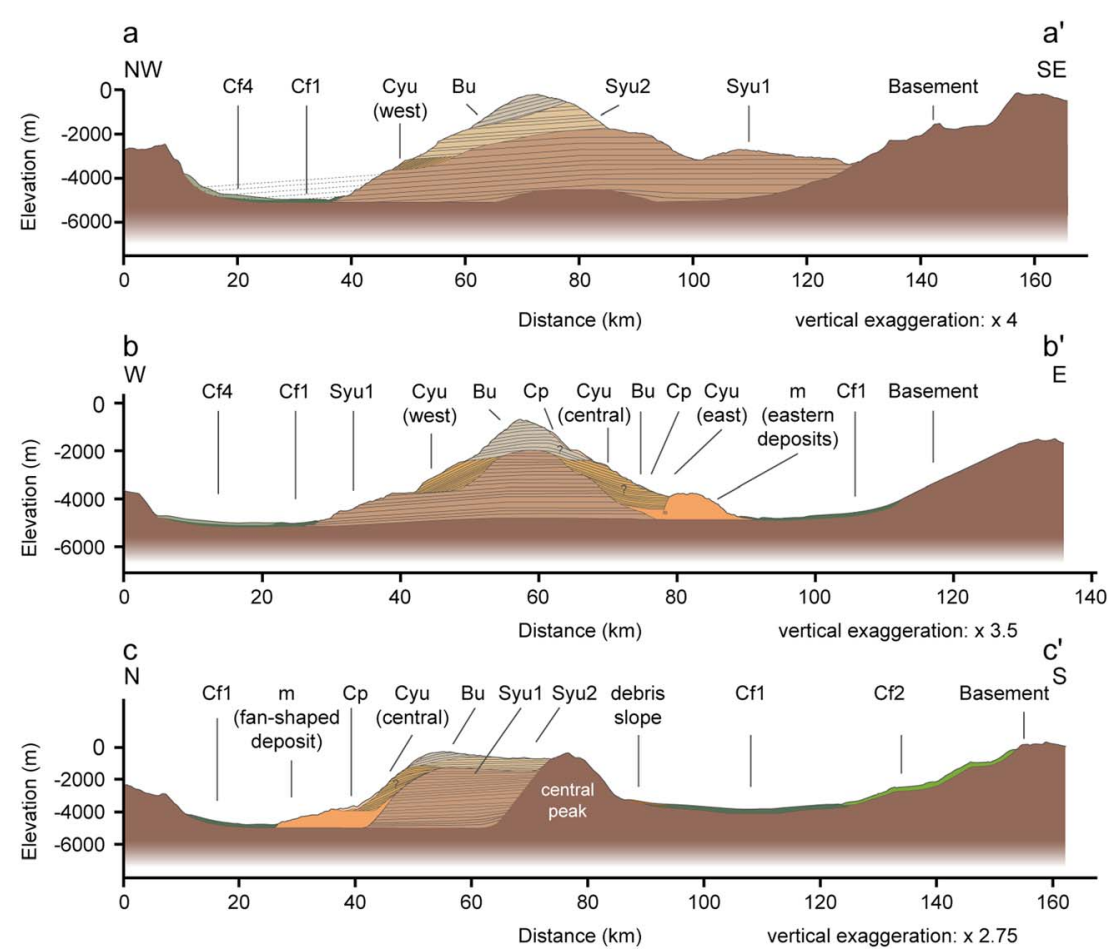

Figure 6. Interpretative cross sections based on HRSC topographic profiles. Their location is indicated in Figure 5. Valleys, sinuous ridges, dark dunes and superficial material, and layered deposits are not represented in the cross sections.

[2005a, 2005b]. For all displayed layer measurements, the dip error is less than the absolute dip value; hence, symbols indicate the true dip direction.

\section{Age of Gale Crater and of Its Infilling}

[17] To estimate the age of Gale Crater, we counted 375 craters on its ejecta, ranging from $88 \mathrm{~m}$ to $23 \mathrm{~km}$ diameter on a mosaic of HRSC nadir panchromatic images $(25 \mathrm{~m} /$ pixel). Two craters in the counting area $(>2.5 \mathrm{~km})$ have been filled by the ejecta and are therefore older. They were not used for deriving the crater model age of the ejecta. The estimated age of Gale formation is $\sim 3.61^{+0.04} /{ }_{-0.06} \mathrm{Ga}$, which corresponds to the Late Noachian according to the size-frequency distribution of Hartmann [Hartmann, 2005; Werner and Tanaka, 2011] (Figure 3b). Taking into account that the Late Noachian is ranging from $3.85 \mathrm{Ga}$ to $3.57 \mathrm{Ga}$ [Hartmann, 2005; Werner and Tanaka, 2011] and the uncertainties of the measurement, we estimate the age of the Gale impact to range between $\sim 3.55 \mathrm{Ga}$ and $\sim 3.65 \mathrm{Ga}$ and hence to be Late Noachian/Early Hesperian. This result is in agreement with Greeley and Guest [1987]. Thomson et al. [2011] found an older model age, ranging between $\sim 3.6 \mathrm{Ga}$ and $\sim 3.8 \mathrm{Ga}$, but also agreed on a Late Noachian/Early Hesperian age. Consequently, all sedimentary infill has been deposited in Gale since the Late Noachian/Early Hesperian period.

[18] Considering that the deposits of Aeolis Mons display yardangs and other erosion features, the estimated age of the deposits by crater counting probably corresponds to an exhumation age. Therefore, no crater counts on the layered deposits of the mound were produced in this study. In order to estimate the age of deposition of the crater fill, we performed crater counts on the northern crater floor unit (unit Cf1 hereafter). This unit displays many craters and appears well preserved, which suggests that reliable constraints can be obtained on its time of deposition by crater counts. We counted 104 craters ranging from $27 \mathrm{~m}$ and $3.6 \mathrm{~km}$ diameter distributed over three surfaces (Figure 3c). Three craters $(>2 \mathrm{~km})$, which have been embayed by the Cf1 unit, were not used for the age estimation of the Cfl unit. According to our measurements, the Cf1 unit would have been deposited at $\sim 3.46 \mathrm{Ga}$, during the Early Hesperian, which is $\sim 150 \mathrm{Myr}$ after the formation of Gale (Figure 3d). As demonstrated below, the onset of deposition of the lowermost parts of Aeolis Mons (Syu1) is earlier than this floor age (Cf1 unit), because the floor unit is stratigraphically higher. Consequently, the base of the mound was deposited during the Early Hesperian, in agreement with Thomson et al. [2011]. The size-frequency distribution curve indicates that the Cf1 unit has been resurfaced up to $\sim 1.10 \mathrm{Ga}$, which corresponds to the Amazonian (Figure 3d). This resurfacing is likely associated with the last fluvial activity registered on the Cf1 unit. This result suggests that some fluvial activity postdates the Late Noachian/Early Hesperian Epoch, as suggested by, for example, Hauber et al. [2013] for Xanthe Terra.

\section{Geologic Mapping Results}

[19] We defined four groups of geological units and landforms, which are (i) the basement and slope materials, (ii) the mound units, (iii) the crater floor units, and (iv) the fluvial, aeolian, and impact landforms (Figures 5 and 6). The basement corresponds to the Noachian terrain exposed by the impact along the crater rim and in the central peak of 
the crater. Slope deposits are colluvium, located at the foot of the central peak. The fluvial landforms, the Aeolis Mons units, and the crater floor units are described hereafter.

\subsection{Valleys, Canyons, and Sinuous Ridges}

[20] Few valleys are incised into the inner walls of the crater all around the crater (Figure 6). Linear to weakly sinuous, some of them are interconnected and form quasi-dendritic networks in plan view (Figures 6a and 6b). The valleys are $\mathrm{V}$ shaped in cross section and reach lengths of up to several tens of kilometers and minimum widths of $100 \mathrm{~m}$ and are exposed between -4950 and $50 \mathrm{~m}$ in elevation. Larger valleys of kilometer-scale, referred to as canyons, are carved into Aeolis Mons (Figures 5 and $6 \mathrm{c}$ ). A canyon of up to $4 \mathrm{~km}$ width is incised into the southwestern inner crater rim (Figure 5).

[21] Sinuous ridges (SR) are common landforms exposed on sedimentary deposits (crater floor units hereafter) that are superimposed on the inner walls and the crater floor of Gale. They typically display an orientation that is more or less parallel to the topographic gradient, suggesting a formation by a gravity-controlled process (Figure 7a). Their sinuosity appears highly variable, ranging from segments that are almost straight over distances of several kilometers to tight meanders in plan view (Figure 7a, inset A). The width of the ridges is typically a few tens of meters or less, although, at places, the ridges widen considerably before narrowing again (Figure 7a, inset B). The height is not resolved by HRSC DEM, but is estimated on the basis of shadow length measurements to be typically in the order of a few meters. The length of the ridges is highly variable, and many ridges that may once have been continuous appear now segmented by degradation processes. The reconstructed lengths, reflecting the original extent before segmentation, are commonly in the order of a few kilometers and rarely exceed $10 \mathrm{~km}$. The sinuous ridges are generally associated with cone-shaped fan-like deposits (Figure $7 \mathrm{~b}$ ). If the ridges are wide, their tops can be relatively flat (Figures $7 \mathrm{a}$ and $8 \mathrm{~d}$ ), but if they are narrow they are typically characterized by a distinct thin crest. Ridges can occur as singular features, but can also display a braided or anastomosing pattern (Figure 7c), which appears most commonly along the south facing (northern) inner wall of Gale Crater. In many cases, sinuous ridges are connected upslope to incised channels (Figure 7d). While in the case shown in Figure $7 \mathrm{~d}$ the transition from negative topography to positive topography does not seem to be controlled by topographic slope, most SR at the inner wall of Gale Crater originate at the sharp break in slope where the steep rim transitions to the gentler-sloping fan-like deposits which form a bajada along the entire inner northern crater wall. One set of sinuous ridges displays a distinctive texture at their flat tops. The flat tops of these ridges as well as the top of the delta-like deposit are characterized by a polygonal pattern (Figure $7 \mathrm{~g}$ ), which is notably absent from other flattopped ridges that are situated on the inner walls of Gale Crater. This set of ridges forms a distributary pattern on the base of the southern slopes of Aeolis Mons (Figure 7f). Several ridges are connected to a broad deposit which appears delta-like in plan view, which they enter from the north and extend from it in southward directions (Figure 7f).

\subsection{Aeolis Mons Units}

[22] Aeolis Mons is a mound of deposits located in the northern deeper part of the crater between $\sim 4900 \mathrm{~m}$ and $\sim 20 \mathrm{~m}$. The elevation of its summit exceeds that of the northwestern crater rim by $\sim 2.5 \mathrm{~km}$. Five geological units have been defined within Aeolis Mons: the Small yardangs unit (Syu), the mass-wasting deposits (m), the Coarse yardangs unit $(\mathrm{Cyu})$, the Benched unit $(\mathrm{Bu})$, and the Caprock unit (Cp, Figure 5). The Small yardangs unit has been divided into two members: the Small yardangs unit 1 (Syu1, section 5.2.1) and the Small yardangs unit 2 (Syu2, section 5.2.4).

\subsubsection{Small Yardangs Unit 1}

[23] The Syu1 is located at the base of the mound in contact with the crater basement. Mainly exposed between $-4900 \mathrm{~m}$ and $-1800 \mathrm{~m}$, the Syu 1 is the most voluminous unit of Aeolis Mons, with an estimated maximum thickness of $\sim 3 \mathrm{~km}$ (taking into account the presence of the central peak of the crater, Figures 5 and 6). The unit is moderate- to dark-toned at small scale and displays gentle topographic slopes (generally $<20^{\circ}$, Figure $2 \mathrm{~d}$ ), which are locally eroded into small yardangs that are tens to hundreds meters wide and hundreds of meters to kilometers long (Figures 9a and 9b). According to their size, these elongated yardangs would be called megayardangs on Earth [Hagedorn, 1968]. We refer to them as small yardangs compared to those observed on the Coarse yardangs unit, which display a different form. The long axes of yardangs indicate the direction of the dominant winds, which is roughly north-south in Gale. Yardangs are mainly shaped by abrasion and deflation processes [McCauley et al., 1979], with slight modifications possibly caused by water erosion [Laity, 1994]. These erosion features indicate that the Syul consists of a cohesive material such as sandstones. The Syu1 is incised by canyons in the western, eastern, and southern part of the mound, which suggests that the unit has been intensively eroded by fluvial processes after and perhaps during its deposition (Figures 5 and $6 \mathrm{c}$ ).

[24] The Syu1 is composed of light-toned and darker-toned layers, which differ in composition and are visible at large scale (Figures 9c and 9d). Based on the analysis of Compact Reconnaissance Imaging Spectrometer for Mars (CRISM) data, Milliken et al. [2010] showed that the stratigraphically and topographically lowest, light-toned layers of the Syu1, which crop out to the northwest of the unit, contain monohydrated and polyhydrated sulfates. The lack of a strong ferrous iron signature in the sulfate spectra suggest they likely correspond to $\mathrm{Mg}$ sulfates. The monohydrated sulfate likely corresponds to kieserite. Darker-toned clay-rich layers (iron smectite) are located in the upper part of this sulfate-rich lower member [Milliken et al., 2010]. Stratigraphically above the lower member, the moderate-toned middle member contains a mixture of sulfates and minor clays; the spatial resolution of CRISM not allowing discrimination between sulfate-cemented clays and alternating sulfate and clay-rich layers [Milliken et al., 2010]. Finally, the upper member corresponds to light-toned and moderate-toned layers containing monohydrated and polyhydrated sulfates [Milliken et al., 2010]. Polygonal networks are observed at the surface of the upper member in the western part of the mound, especially along benches (Figures $9 \mathrm{e}$ and 9f). Eroded surfaces reveal that these polygonal networks correspond to polygonal ridges exhumed by erosion. These erosion-resistant ridges may correspond to filled or cemented fractures as suggested by Thomson and Bridges [2008] and Anderson and Bell [2010]. Similar features in layered sediments in Candor Chasma have been attributed to alteration fluids flowing along fractures [Okubo and McEwen, 2007]. 

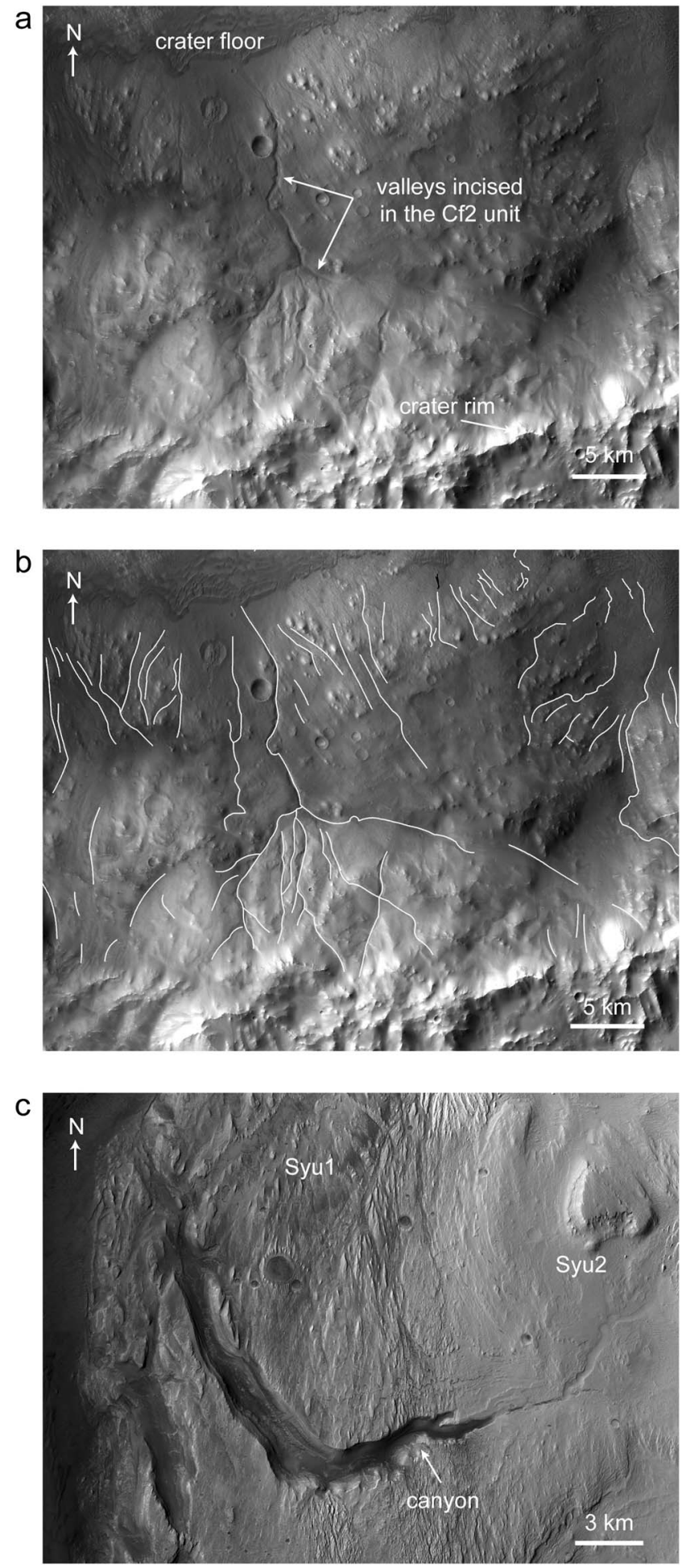

Figure 7. Valleys and canyons in Gale Crater. (a) Valley systems incised into the southern crater wall. (b) Representation of Figure 6a. (c) Canyon up to $400 \mathrm{~m}$ deep and $2.5 \mathrm{~km}$ wide carved into the western flank of Aeolis Mons. Mosaic of CTX images. Locations of Figures $6 \mathrm{a}-6 \mathrm{c}$ are indicated in Figure 1.

The presence of filled fractures in sulfate and clay-rich material is consistent with the alteration of unit Syu1 by fluids.

[25] Layer attitude and thickness were measured at exposures of Syul in the East, the West, and the South of Aeolis
Mons (Figures 10a-10i and 11). The location, the mean dip value, and the range of layer thicknesses for each measurement site are reported in Table 2 . The layer dips are very low $\left(<3^{\circ}\right.$ on average) and are ranging between $1-4^{\circ} \mathrm{N}, 2-5^{\circ} \mathrm{NW}$, and $2-5^{\circ} \mathrm{SE}$ for the eastern, western, and southern sites, respectively. The layers are subparallel and dip toward different directions dependent on their location, which could be consistent with the Syul layers dipping in a direction parallel to the basement dip direction inferred from the typical topography of a crater with a central peak (Figure 12). The layer thickness is consistent between the measurement sites and is ranging mainly between $<1 \mathrm{~m}$ and $\sim 30 \mathrm{~m}$. The high thickness values $(>50 \mathrm{~m})$ measured at the eastern site are due to a gap in the HiRISE DEM and are not taken into consideration. The layer thickness is not regular and does not exhibit any obvious cyclicity. However, the measurements reveal a general trend of thickening of the layers upward.

\subsubsection{Mass-Wasting Deposits}

[26] The northern side of Aeolis Mons corresponds to extensive mass-wasting deposits (Figures 5 and 12c). They lie on the crater floor up to $10 \mathrm{~km}$ from the base of the mound over a distance of $40 \mathrm{~km}$ along the mound and cover the mound flank up to an elevation of $-2100 \mathrm{~m}$. The masswasting deposits may be divided into four types. The lowest deposits display a smooth to rugged surface texture and are nearly flat-lying deposits located on the crater floor at the base of the mound (Figures 13a-13d). The toe of the lowest deposits exhibits hills with a height of up to $100 \mathrm{~m}$ (Figure 13d). The crater floor unit 1 (Cf1) is lying stratigraphically above the lowest deposits, which implies that the lowest deposits were formed before the deposition of the Cf1 unit (Figure 13d).

[27] The second type, lobate deposits, form tongues that are each 1 to $1.5 \mathrm{~km}$ wide and up to $\sim 100 \mathrm{~m}$ thick, lying along the flank of Aeolis Mons on slopes ranging between $12^{\circ}$ and $18^{\circ}$ (Figures 13a-13c, and 13e). They are located topographically and stratigraphically above the lowest deposits. The western part of the lobate deposits covers the Syu1, and they are themselves overlain by the westernmost Cyu outcrop (Figure 13c) and by the Bu (Figures $13 \mathrm{~b}$ and 13e). This suggests that the lobate deposits formed after the deposition of the Syu 1 and the lowest deposits, and before the deposition of the Cyu and the $\mathrm{Bu}$. No boulder or any rugged texture is visible at the surface of these lobate features, the orientation of which is parallel to the one of the steepest slope. No scarp or surface rupture is visible uphill, but these could have probably been buried below the Cyu and the $\mathrm{Bu}$.

[28] To the east of the lobate deposits, some fan-shaped deposits of $11 \mathrm{~km}$ in diameter and up to $200 \mathrm{~m}$ thick are lying stratigraphically above the lowest deposits (Figures 13a, $13 \mathrm{~b}$, and 13f). They display a very rugged surface texture and are located at the outlet of a valley, which probably corresponds to the main pathway of the transported material. Some transverse cracks are visible on the fan-shaped deposits that have probably been formed during the mass movement (Figure 13f).

[29] The fourth type of mass-wasting deposits, the eastern deposits, is accumulated downslope of the Syul outcrop, at an elevation between $-4800 \mathrm{~m}$ and $-3750 \mathrm{~m}$ (Figures 13a and 13b). They mainly display a chaotic surface texture, but one finely layered outcrop, which likely corresponds to the Syu1, has been locally preserved (Figure 13g). The eastern 


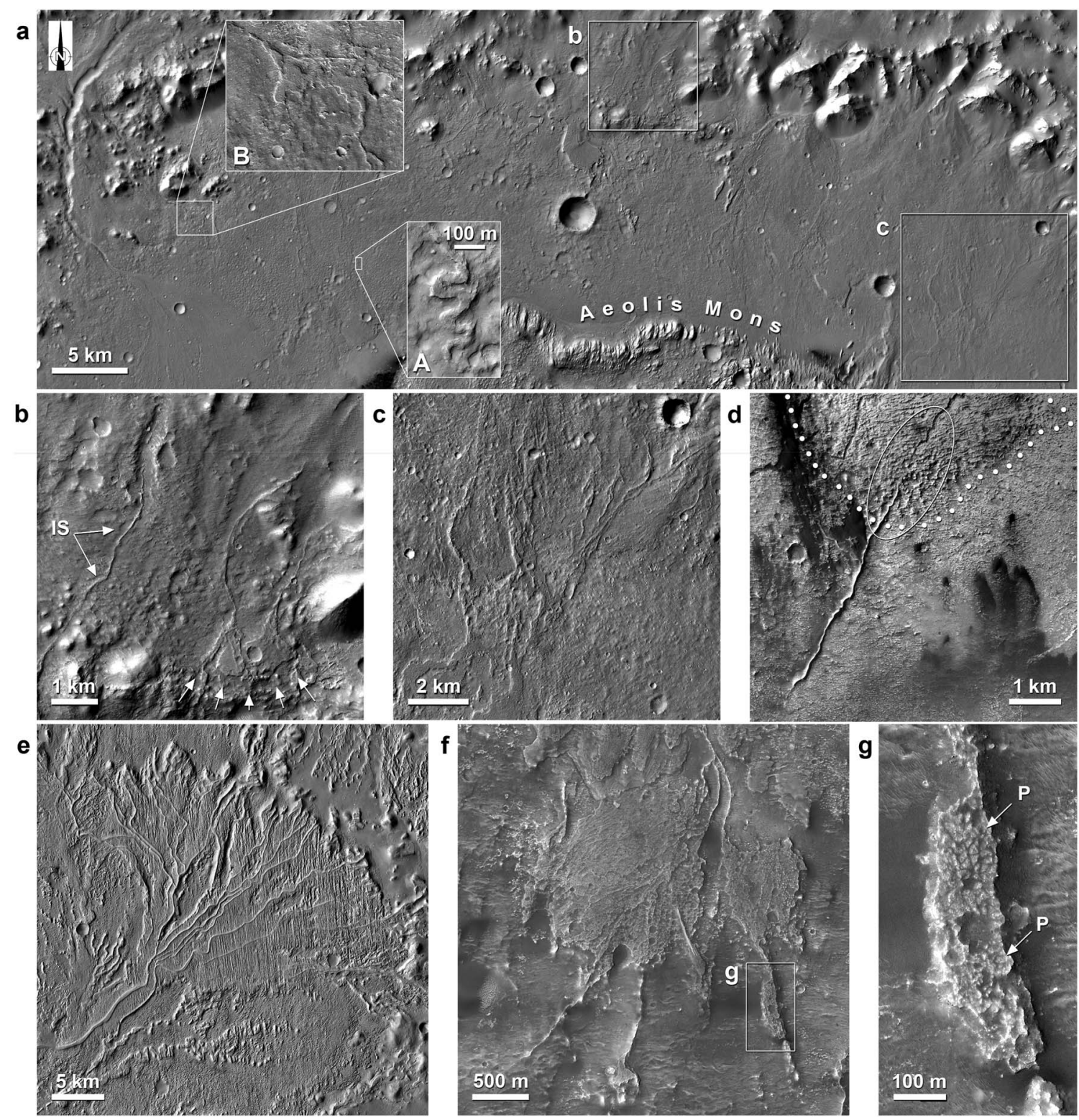

Figure 8. Sinuous ridges on slopes of Gale Crater and Aeolis Mons. (a) Regional view of south facing inner wall of Gale Crater. Most of the slopes are covered by a bajada, which is superposed by many sinuous ridges. Boxes mark locations of Figures 7b and 7c (CTX mosaic). Here and in all other panels: illumination is from the west (left), north is up. Inset A shows blow-up of a meandering sinuous ridge with a flat top and steep sidewalls (detail of HiRISE image PSP_009571_1755). Inset B shows blow-up of a sinuous ridge that widens and narrows again (detail of HiRISE ESP_021900_1755). (b) Detail of Figure 7a, with individual ridge segment ("IS") and ridges that are terminating into fan-like deposits (array of white arrows at the lower right). (c) Detail of Figure 7a, with branching and anastomosing ridge patterns in plan view. (d) Individual ridge with low sinuosity at the base of the southern slopes of Aeolis Mons. Note that an incised channel in the northeast (upper left) turns into a topographic ridge (white ellipse). The change occurs where the pitted material that the channel is carved into ends toward the southern floor of Gale Crater, creating a gradual topographic scarp (approximately at dotted line; detail of CTX image B18_016731_1747, center near $5.66^{\circ} \mathrm{S} / 138.08^{\circ} \mathrm{E}$ ). (e) Distributary pattern of sinuous ridges in the Aeolis Dorsa region of Mars (center of panel near $6.3^{\circ} \mathrm{S} / 151.3^{\circ} \mathrm{E}$ ), interpreted as inverted fluvial channels by, e.g., Burr et al. [2010]. (f) Deltalike deposit in plan view, located at the base of the southern slope of Aeolis Mons near $5.69^{\circ} \mathrm{S}, 137.96^{\circ} \mathrm{E}$ (detail of HiRISE image PSP_006288_1740). Note the similarity to Figure 7e, with a distributary pattern of sinuous ridges associated with the deposit. (g) Detail of Figure $7 \mathrm{f}$, showing a flat-topped ridge with a distinct polygonal pattern at the surface. White box marks location of Figure $7 \mathrm{~g}$. Locations of Figures $7 \mathrm{a}, 7 \mathrm{~d}$, and $7 \mathrm{f}$ are reported in Figure 1. 

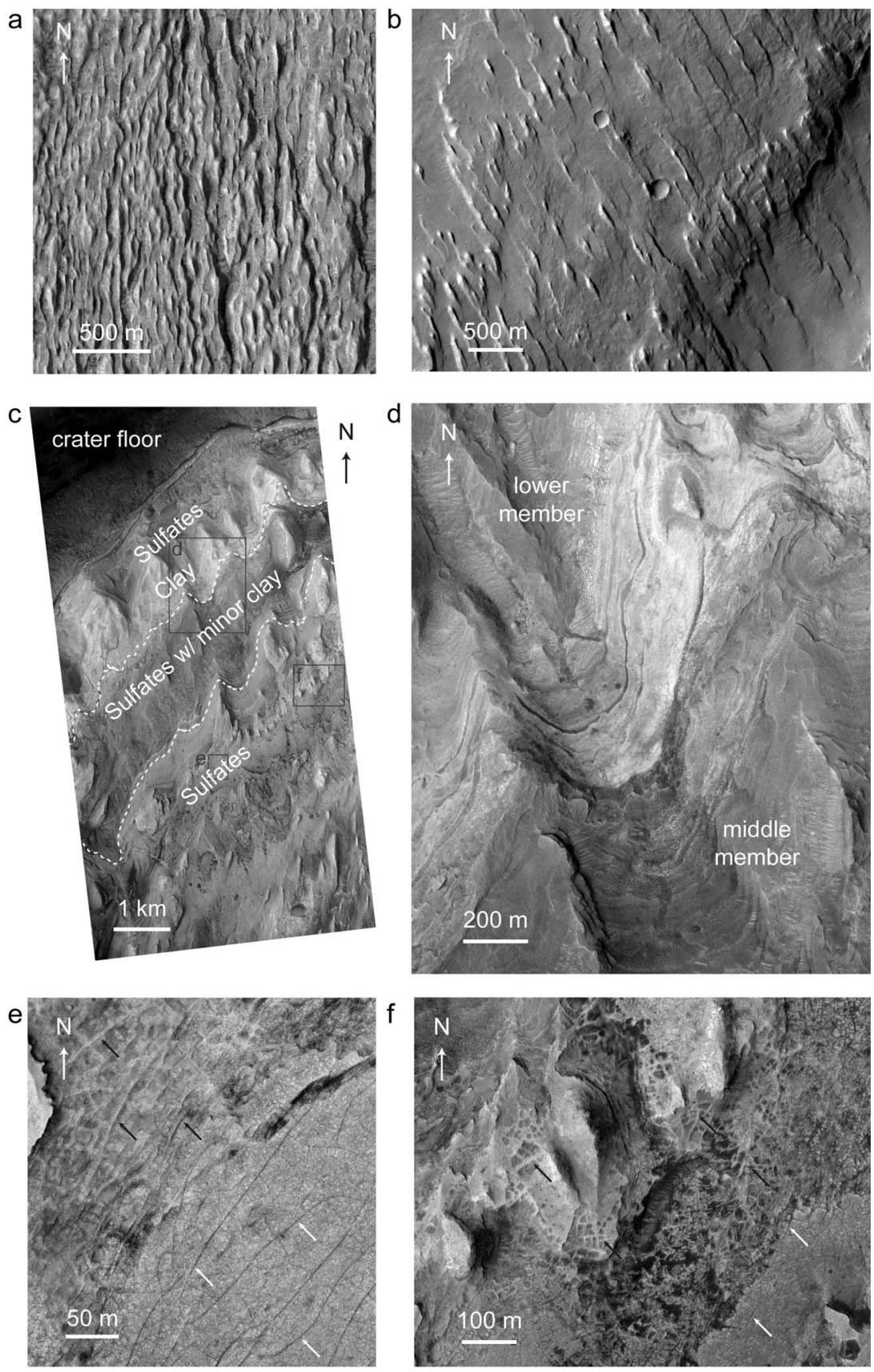

Figure 9. Morphology and mineralogy of the Small yardangs unit 1. (a) Dense group of yardangs located in the west part of the mound. Portion of HiRISE image ESP_012340_1750 (image center: $137.38^{\circ} \mathrm{E},-5.24^{\circ} \mathrm{N}$ ). Illumination is from west. (b) Sparse group of yardangs located in the eastern part of the mound. Portion of CTX image P01_001554_1745 (image center: $138.06^{\circ} \mathrm{E},-5.22^{\circ} \mathrm{N}$ ). (c) Northwest outcrops constituted of sulfate and clay-rich layers [Milliken et al., 2010]. The two dotted lines mark the contact between members of different mineralogy identified by Milliken et al. [2010] from visible images. Portion of HiRISE image ESP 012551_1750. Locations of Figures 9a-9c and 9d-9f are indicated in Figures 1 and 10c, respectively. (d) Scarp exhibiting the contact between the light-toned lower member and the moderate-toned middle member. (e) Bench in the sulfate-rich upper member displaying a polygonal network (arrows), which corresponds to polygonal ridges that are the most exhumed in the northern part of the image (back arrows). (f) Nonexhumed (white arrows) and exhumed linear ridges (black arrows). 


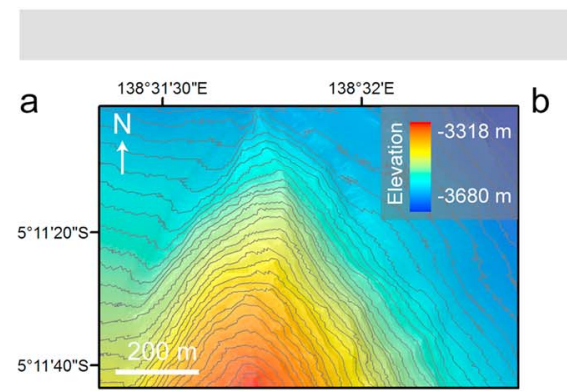

Small yardangs unit 1
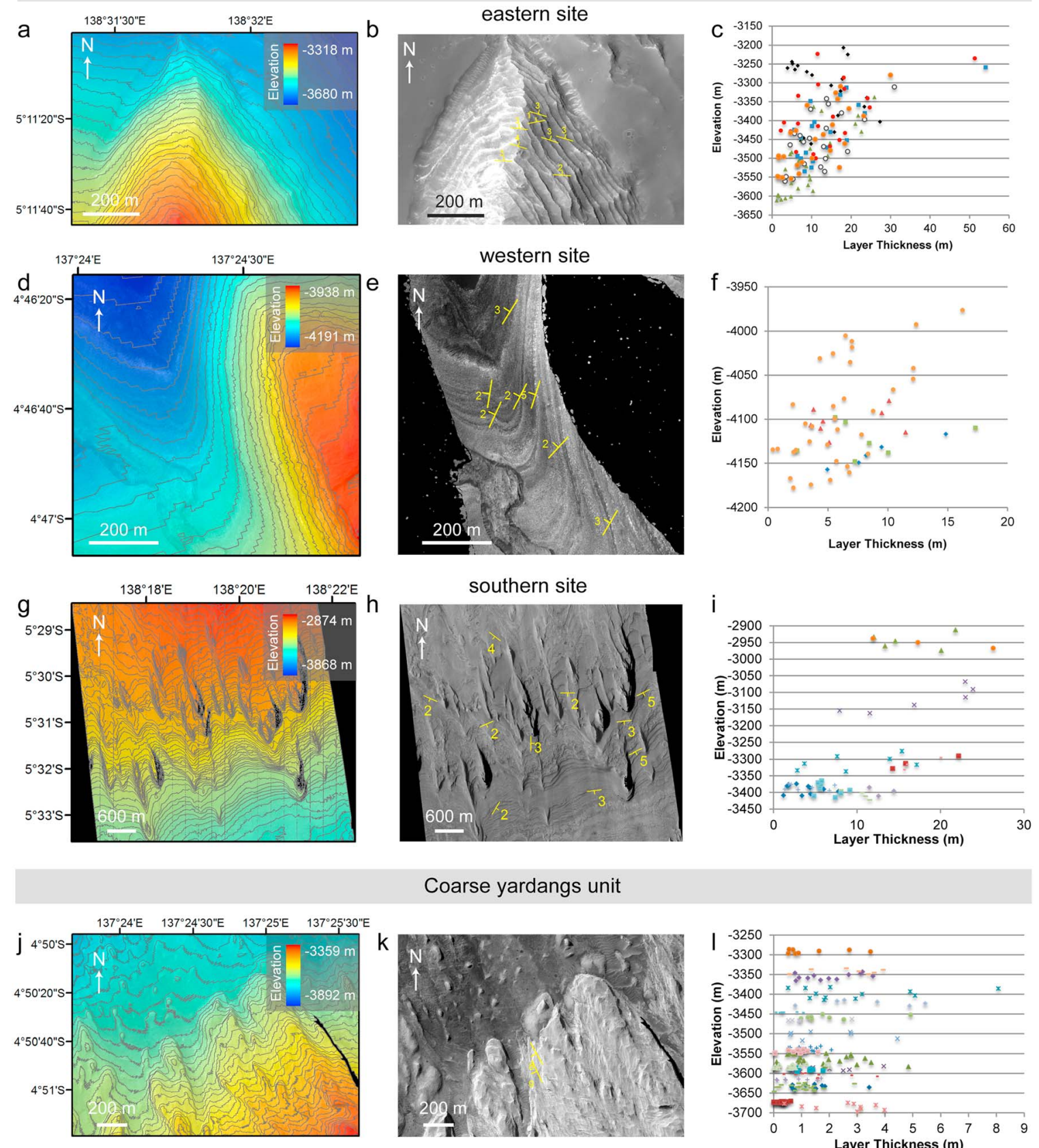

\section{Coarse yardangs unit}
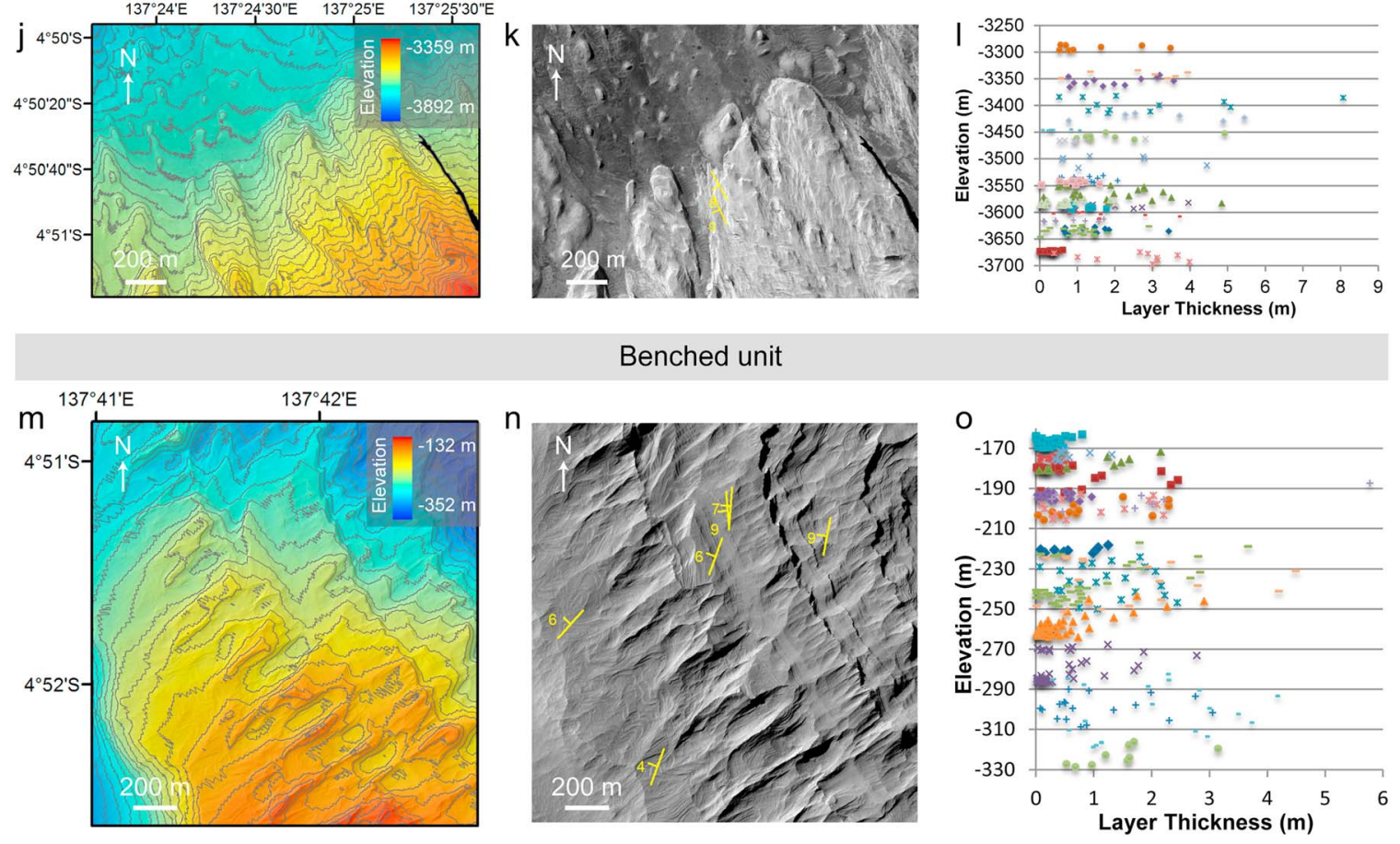

Figure 10 


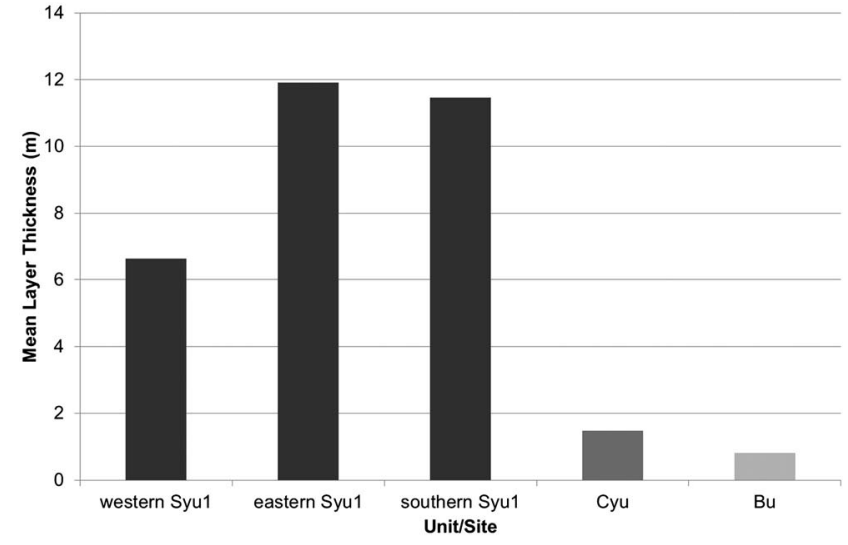

Figure 11. Mean layer thickness for each measurement site of Aeolis Mons.

Cyu outcrops fill the valley uphill of the eastern deposits that likely corresponds to the scar of the mass movement. Consequently, the eastern Cyu unit has been deposited after the mass-wasting event.

[30] The occurrence of these mass-wasting deposits to the north of the mound shows that Aeolis Mons has been affected by several episodes of mass-wasting after the deposition and erosion of the Syul and before the deposition of the $\mathrm{Cyu}$, the $\mathrm{Bu}$, and the $\mathrm{Cf} 1$ units.

\subsubsection{Coarse Yardangs Unit}

[31] The Cyu is light-toned as compared to the other units of Aeolis Mons and is only exposed in three main areas in the northern part of Aeolis Mons (Figures 5 and 6). The western outcrop is lens-shaped in plan view and lies unconformably between the Syu1 and the Syu2, between $-3900 \mathrm{~m}$ and $-2200 \mathrm{~m}$ in elevation (Figure 14a). The unconformity surface between the Syu 1 and the Cyu is marked by an impact crater at the surface of the Syu1, which is partially filled with the Cyu material [Malin and Edgett, 2000; Anderson and Bell, 2010; Thomson et al., 2011]. Similarly, the Syu2 unconformably overlies the Cyu (Figures 14a and 14b). The central outcrop of Cyu is located stratigraphically below the Caprock unit $(\mathrm{Cp})$ and the Benched unit (Bu), and above the mass-wasting deposits (m; Figures $14 \mathrm{e}$ and $14 \mathrm{f}$ ). It is exposed along a $\sim 15^{\circ}$ slope between $-3900 \mathrm{~m}$ and $-1100 \mathrm{~m}$. The eastern outcrop of the Cyu is a relatively flat exposure cropping out between $-4100 \mathrm{~m}$ and $-3400 \mathrm{~m}$ and located at the bottom of a depression carved into the Syul that likely corresponds to the scar of the mass-wasting deposits downhill. The comparison with the stratigraphical relationships between the other Cyu outcrops and the surrounding units suggests that the Cyu material fills the depression and is stratigraphically above the Syul.

[32] The surface of the western and eastern outcrops of the Cyu is characterized by several hundred meter wide yardangs with an aspect ratio (length/width) $\geq 2: 1$ (Figure 14d). These yardangs appear larger than those of the Small yardangs unit 1 (Figures 9a and 9b), which is why we suggest the collective name "Coarse yardangs unit" for this unit. These yardangs highlight the important role of aeolian erosion of the Cyu.
Some valleys between the yardangs crests appear to fan downward (Figure 14d). It may be the effect of slope winds that are deflected on local scales or possibly of running waters (e.g., snowmelt). Other erosion features, which are parallel and elongated crests, are exposed along the central outcrop (Figure 14f). They share some morphological similarities with the so-called "flutes" carved along the wall slopes of layered deposits in Valles Marineris [e.g., Lucchitta et al., 1992] that are probably mainly formed by gravitydriven erosion since they are parallel to the direction of the steepest topographic slopes. The northern face of the western outcrop also exhibits "flute-like erosion features" (Figure 14c). However, the mean direction of these erosion features carved into the Cyu is not parallel to the direction of the steepest slope, which suggests that gravity did not play an important role in their formation. Instead, aeolian erosion may be the main erosion agent of these features. Their shape may have been affected by the bedding planes of the Cyu that are directed toward southwest.

[33] Only a very weak sulfate signature has been detected by Milliken et al. [2010] and Thomson et al. [2011] on the western Cyu outcrop. The Thermal Emission Imaging System (THEMIS) thermal inertia map of Aeolis Mons shows that the thermal inertia of the surface is decreasing with increasing elevation up to 50 SI (Figure 2c). A surface characterized by a thermal inertia $\leq 200$ SI is usually interpreted as fine-grained and/or unconsolidated material [Mellon et al., 2000]. Consequently, either the Cyu does not contain much sulfate, or the dust cover on the Cyu prevents from detecting any mineralogic signatures of the Cyu by remote near-infrared spectroscopy.

[34] We produced layer thickness measurements of the western Cyu. The layer thickness of the Cyu ranges primarily between a few centimeters and $5 \mathrm{~m}$ and locally reaches up to $8 \mathrm{~m}$ (Table 2 and Figures 10, 11, and 14d). Hence, the layers of the Cyu are thinner than those of the Syul and are more regularly spaced considering their smaller range of thickness. The layer dips of the Cyu are higher than those of the Syu and show values of $8-9^{\circ} \mathrm{SW}$.

\subsubsection{Small Yardangs Unit 2}

[35] The Syu2 lies unconformably over the western Cyu outcrop, primarily between $-3200 \mathrm{~m}$ and $-270 \mathrm{~m}$ in elevation (Figures 5 and 14a). The stratigraphic contact between the Syu1 and Syu2 is unclear because they display similar geologic properties including their dark-toned layering and the occurrence of small yardangs carved into the surface. Only a very weak signature of sulfate has been detected on the Syu 2 by Milliken et al. [2010]. No HiRISE image is available in the public domain at the time of writing to make precise layer attitude measurements, but the layers of the Syu2 appear to be subhorizontal and drape the paleotopographic surface, as the Syu1 does (Figure 15a).

\subsubsection{Benched Unit}

[36] The Benched unit lies stratigraphically above the Syu2 at the top of Aeolis Mons between -3700 and $25 \mathrm{~m}$ (Figures 5 and 12). The Bu displays layers forming a cliff-bench morphology, which suggests differences of competency between

Figure 10. Layer attitude and thickness of the Aeolis Mons unit. (a, d, g, j, m) HiRISE DEM and its elevation contours (interval $10 \mathrm{~m}$ ) superposed on the corresponding orthorectified HiRISE image. (b, e, h, k, n) Orthorectified HiRISE image displaying the measured layer attitude. (c, f, i, l, o) Layer elevation versus layer thickness. Locations of Figures 10a-10b, $10 \mathrm{~d}-10 \mathrm{e}, 10 \mathrm{~g}-10 \mathrm{~h}, 10 \mathrm{j}-10 \mathrm{k}$, and $10 \mathrm{~m}-10 \mathrm{n}$ are indicated in Figure 1. 
a

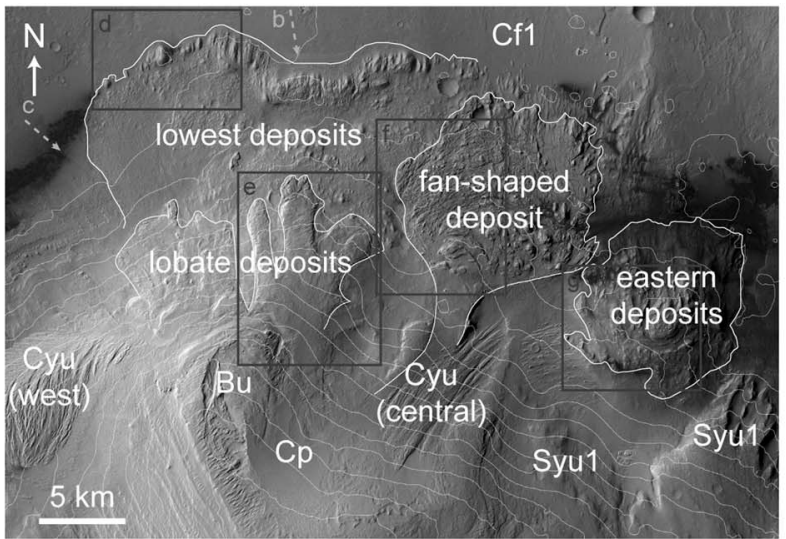

b

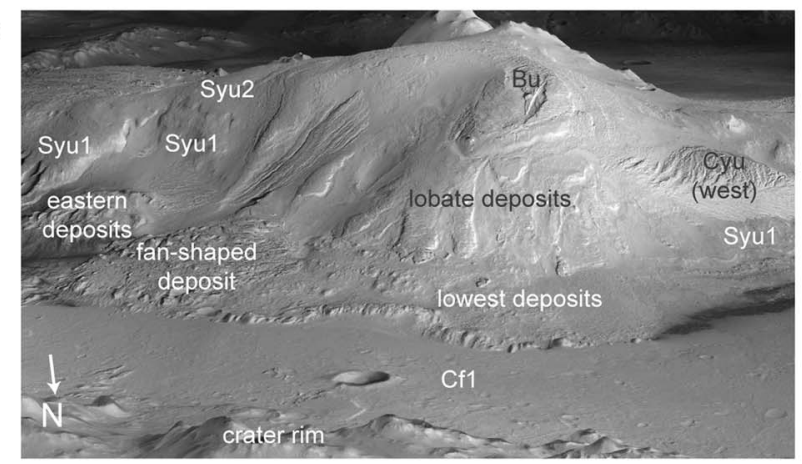

C

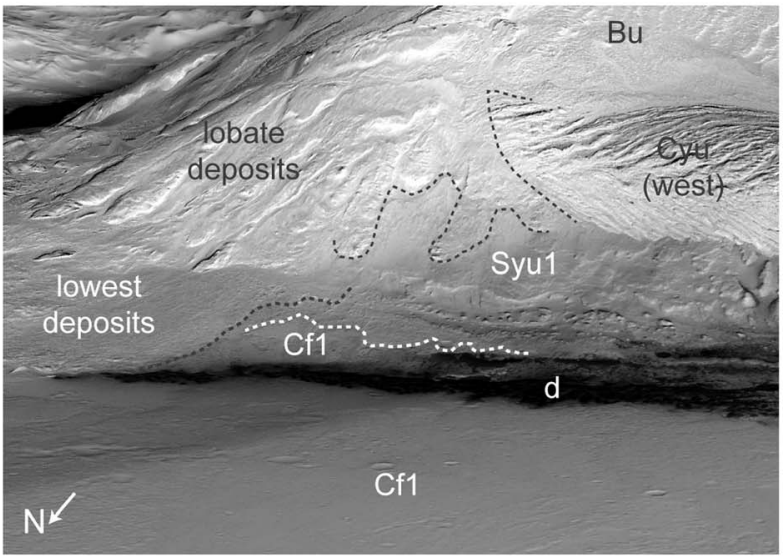

d

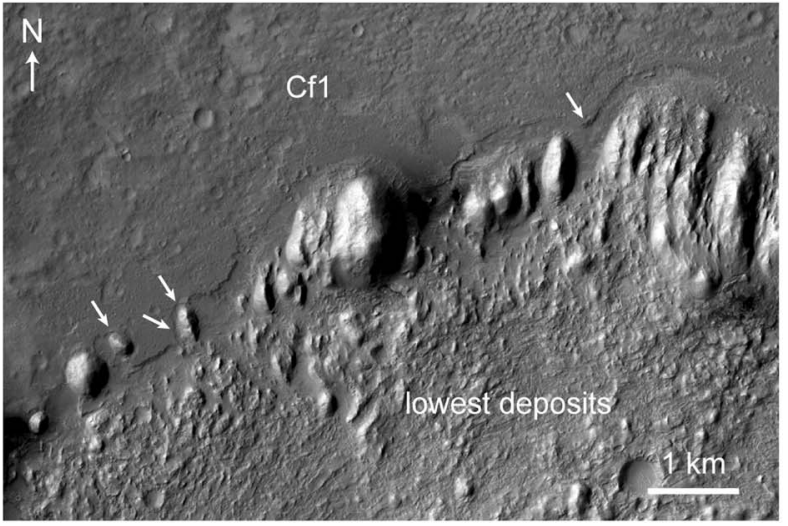

e

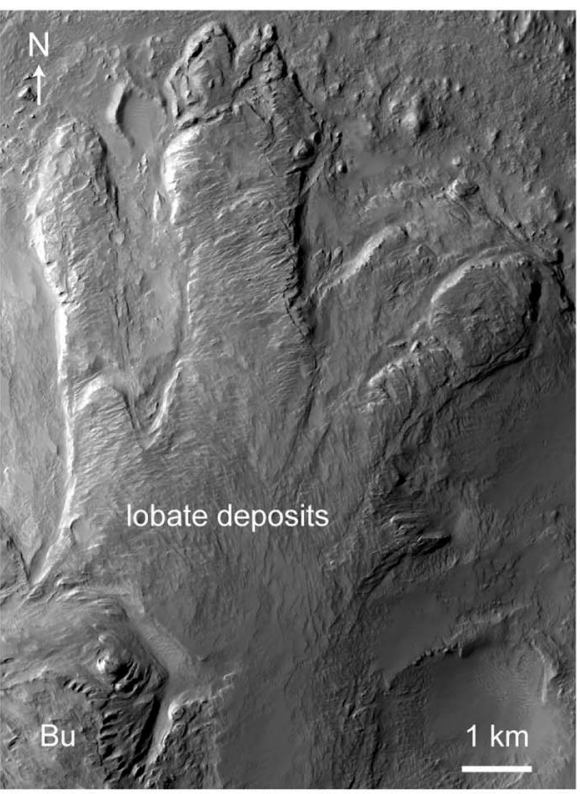

f

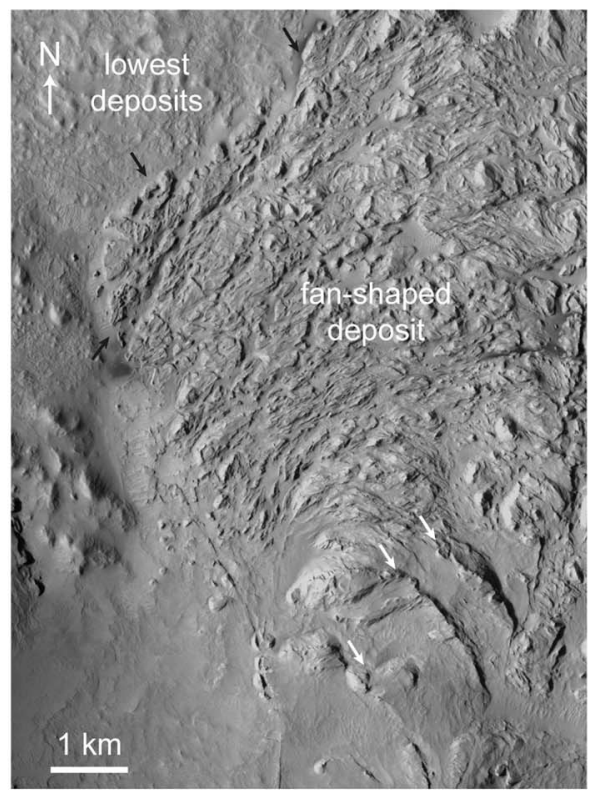

g

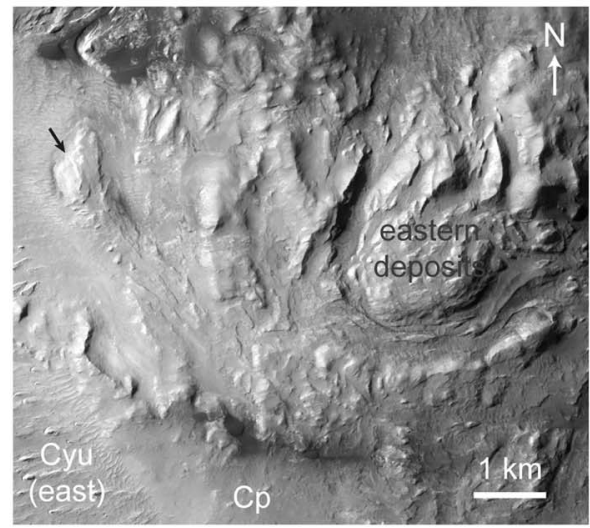

Figure 12 
the layers (Figure 15b). The stratigraphic contact between the Syu 2 and the Bu corresponds to an unconformity since the two units are not dipping similarly (Figure 15a). While the layering of the Syu2 is subhorizontal, the layers of the Bu have dips of $4-9^{\circ} \mathrm{NW}$, with a mean dip of $6.83^{\circ} \mathrm{NW}$. The Bu also lies unconformably over the western Cyu outcrop, whose layers are dipping toward the southwest. The Bu layers are thinner than those of the Cyu since their thickness mainly ranges between a few centimeters and $3 \mathrm{~m}$ (Table 2 and Figures 10o and 11). The thickest layer or group of layers measured is $5.8 \mathrm{~m}$ thick.

[37] Anderson and Bell [2010] observed sedimentary structures similar to cross beds visible on benches of layers (Figure 15c). These cross beds are indicative of sediment deposited and possibly reworked by wind or running waters. The $\mathrm{Bu}$ is characterized by a low thermal inertia consistent with the fact that no hydrated minerals have been detected on the $\mathrm{Bu}$ from CRISM data by Milliken et al. [2010] (Figure 2c). No fluvial features are observed at the surface of the $\mathrm{Bu}$ either, which suggests that either fluvial activity stopped before its deposition or it did not operate that high up the mound.

\subsubsection{Caprock Unit}

[38] The Caprock unit corresponds to thin intermediate to dark-toned deposits with a maximum thickness of a few tens of meters that are unconformably overlying the other mound units and are lying parallel to the topographic surface (Figures 15a and 15d). The main $\mathrm{Cp}$ exposure covers the $\mathrm{Bu}$ and the Cyu located to the north of Aeolis Mons (Figure 5). Localized small exposures also crop out on the mound and on the crater floor but are not mapped in Figure 5.

\subsubsection{Major Differences to Previous Mapping Studies}

[39] Our mapping approach resulted in a map of Gale that differs in several aspects from previous mapping efforts. Anderson and Bell [2010] assigned our Syu1 and Syu2 to a single unit (dark-toned layered yardangs) and proposed that our western Cyu outcrop is stratigraphically above the Syu. Instead, we divided the Syu into two subunits since we interpret the western Cyu outcrop to be stratigraphically between the Syu1 and the Syu2 (Figures 12a, 12c, 14a, and 14b). While some parts of the upper mound formation in Thomson et al. [2011] correspond to our $\mathrm{Bu}$, others correspond to our Syu1 [cf. Thomson et al., 2011, Figure 3]. Since location, elevation, and geometry appear different between them, they do not correspond to the same stratigraphic unit and we did not assign them to the same formation.

\subsection{Crater Floor Units}

[40] The crater floor units are deposits located on the floor and along the rim of Gale Crater, between $-5050 \mathrm{~m}$ and
$-50 \mathrm{~m}$ in elevation (Figure 5). Four extended crater floor units (Cf1-4) have been defined according to their location in the crater and their stratigraphic relationships. Layered deposits (ld) and fan-shaped deposits (fd) are localized deposits also lying on the crater floor.

\subsubsection{Crater Floor Units 1-4}

[41] The Cf1 unit is located to the north and to the south of Aeolis Mons (Figure 5). It corresponds to nearly flat deposits forming the crater floor (Figures 16 and 17a). The northern Cf1 unit is located at the foot of the northern crater rim, which corresponds to a topographic ridge that is approximately $15 \mathrm{~km}$ wide and at least $1000 \mathrm{~m}$ high. The crater rim and the northern Cf1 unit are incised by fluvial valleys oriented radially to the crater. Most of the northern Cf1 deposits likely correspond to sediment transported in these fluvial valleys and deposited downstream. These fluvial valleys are associated with sinuous ridges that have been exhumed at the surface of the Cf1 unit (Figure 16a). The sediment of the Cf1 unit locally forms fan-shaped deposits, which are partially overlapping with each other and form a bajada. This suggests that they were formed in several depositional events (Figure 16a). The southern Cfl unit is located between the foot of the southern crater rim and the central peak. The southern Cf1 unit is flat and exhibits less fluvial features than the northern Cf1 unit (Figure 5). The Cf1 unit is located stratigraphically above the Syul of Aeolis Mons (Figure 16c) and the masswasting deposits (Figure 13d). Hence, the Cf1 unit formed after the deposition of the Syul and the mass-wasting deposits.

[42] The Cf2 unit is located in the southeastern part of the crater (Figure 5). It overlies the crater wall, which corresponds to basement outcrops located between $-3500 \mathrm{~m}$ and $200 \mathrm{~m}$. The southern crater wall has a width of $30 \mathrm{~km}$ and a regional slope of $\sim 5^{\circ}$. The $\mathrm{Cf} 2$ unit embays basement outcrops and is incised by many fluvial valleys (Figures 5, 6a, $6 \mathrm{~b}$, and $16 \mathrm{~d})$. It partially covers the Cf1 unit exposed on the crater floor (Figure 16d) where it partially embays sinuous ridges (Figure 16e).

[43] The Cf3 unit is situated in the southwestern part of Gale and is exposed between $-4800 \mathrm{~m}$ and $-2500 \mathrm{~m}$. The Cf3 deposits form a gently inclined plain of $1.5^{\circ}$ covering the lower part of the crater wall over an area of $\sim 71 \mathrm{~km}^{2}$ (Figures 5 and 16f). The plain is crossed by a wide fluvial canyon up to $\sim 4 \mathrm{~km}$ wide corresponding to the main entrance breach to the crater. This fluvial canyon begins northeast of Herschel crater, $\sim 400 \mathrm{~km}$ to the south of Gale. A fan-shaped deposit partially masked by dunes is located at the outlet of this wide canyon. Other smaller-scaled fluvial valleys are incised in the Cf3 unit.

[44] The Cf4 unit is located in the northwestern part of the crater, to the north of the Cf3 unit between $-5000 \mathrm{~m}$ and

Figure 12. Mass-wasting deposits located to the north of Aeolis Mons. (a) Portion of a CTX mosaic showing a global view of the four types of mass-wasting deposits: the lowest, the lobate, the fan-shaped, and the eastern deposits (HRSC elevation contours interval: $300 \mathrm{~m}$ ). The best visible contacts are marked in white. Locations of Figures $13 \mathrm{a}$ and $13 \mathrm{~b}-13 \mathrm{~g}$ are indicated on Figures 1 and 13a, respectively. (b) Oblique view of the mass-wasting deposits and their surrounding units (CTX mosaic overlain on a HRSC DEM, vertical exaggeration: x2). (c) Oblique view of the lowest and lobate deposits and their surrounding units (CTX mosaic overlain on a HRSC DEM, vertical exaggeration: x2). (d) Close-up view of Figure 13a showing the contact between the lowest deposits and the Cf1 unit. The latest embays the outcrops of the lowest deposits (arrows). (e) Close-up view of the lobate deposits. (f) Close-up view of the fan-shaped deposits, which overlie the lowest deposits. The contact between the two units is marked by black arrows. The transverse cracks are marked by white arrows. (g) Close-up view of the eastern deposits. Location of the layered outcrop (layers not visible at this scale) is marked by a black arrow. 
LE DEIT ET AL.: SEDIMENTARY INFILLING IN GALE CRATER

a

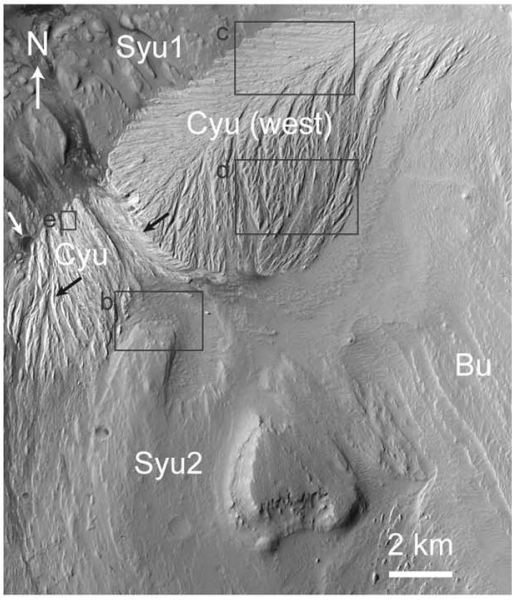

C

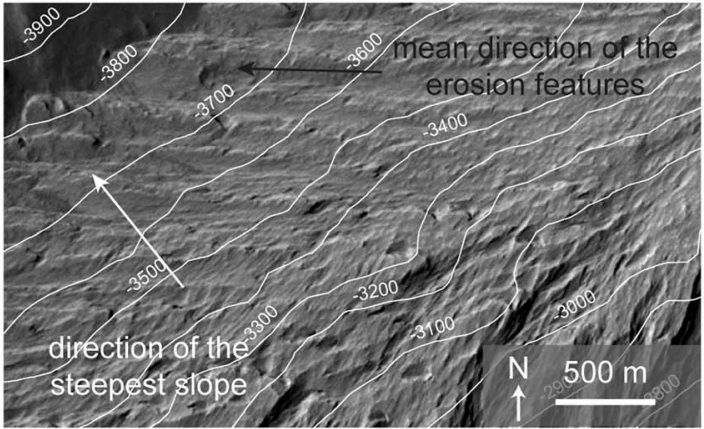

d

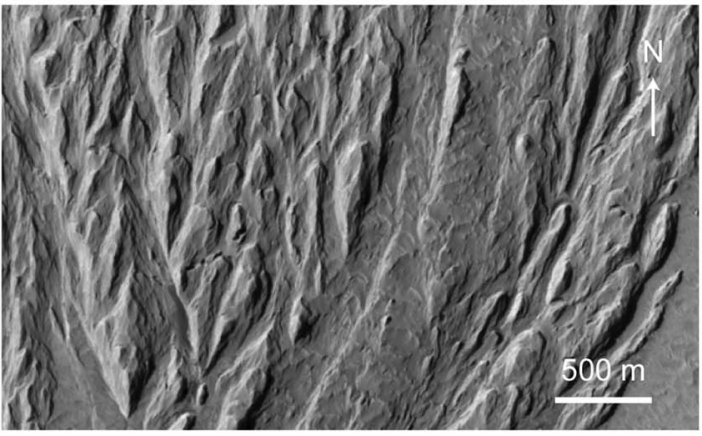

b

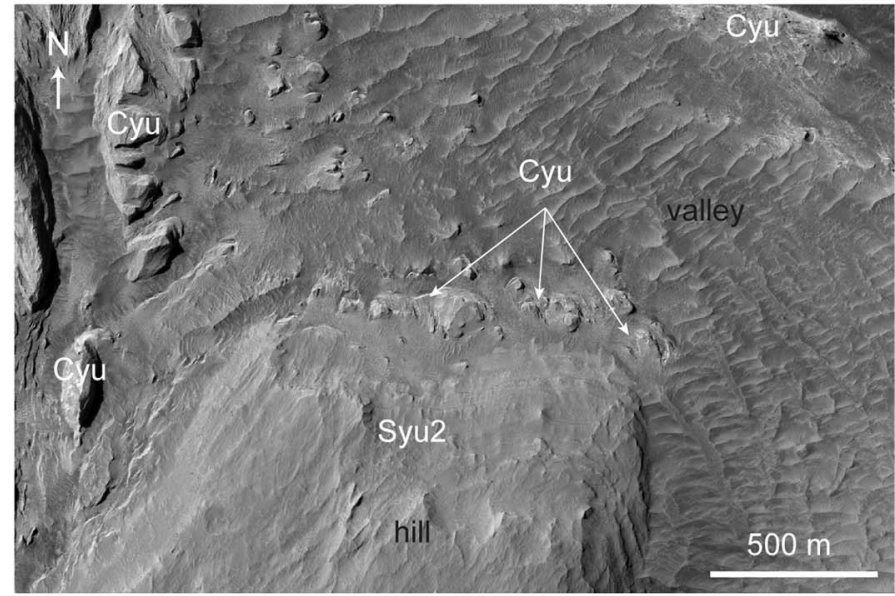

e

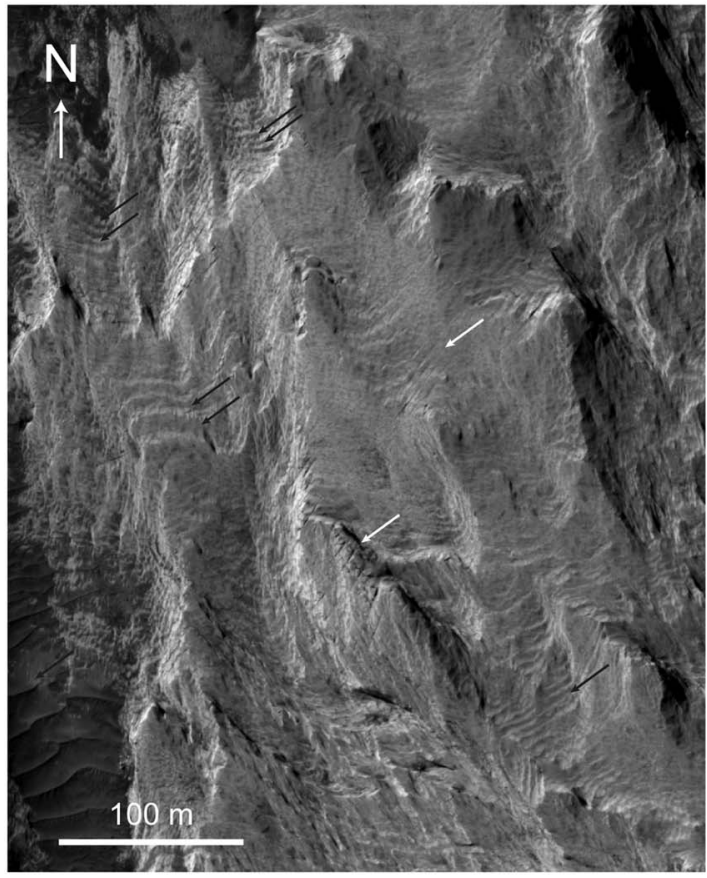

f
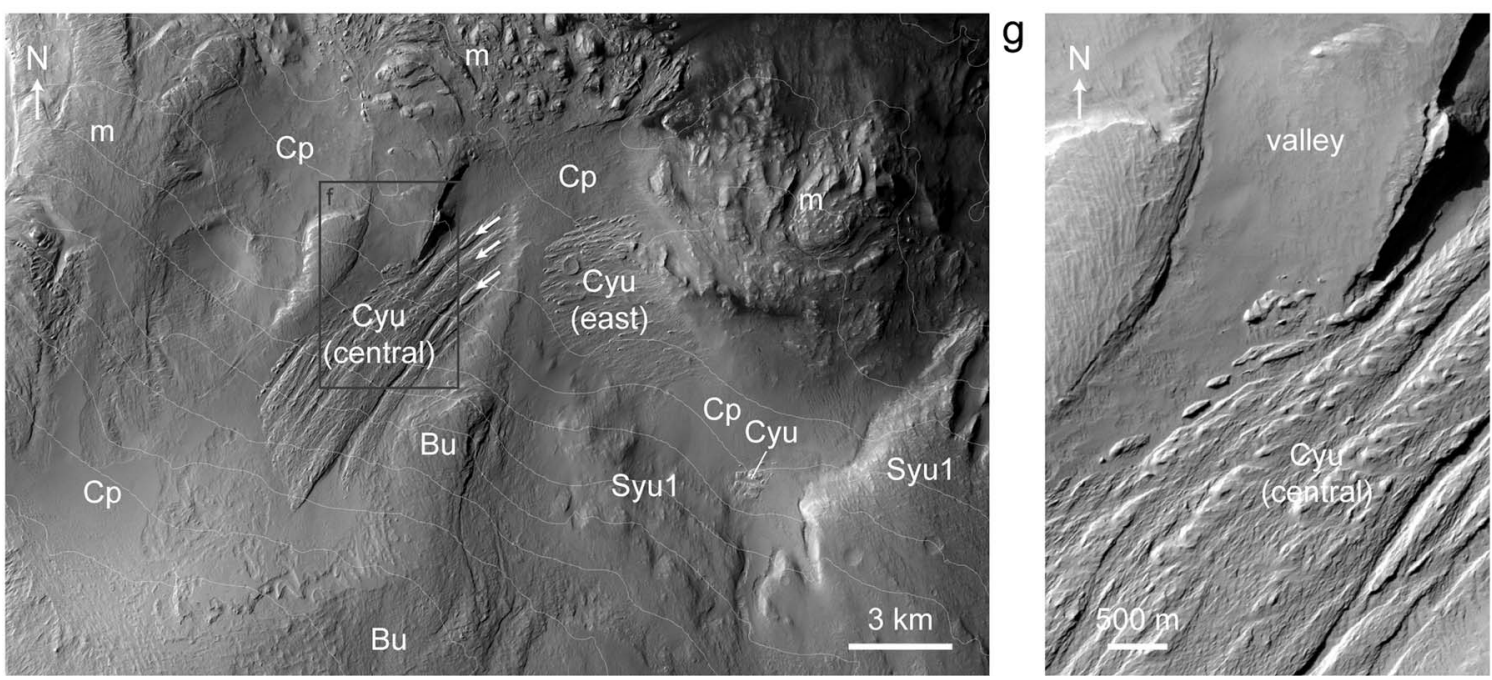

Figure 13 
a

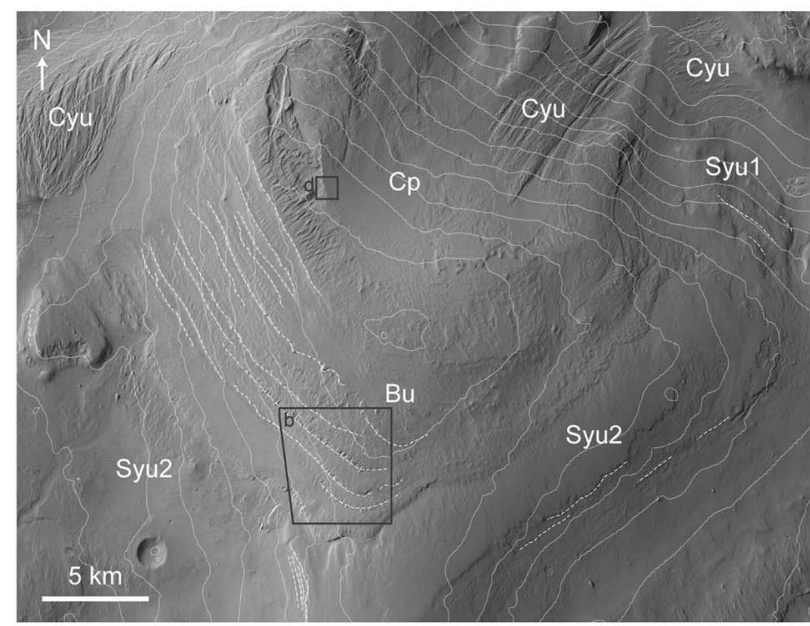

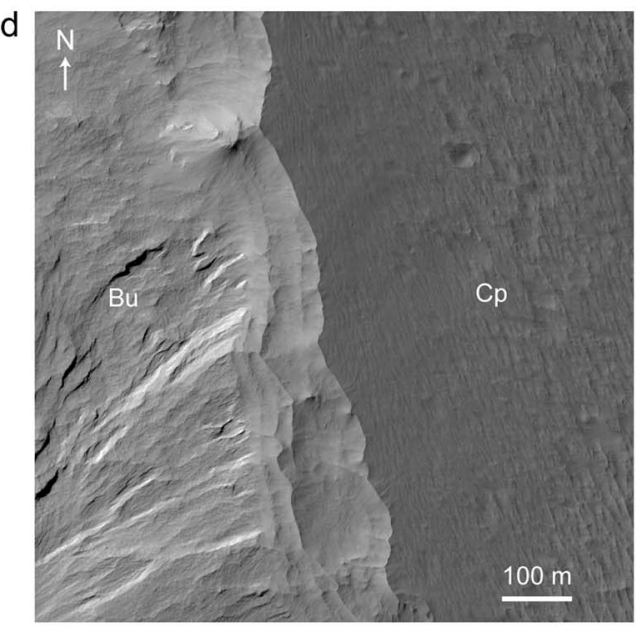

b

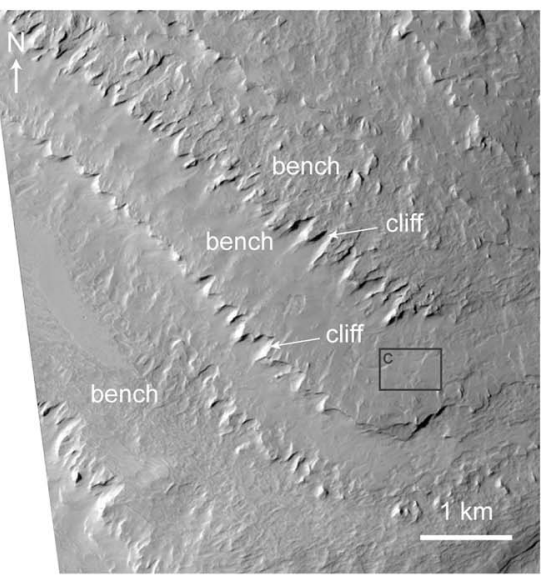

C

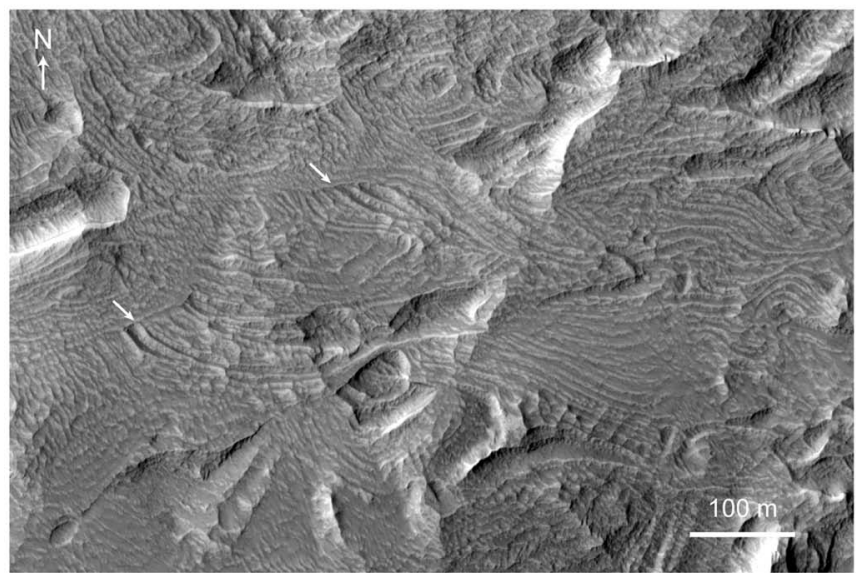

Figure 14. Morphology and stratigraphy of the upper units of Aeolis Mons. (a) Portion of a CTX mosaic displaying the Syu2, the $\mathrm{Bu}$, and the $\mathrm{Cp}$ (image center: $137.8^{\circ} \mathrm{E},-4.97^{\circ} \mathrm{N}$ ). The Syu2 layers (dotted lines) are subhorizontal since they are parallel to the contour lines (interval: $300 \mathrm{~m}$ ) contrary to the Bu layers. Locations of Figures $15 \mathrm{~b}$ and $15 \mathrm{~d}$ are indicated. Location of Figures 15a is reported in Figure 1. (b) Cliffbench morphology of the Bu. Portion of HiRISE image PSP_001620_1750. (c) Close-up view of Figure 15b showing possible cross beds (arrows) visible on benches of the Bu. Location of Figure $15 \mathrm{c}$ is reported. (d) Unconformable contact between the Bu and the Cp. Portion of HiRISE image PSP_00992_1750.

$-3600 \mathrm{~m}$. It is a nearly flat unit covering the crater floor that is stratigraphically above the Cf1 unit (Figure 16b). The Cf4 unit is darker-toned than the Cf1 unit (Figure 16b). The Cf4 unit has also a lower thermal inertia than the Cf1 unit (blue and yellow-red color, respectively, in Figure 2d). This implies that the Cf4 unit may consist of fewer rocks and/or more loose, fine-grained, and unconsolidated particles than the $\mathrm{Cf1}$ unit. A thin dust mantle may also cover the unit. The presence of a large dune field masks a hypothetical contact between the fan-shaped deposit located at the outlet of the canyon and the Cf4 unit. The highest northern part of the Cf4 unit is covered by mass-wasting deposits (not mapped

Figure 13. Morphology of the Coarse yardangs unit (Cyu). (a) The western Cyu outcrop is located stratigraphically between the Syu1 and the Syu2. Valleys probably carved by water are marked by black arrows. The impact crater indicative of an unconformity contact is marked by a white arrow. Mosaic of CTX images (image center: $137.5^{\circ} \mathrm{E},-4.9^{\circ} \mathrm{N}$ ). Locations of Figures 14a and 14b-14e are indicated in Figures 1 and 14a, respectively. (b) Portion of HiRISE image (ESP_025935_1750) showing the contact between the Cyu (west) and the Syu2. (c) Close-up view of elongated erosion features probably carved by wind visible on the northern part of the outcrop. (d) Close-up view of coarse yardangs. (e) Portion of HiRISE image (PSP_009294_1750) showing layers and groups of layers (black arrows) only visible at large scale. White arrows do not mark exposed layers but groups of fractures. (f) View of the central and eastern Cyu outcrops. Mosaic of CTX images (image center: $138^{\circ} \mathrm{E},-4.8^{\circ} \mathrm{N}$ ) overlain by HRSC elevation contours (interval: $400 \mathrm{~m}$ ). The "flute-like" erosion features are marked by arrows. Locations of Figures 14f and 14g are indicated in Figures 1 and 14f, respectively. (g) Close-up view of the central Cyu exposure, which is partially filling the valley corresponding to the main track of the mass-wasting deposits. 
in Figure 5) that have likely slumped from the crater rim and by sinuous ridges for which the source of the transported and deposited sediment is also the crater rim.

\subsubsection{Layered Deposits}

[45] Layered deposits fill depressions on the crater floor (Figures 5 and 8). On the northwestern part of the crater floor, light-toned subhorizontal layered deposits partially fill a $\sim 3.7 \mathrm{~km}$ diameter impact crater with a serrated rim (Figures $8 \mathrm{a}$ and $8 \mathrm{~b}$ ). It exhibits alternating "alcoves and promontories" like Victoria crater in Terra Meridiani [Grant et al., 2008; Geissler et al., 2008] and an inner lower rim likely corresponding to the pristine crater rim of $\sim 2.9 \mathrm{~km}$. By analogy with Victoria crater, aeolian processes may be responsible for most crater degradation [Grant et al., 2008; Geissler et al., 2008].

[46] Layered deposits are also cropping out on the northeastern part of the crater floor over a length of $15 \mathrm{~km}$ and a width up to $4 \mathrm{~km}$ (Figure $8 \mathrm{c}$ ). These deposits are mainly exposed as thinly layered small mounds located topographically below the Syu1 and have a maximum thickness of $\sim 150 \mathrm{~m}$ (Figure $8 \mathrm{e}$ ). The mounds are embayed by $\mathrm{Cp}$ outcrops showing that deposition and erosion of the layered deposits mainly occurred before the deposition of the $\mathrm{Cp}$ unit. The absence of stratigraphic contact between the Syul and the layered deposits prevents from determining if the latter are stratigraphically below or above the Syu1. Polygonal ridges with a regular roughly orthogonal pattern and a size between $5 \mathrm{~m}$ and $10 \mathrm{~m}$ in diameter are exposed at the surface of layered deposits (Figure 8f). They may be filled and cemented desiccation cracks. They may also be paleosand wedges corresponding to thermal contraction polygonal fractures filled by sand that are indicative of former permafrost conditions [e.g., Péwé, 1959]. The sand may have been hardened by chemical precipitation of hydrated minerals.

\subsubsection{Fan-Shaped Deposits}

[47] Different types of fan-shaped deposits are located on the crater floor including two scarp-fronted fans, a possible extended deposit at the mouth of the canyon to the south of the crater, and thick fan-shaped deposits at the foot of Aeolis Mons (Figure 5). One of the front-scarp fans is situated at the outlet of a deeply incised channel cutting through the western crater wall (Figure 18a). The fan has a steep front and is morphologically similar to Gilbert-type fan deltas on Earth. The portions of the delta that are proximal to the apex display a stair-stepped topography, which is thought to be indicative of short-term fluvial processes [Kraal et al., 2008]. A second, smaller delta is visible to the left (West) of the delta. This smaller delta also has a stepped topography and seems to be sourced from an alcove-like reentrant in the crater wall. Another front-scarp fan is located on the southern floor of Gale laterally passing to the Cf3 unit (Figure 18b). It had been first described by Cabrol and Grin [2001] and Irwin et al. [2005]. The surface appears very smooth at the $10 \mathrm{~m}$ scale. The frontal scarp of the fan is steep and displays a lobe-like shape in plan view, suggesting limited erosion after its emplacement. Additionally, the absence of entrenched channels at the surface of the fan suggests that the flows stopped rather suddenly [Irwin et al., 2005].

[48] One of the fan-shaped deposits is fed by a canyon from the south that continues southward (i.e., upstream) beyond the rim of Gale Crater. The fan is partly covered by superficial dark material and dunes (Figure 18c). However, an outcrop of light-toned layered material is visible about
$20 \mathrm{~km}$ toward the north from the mouth of the canyon (Figure 18d). The outcrop is flat-topped and displays an impact crater. This layered material may partially correspond to pedestal crater ejecta (the base of the layered material being the distal part of the fan-shaped deposit shown in Figure 18c) or to an outlier of the Syu1.

[49] Fan-shaped deposits are located at the mouth of deep reentrants with steep headwalls on the western and southern slopes of Aeolis Mons (Figure 18e). These fan-shaped deposits reach thicknesses of up to $200 \mathrm{~m}$ to $500 \mathrm{~m}$. The one presented in Figure $18 \mathrm{e}$ is associated with a bowl-shaped valley as a source of material. This valley has a diameter of $\sim 8 \mathrm{~km}$ and a steep headwall of $500 \mathrm{~m}$ height.

\section{Sedimentation Processes}

\subsection{Valleys, Canyons, and Sinuous Ridges}

[50] The valleys carved along the crater rim may have been formed by surface runoff derived from rain and snow or by groundwater discharge. The large width of the canyons may be due to the occurrence of more frequent episodes of flowing in the canyons than in the valleys. Sapping may have also led to channel widening, either by channel avulsion or by undermining of the sidewalls by influx of water from the sides. The canyons are primarily observed along Aeolis Mons. That may be due to more frequent channel avulsion possibly related to the lower slope, a reduced infiltration capacity due to the possibly finer-grained or less permeable substrate, and/or to the more irregular morphology of the crater rim with respect to the flanks of Aeolis Mons.

[51] The two most likely hypotheses to explain the origin of sinuous ridges (SR) would be a formation as subglacial eskers or an inversion of relief by differential erosion, exhuming, and turning former fluvial channels to positive topographic ridges. The pattern of sinuous ridges as seen in plan view displays strong similarities to the courses of terrestrial fluvial channels. Branching and anastomosing courses, meandering and the association with possible incised channels upslope, and fan-like deposits downslope all resemble the courses of river channels in gently sloping alluvial floodplains. The downslope orientation of the ridges is consistent with the idea that they represent an ancient aqueous drainage pattern. While an origin as eskers cannot definitely be ruled out, some characteristics of the SR in Gale appear to be more consistent with an original formation by aqueous surficial flows. As pointed out by Pain et al. [2007], the only definite criterion to distinguish eskers from inverted channels in remote sensing data is the topographic slope along the ridges, because only eskers can cross topographic divides (neglecting postformation modification of fluvial channels or inverted ridges). Although the small scale of the sinuous ridges in Gale does not allow analyzing their topography in detail, it appears that all of them display a monotonous decrease in elevation along their extent. While this is no evidence against eskers, the flat tops of the ridges (most curvilinear ridges interpreted as eskers on Mars display sharp or rounded crests; Pain et al. [2007]), their clear association with fan-like deposits (Figures $7 \mathrm{~b}$ and $7 \mathrm{f}$ ), and the observed transition from channels to ridges (Figure 7d) strongly point toward an origin as subaerial fluvial channels later modified by erosion to inverted channels. In agreement with previous authors [Anderson and Bell, 
LE DEIT ET AL.: SEDIMENTARY INFILLING IN GALE CRATER

a
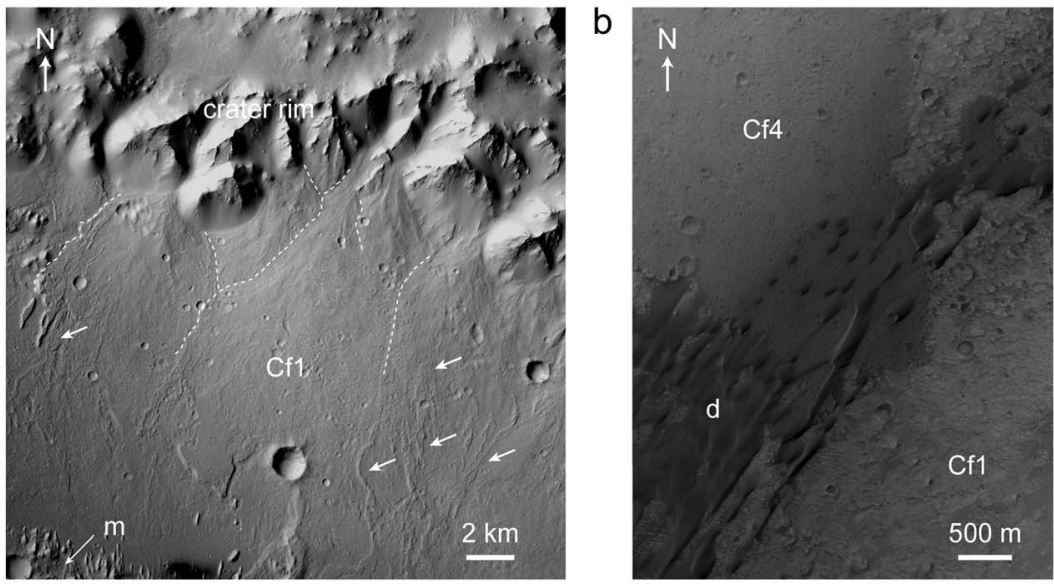

C

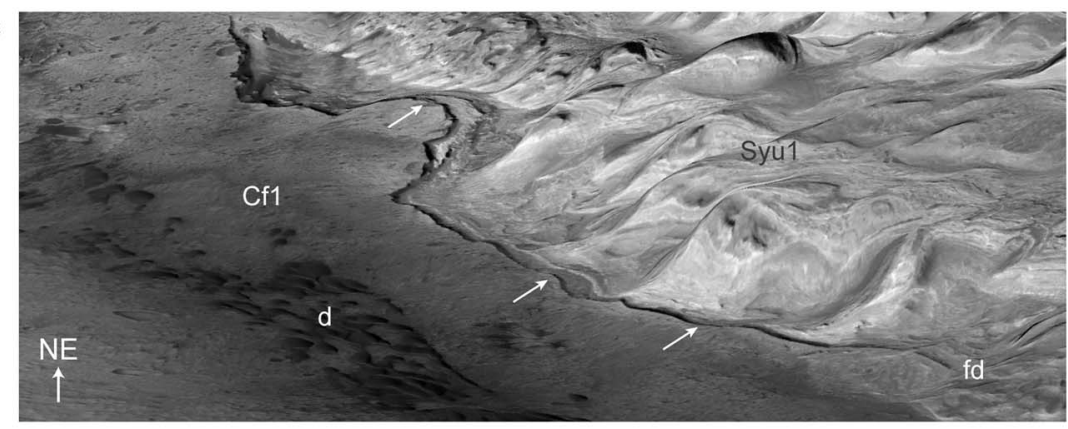

d
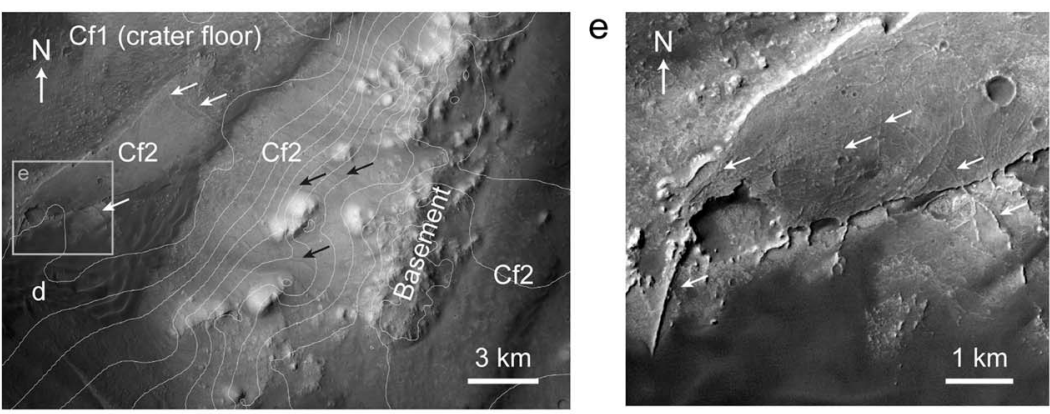

f

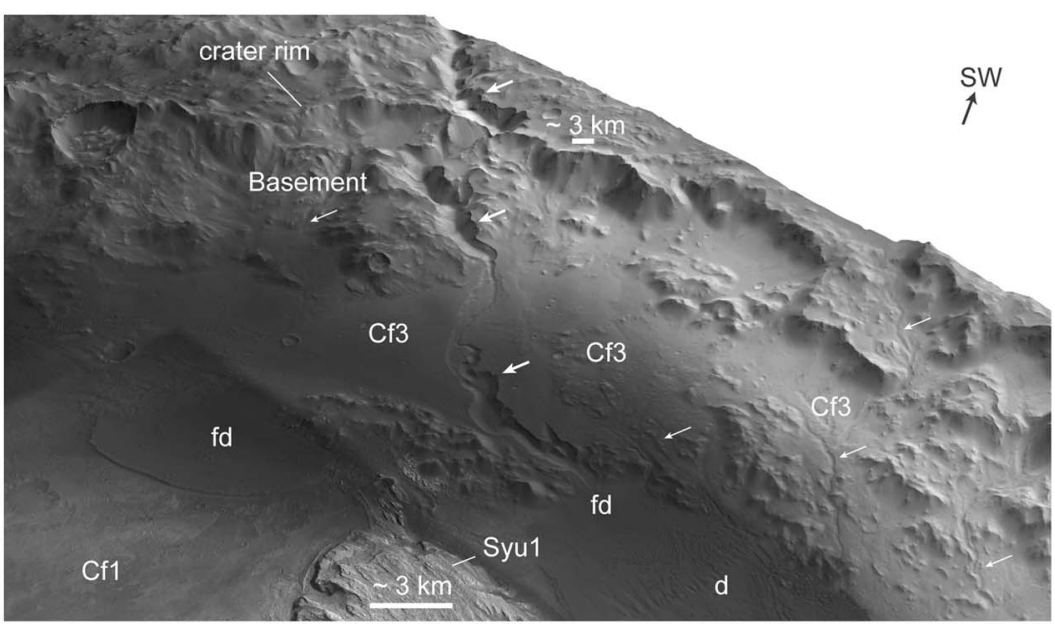

Figure 15 
2010; Thomson et al., 2011], we, therefore, interpret the sinuous ridges in Gale as exhumed and inverted paleochannels.

[52] Exhumed channels are common landforms on Mars [Edgett, 2005; Pain et al., 2007], and they are particularly well preserved in the Aeolis region adjacent to Gale Crater (Figure 7e) [e.g., Burr et al., 2010; Williams et al., 2013a]. The morphologic diversity of sinuous ridges in Aeolis is larger than in Gale, though. Of the three morphologic classes of sinuous ridges interpreted as inverted channels by Burr et al. [2010], only thin ridges are observed in Gale (Figure 7). The other two classes, flat SR and multilevel SR [cf. Burr et al., 2010, Figure 2], are absent. Nevertheless, the dimensions of the thin SR are quite similar in Aeolis and Gale [cf. Burr et al., 2010, Table 1]. Similarities can also be observed with terrestrial inverted channels. A morphometric comparison with respect to their dimensions reveals that the sinuous ridges in Gale Crater are most similar to the inverted paleochannels in Utah [Harris, 1980; Williams et al., 2007, 2011], whereas other well-known terrestrial inverted channels such as those in Oman or Australia can display similar widths, but are much longer (see comparison in Clarke and Stoker [2011]).

[53] Inversion of topography is a result of differential erosion, where a former topographic low is relatively more erosionresistant and eventually changes into a positive topographic landform. The three basic mechanisms to increase the resistance to erosion in fluvial (paleo)channels are infilling (e.g., with lava), armoring with relatively coarser-grained particles, and chemical cementation [Pain and Ollier, 1995]. Infilling with lava seems unlikely in Gale Crater, because of the total lack of observable volcanic vents and lava flows. Moreover, as pointed out by Burr et al. [2010] for the case of the Aeolis raised channels, there are no fine-scale indicators of lava flows such as columnar jointing (which can be detected on Mars, see Milazzo et al. [2009]) in the available HiRISE images of sinuous ridges. Armoring of channel floors by coarse particles and subsequent relief inversion by differential erosion is rarely documented on Earth [Williams et al., 2007], occurs mostly on mountain slopes that are steeper than those in Gale [e.g., Mills, 1981], and is not expected to uniformly protect the whole width of a channel floor along its winding path (cf. Figure 8d) [Williams et al., 2007]. In summary, we consider it unlikely that mechanical armoring was mainly responsible for the protection of channel floors. We follow the argumentation of Williams et al. [2007, 2013a] and Burr et al. [2010] who prefer chemical cementation as the most likely hypothesis for relief inversion responsible for SR formation. Cementation is a common induration process on terrestrial channel floors and is responsible for the formation of inverted channels in Utah [Harris, 1980], Oman [Maizels, 1987], and other locations such as the Mirackina raised channel in Australia [McNally and Wilson, 1995]. Cementation is also known from Mars, as sulfur-rich fractured duricrusts have been found at both Viking landing sites [Binder et al., 1977]. Other examples of cementation can be found at fracture zones in the Valles Marineris [Okubo and McEwen, 2007] and at fractures on Aeolis Mons in Gale Crater itself [Thomson et al., 2011]. Much of Aeolis Mons itself is a cemented deposit, as indicated by the detection of sulfates within the layered sediment. Similarly, the Meridiani rocks are cemented sandstones [e.g., Grotzinger et al., 2005]. We interpret the existence of polygons at the top of the inverted channel seen in Figure $7 \mathrm{~g}$ as possible evidence for cementation. The polygonal fracturing suggests that the surface material has some cohesive strength, which would not be expected from loose coarse-grained particles armoring the former channel floor. Moreover, this textural pattern does not resemble polygonal cooling joints at the top of basaltic lava flows. Alternatively, the polygonal pattern may have been caused by thermal contraction cracking, which was observed at midlatitudes and high latitudes on Mars. In this case, the polygons would have had a similar origin as the hypothesized paleosand wedge polygons in the layered crater floor deposits (ld). However, thermal contraction polygons are very rare, if present at all, at equatorial latitudes [e.g., Levy et al., 2010]. Instead, the cementation of fine-grained sediment, which was delivered from the layered deposits forming Aeolis Mons, would provide the cohesive strength and the eventual formation of polygonal patterns by desiccation. However, except for the inverted channels draining Aeolis Mons, the cementation of channel floors elsewhere in Gale (Figure 7a) does not exclude coarser grain sizes. More permeable sediments on coarse-grained channel floors, as opposed to adjacent floodplains, favor high flow rates and associated increased cementation [Clarke and Stoker, 2011]. Indeed, the floors of inverted paleochannels in Oman are characterized by cemented coarse-grained channel sediments that have been more resistant to deflation than adjacent poorly cemented and fine-grained interfluve deposits [Maizels, 1987]. In fact, abundant supply of coarse-grained clastic particles would be expected in the drainage areas at the higher reaches of the Gale Crater rim (Figure 7a), where bedrock would be heavily fractured.

[54] Cementation mechanisms are discussed by Pain et al. [2007] and include degassing, fluid mixing, cooling, evaporation, and sublimation of icy regolith. While all of these may have worked on ancient Mars, cooling, evaporation, and sublimation seem the most likely, and the available data do not allow discriminating between them. The fact that

Figure 15. Morphology and stratigraphy of the Crater floor units $1-4$. Locations of Figures $16 \mathrm{a}-16 \mathrm{~d}$ and $16 \mathrm{f}$ are indicated in Figure 1. (a) Characteristic view of the Cfl located to the north of the crater showing alluvial deposits spread over the flat crater floor. Arrows mark some sinuous ridges interpreted as inverted channels. Portion of CTX image (P01 001554 1745). (b) Stratigraphic contact between the of Cf1 and Cf4 units. Portion of HiRISE image (PSP_008002_1750). (c) Oblique view of the northwestern portion of the Cfl unit partially overlapping the Syul at the base of the mound (CTX image P01_001488_1751 overlain on a HRSC DEM, vertical exaggeration: x2). (d) Southeast portion of the Cf2 unit, which embays basement outcrops along the crater rim and extends up to the crater floor covering the Cf1 unit. The Cf2 unit is locally incised by fluvial valleys (black arrows) and displays partially exhumed sinuous ridges. Portion of CTX image (P01_001554_1745) overlain by HRSC contour lines (interval: $100 \mathrm{~m}$ ). (e) Close-up view of the outcrop of Cf 2 unit lying on the crater floor and of partially buried sinuous ridges. Location of Figure 16e is indicated in Figure 16d. (f) Oblique view of the Cf3 unit, which is incised by a wide canyon (thick arrows) and fluvial valleys (thin arrows). Mosaic of CTX images overlain on a HRSC DEM (vertical exaggeration: x2). 
a
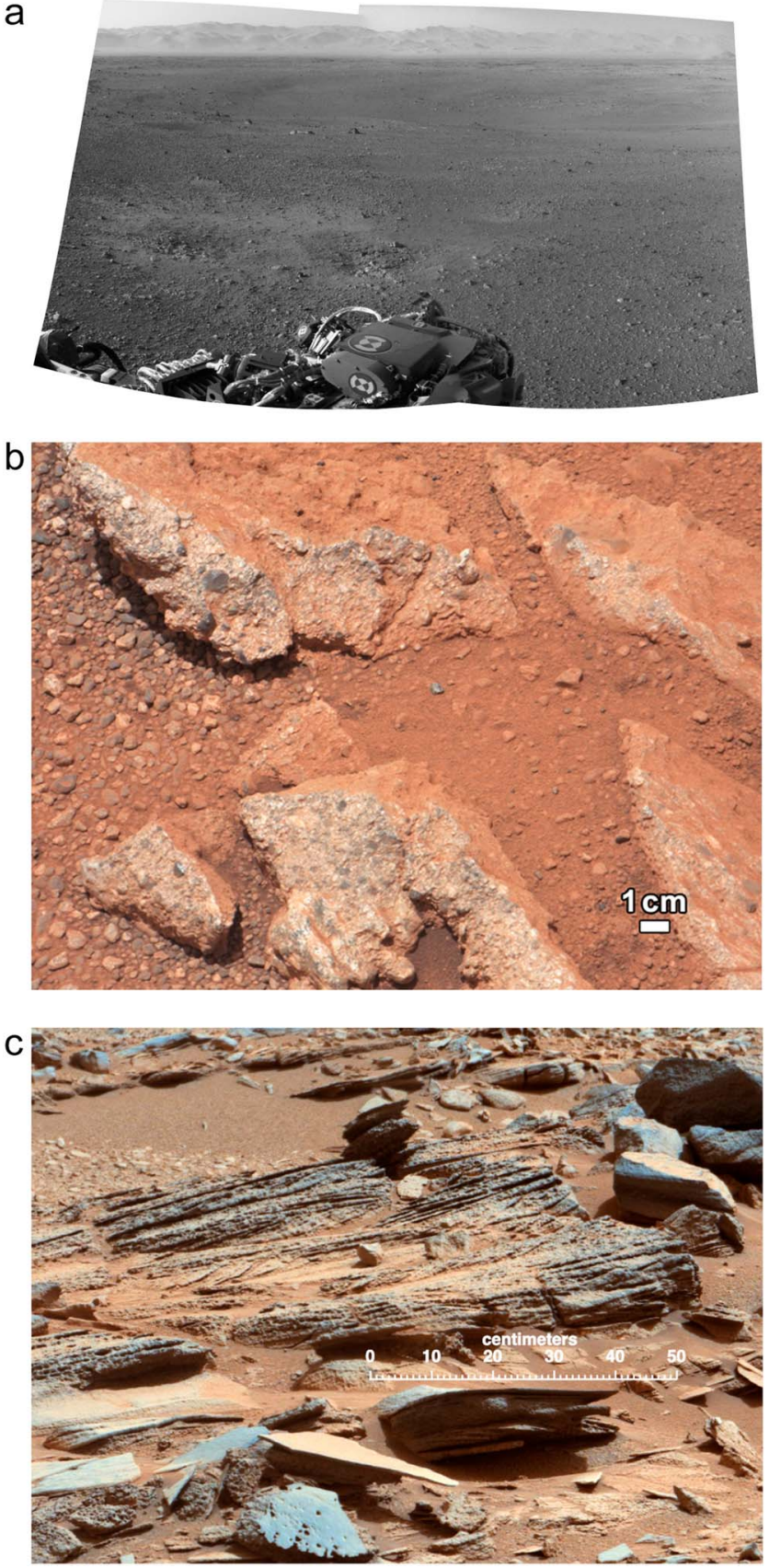

Figure 16. Images of the Cf1 unit from Curiosity. (a) View to the north showing the $\mathrm{Cfl}$ unit in the foreground and the crater rim in the background located $\sim 20 \mathrm{~km}$ away. Navcam mosaic from Bradbury Landing (NASA/JPL/Michael Howard). (b) Close-up view of an outcrop called Link corresponding to a puddingstone, a conglomerate containing rounded pebbles up to a few centimeters in size. Mast Camera image (NASA/JPL-Caltech/MSSS). (c) Close-up view of crossbedding in an outcrop called Shaler. Mast Camera image (NASA/JPL-Caltech/MSSS).

some inverted channels turn into prominent fan-shaped mesas (Figure 7a, inset B, Figures 7b, and 7e) may indicate that evaporation and/or sublimation have had a significant role in concentrating the soluble minerals beyond saturation. Reduced flow velocity associated with the widening of the channels may have enhanced the loss of the more stagnant water by evaporation and/or sublimation. Similarly, the nature of the cementation agent is unknown. Several chemical precipitates are known to be relevant in landscape evolution on Earth, including calcrete, laterite, ferricrete, and silcrete [Twidale and Bourne, 1998; Nash and McLaren, 2007]. Since sulfates have been detected in the lower strata of Aeolis Mons [Milliken et al., 2010], and sulfur is an important component in duricrusts elsewhere on Mars, it appears plausible that sulfates are a major component of the chemical cement in the sinuous ridges of Gale Crater.

[55] The process that exhumed the paleochannels and inverted their topography is most likely wind erosion. No fluvial channels seem to cut or erode the inverted channels. Instead, the yardangs on Aeolis Mons are strong indicators for significant aeolian erosion in Gale Crater, and many rocks as observed by the Mastcam of MSL display morphological characteristics of ventifacts such as facets (planar surfaces) separated by sharp keels (Figure 19) [Laity, 1994; Laity and Bridges, 2009]. Taken together, these observations strongly suggest that the denudation in Gale Crater that formed the inverted channels was mostly, if not exclusively, caused by aeolian abrasion.

\subsection{Aeolis Mons Units}

\subsubsection{Small Yardangs Units}

[56] The Syul consists of cohesive sediment containing sulfates and clays [Milliken et al., 2010]. It is structured in subparallel layers or groups of layers up to tens of meters thick; the estimated maximum thickness of the Syul is $\sim 3 \mathrm{~km}$. The unit may consist of alluvial deposits corresponding to the erosion products of the terrains surrounding the crater transported in the fluvial channels and accumulated inside the crater. However, the fluvial networks carved into the crater rim are poorly hierarchized, suggesting that their activity has been limited in time. Consequently, a limited volume of sediment has likely been supplied by the fluvial channels.

[57] Geometric measurements of the Syul show that its layers appear to drape the basement with a very low dip $\left(<3^{\circ}\right.$ on average; Table 2 and Figures 10and 12). This value is in agreement with recent dip measurements by Kite et al. [2013]. At first order, this layer geometry may be consistent with deposition both in a lake [e.g., Leeder, 1999] and by settling of particles in the atmosphere [e.g., Bourdier, 1994]. The lack of a fan delta of consistent dimensions in Gale (compared to Eberswalde crater [Pondrelli et al., 2008]) suggests that fluvial transport and lacustrine deposition of the Syu1 is unlikely. Sediments in fan deltas are typically coarser than more distal lacustrine sediments so it would have been easier to preserve the fan delta from erosion as compared to the Syul. However, a lake may have acted as a trap for volcanic ash, dust, and other airborne deposits [Cabrol et al., 1999; Malin and Edgett, 2000]. Authigenic clays may have formed in long-lasting subaqueous environments [e.g., Bristow and Milliken, 2011], and sulfates may have formed either by direct evaporation in shallow waters such as playa environments, or by alteration of the pristine lacustrine sediment [e.g., McLennan et al., 2005]. However, a lacustrine sedimentation suggests that the entire crater has once been filled by sediment. Some studies demonstrated that sedimentary deposits on Mars can be eroded very efficiently over large areas, e.g., in Meridiani Planum and Arabia Terra [Hynek et al., 2002; 
a

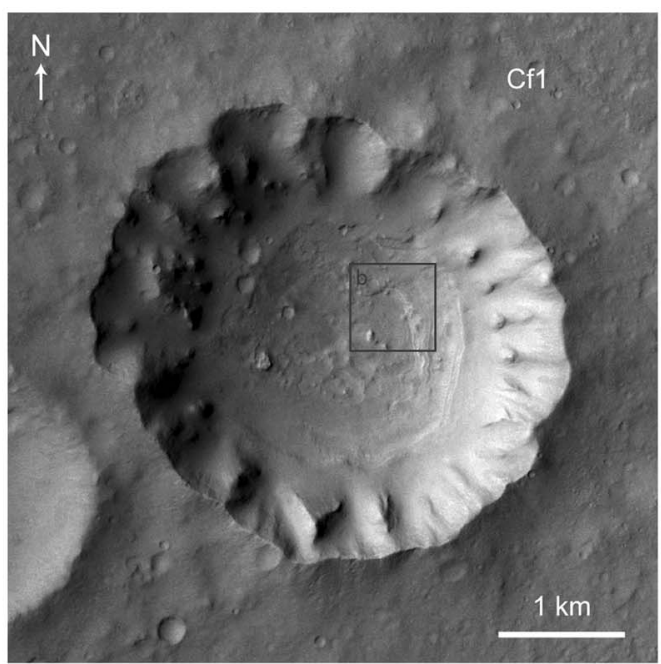

C

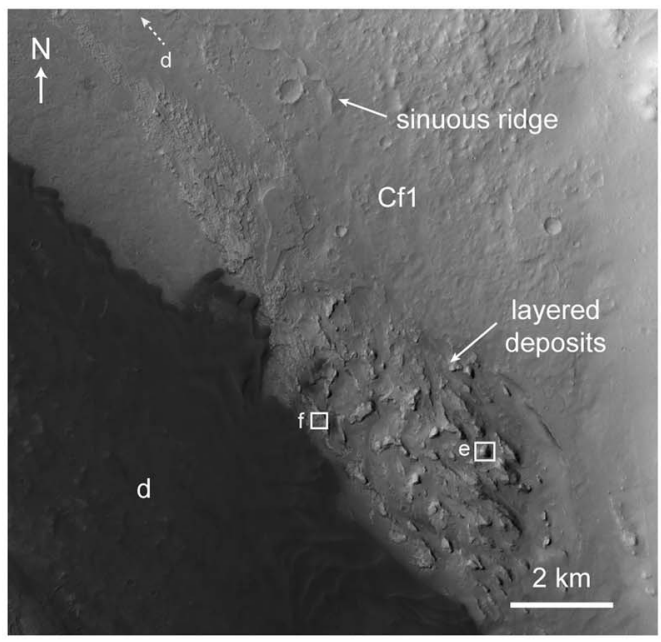

e

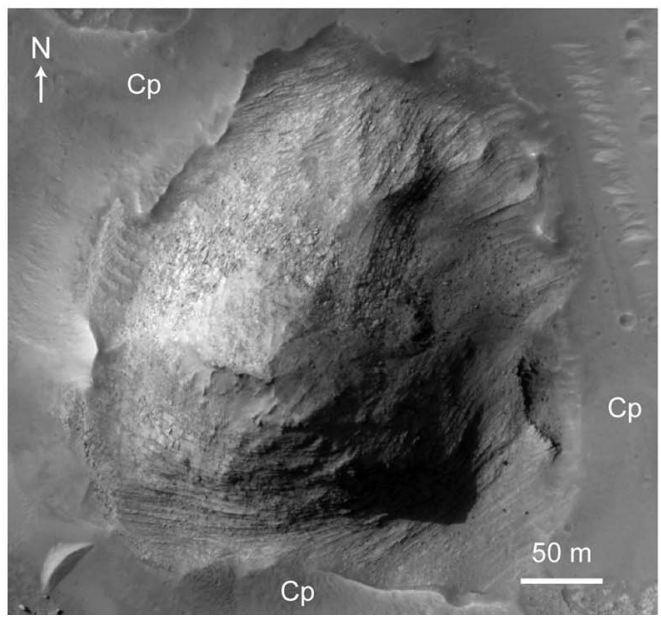

b

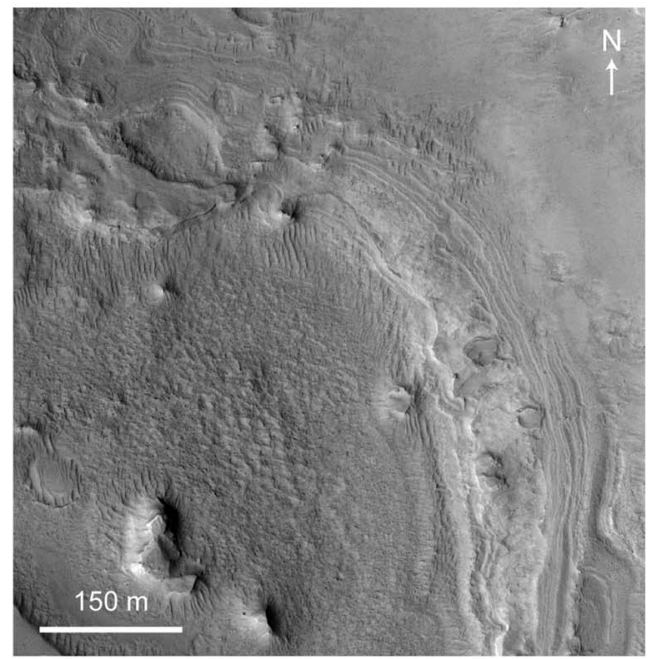

d

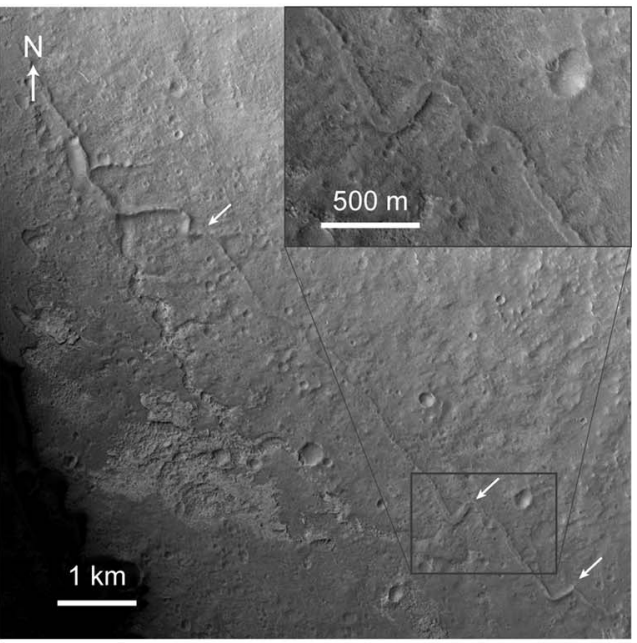

f

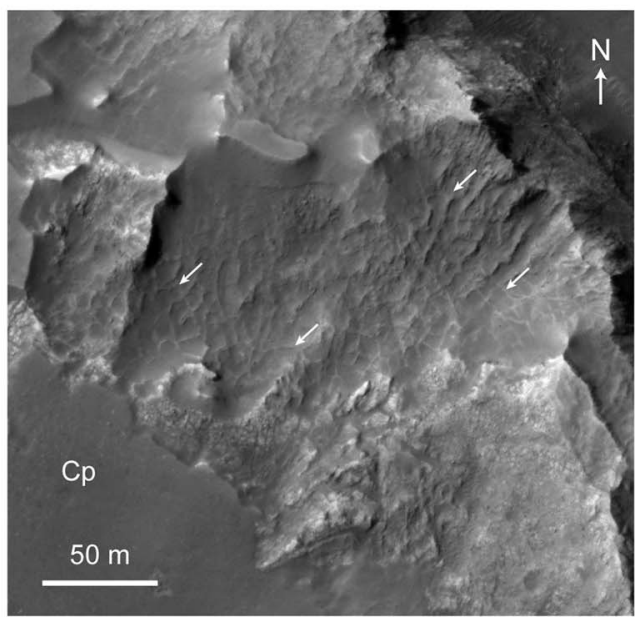

Figure 17. Layered deposits exposed on the crater floor in topographic lows. (a) Layered deposits filling an impact crater exhibiting a serrated rim located in the northwest part of Gale. Mosaic of CTX images. Location of Figure 8a is indicated in Figure 1. (b) Close-up view of the layered deposits. Portion of HiRISE image ESP_011984_1755. (c) Outcrops of layered deposits exposed east of Aeolis Mons, topographically below the base of the mound (mosaic of CTX images). Location of Figure 8c is indicated in Figure 1. (d) Close-up view of a sinuous ridge north of the layered deposits that displays right angles. Inset shows a blow-up (detail of MOC image S03-00700) of the exhumed and inverted channel. (e) Close-up view of a mound of finely layered deposits embayed by the Cp unit. Portion of HiRISE image ESP_026647_1750. (f) Exposure of layered deposits exhibiting polygonal fractures (arrows). Locations of Figures $8 \mathrm{e}-8 \mathrm{f}$ are indicated in Figure $8 \mathrm{c}$. 
a

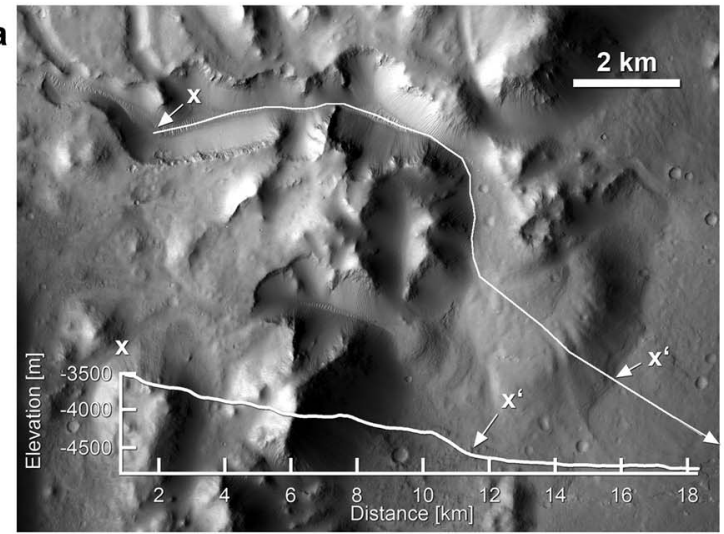

c

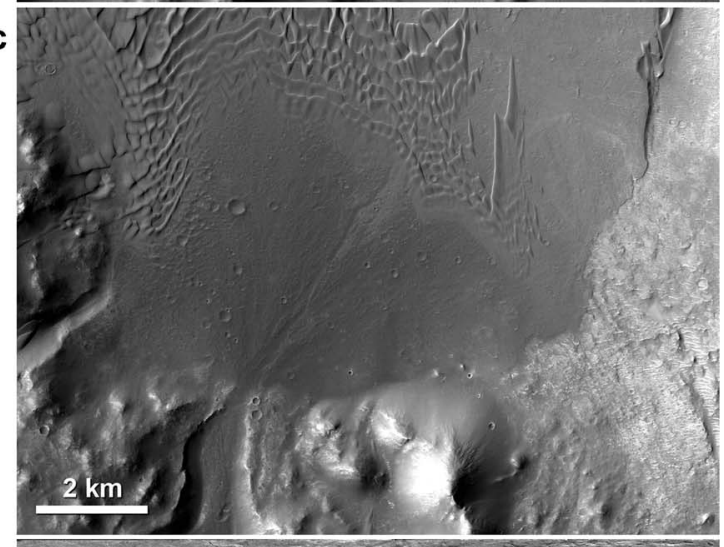

e

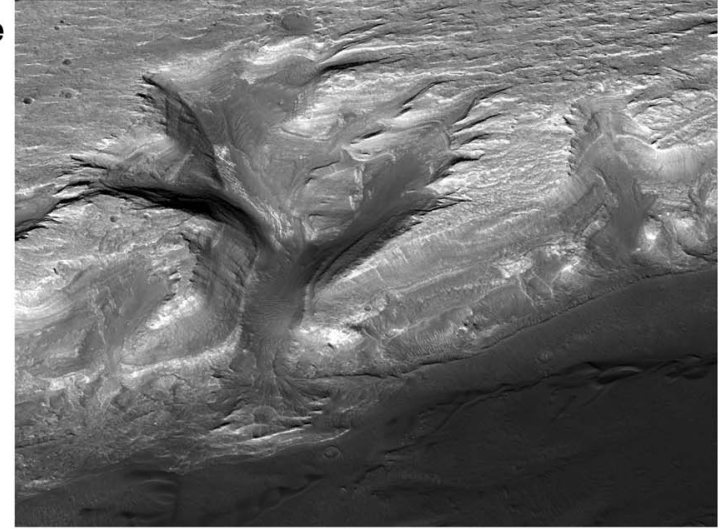

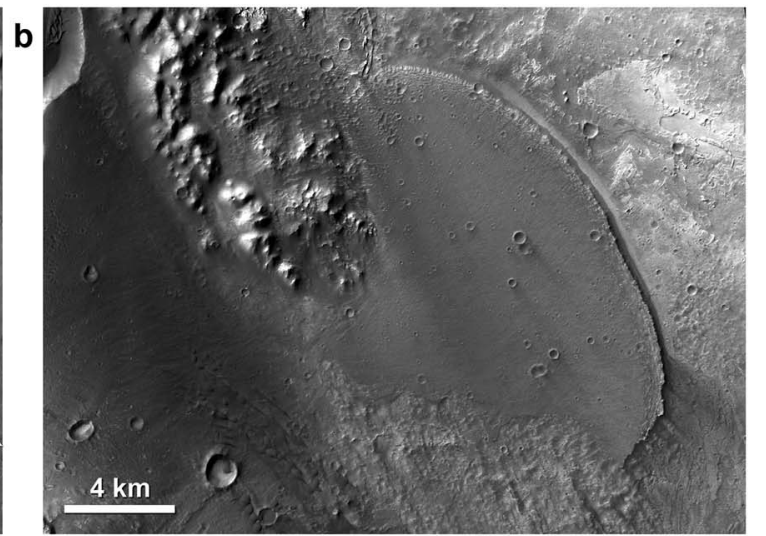

d
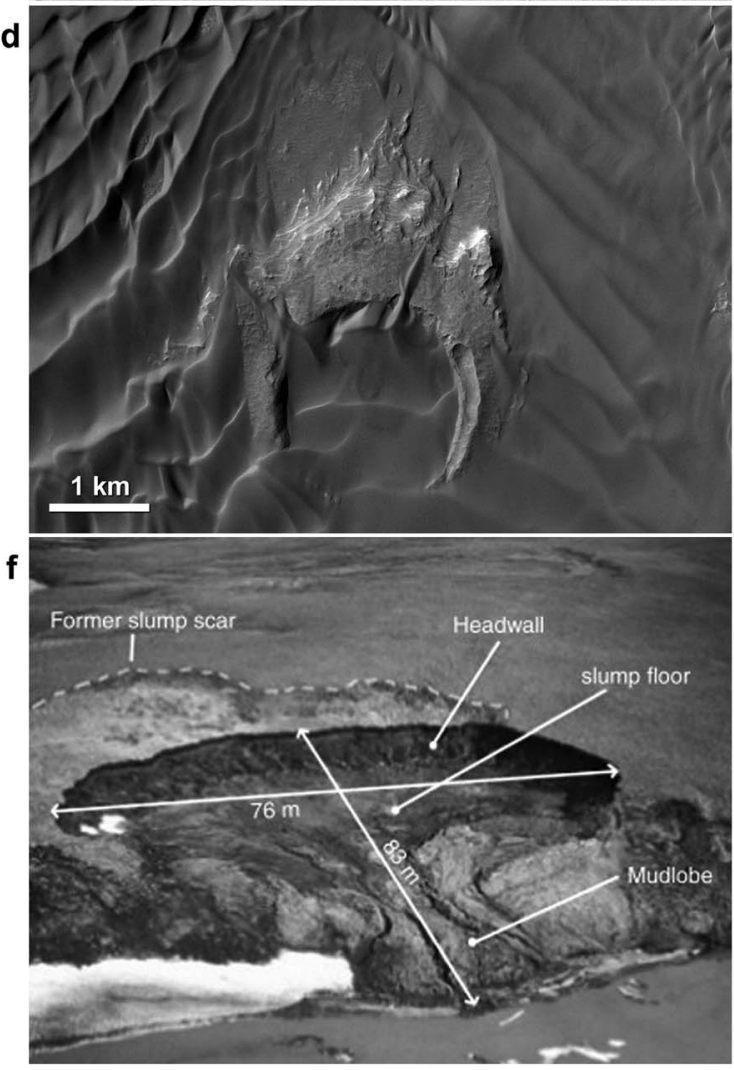

Figure 18. Different types of fan-shaped deposits inside Gale Crater and on Earth. (a) Scarp-fronted fan at the mouth of a deeply incised channel cutting through the western crater wall. Detail of CTX image G05_020265_1746, centered at $5^{\circ} \mathrm{S} / 136.7^{\circ} \mathrm{E}$. North is up. (b) Fan-like deposit on the southern floor of Gale displaying a steep frontal scarp. Detail of CTX image B21_017786_1746, centered at $5.78^{\circ} \mathrm{S} /$ $137.2^{\circ}$ E. North is up. (c) Fan on crater floor west of Aeolis Mons, displaying a faint radial pattern of fluvial dissection. Detail of CTX T01_000881_1752, centered at 5.43 ${ }^{\circ} \mathrm{S} / 137.0^{\circ} \mathrm{E}$. North is up. (d) Outcrop of layered deposits around degraded impact crater. Detail of CTX T01_000881_1752, centered at 5.13 ${ }^{\circ} \mathrm{S} /$ $137.02^{\circ} \mathrm{E}$. North is up. (e) Fan-shaped deposit at the mouth of a deep reentrant on the western slopes of the Aeolis Mons. 3-D perspective looking eastward, generated from a detail of CTX image B21 017786 1746 and a HRSC DEM, centered at $5.28^{\circ} \mathrm{S} / 137.17^{\circ} \mathrm{E}$ (scale: the valley directly above the fan is $\sim 1.5 \mathrm{~km}$ wide). (f) Retrogressive thaw slump in Thetis Bay, Herschel Island at the arctic coast of Canada (published by Lantuit and Pollard [2008]). Note the morphologic similarity to Figure 18e. Locations of Figures 18a-18e are indicated in Figure 1.

Fassett and Head, 2007; Zabrusky et al., 2012]. Even if the sediments of Meridiani Planum and Arabia Terra may have a different origin from those of the Syu1, one could suggest that the Syul may have also been eroded significantly and once filled the entire crater [Malin and Edgett, 2000]. The occurrence of canyons and yardangs carved into the Syul shows that the Syul has been eroded and was larger in the past. However, outcrops of the Syul reach an elevation of up to $-1800 \mathrm{~m}$, which exceeds the elevation of the northwestern crater rim, and hence, the maximum level of the potential 

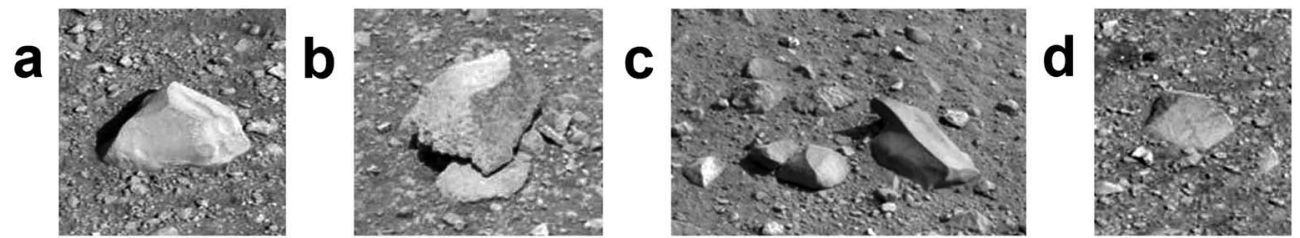

Figure 19. Ventifacts as seen by the Mastcam on the MSL rover, Curiosity (NASA/JPL-Caltech/MSSS).

lake by at least a kilometer (Figures 2b, 5, and 12a). Consequently, a lacustrine deposition of the Syu1 is unlikely.

[58] These observations let us suggest that the sediment of the Syu consists of air fall and likely aeolian material deposited in a nonlacustrine environment. Also, the sediment of the Syu and of the entire Aeolis Mons is not an isolated or unique exposure in the region, which would be expected for lacustrine or fluvio-deltaic deposits that usually fill topographic lows. Some exposures of the MFF, which lie on extended plains and plateaus, have been mapped in the very close vicinity of Gale Crater by Zimbelman and Scheidt [2012]. Whatever the origins proposed for the MFF, all of them imply atmospheric transport and air fall deposition of the sediment. It shows that air fall material has been deposited in the surroundings of Gale Crater and may have similarly filled the crater itself. Moreover, the recent slope wind-enhanced erosion and transport (SWEET) model of Kite et al. [2013] shows that the current dome-shape of Aeolis Mons can result from the deposition of air fall and aeolian sediment mediated by slope winds that move downward along the mound flank. This sediment may be dust, volcanic ash, fine-grained impact products, and possibly snow accumulated during suitable orbital and obliquity configurations, and wind-blown sands. The material of the Syu2 is interpreted to be similar air fall and aeolian sediment to that of the Syu1. Sulfates and clays may have formed in situ after the initial deposition of the sediment. These hydrated minerals have cemented the Syu1, which has likely contributed to preserve it from later erosion compared to air fall sediment deposited outside Gale.

[59] Since the material of the Syu consists of sulfate-rich layered sediment, it may share a similar origin with the sulfate-rich layered sedimentary rocks at Meridiani Planum which have been investigated by the Mars Exploration Rover Opportunity. Despite many in situ, experimental, thermodynamic, and kinetic studies, the formation process of the sulfates of the Meridiani rocks is still under debate [e.g., Squyres and the M.E.R. team, 2004, Squyres et al., 2006; Grotzinger et al., 2005; McLennan et al., 2005; McCollom and Hynek, 2005; Chevrier and Mathé, 2007; AndrewsHanna et al., 2007; Berger et al., 2009; Niles and Michalski, 2009; Kite et al., 2013]. However, in situ evidence shows that they are primarily aeolian sediment [e.g., McLennan et al., 2005]. This origin would be generally consistent with the air fall and aeolian origin that we propose for the material of the Syu in Gale.

\subsubsection{Mass-Wasting Deposits}

[60] The mass-wasting deposits are characterized by different morphologies, which probably reflect different formation processes and/or physical and mechanical properties of the mass-wasted material.

[61] The maximum extent of the lobate deposits is the base of Aeolis Mons' flank, which suggests that they correspond to viscous flow lobes resulting from slow movement such as creep (Figure 13c). They may correspond to rock glaciers, as previously suggested by Anderson and Bell [2010]. Rock glaciers are lobate or tongue-shaped features of unconsolidated material which are supersaturated with interstitial ice and ice lenses that move downslope by creep as a consequence of the deformation of the ice crystals [Wahrhaftig and Cox, 1959; Barsch, 1996; Gutiérrez, 2005]. Rock glaciers are permanently frozen, and they may reach a total thickness of more than $50 \mathrm{~m}$ on Earth [e.g., Barsch, 1996].

[62] The fan-shaped deposits located to the east of the lobate deposits share morphologic similarities with spatulate rock glaciers, which are talus-derived rock glaciers formed beneath scree slopes and composed of ice-cemented debris displaying a broad lower part [Barsch, 1996]. They display a steep front and arcuate ridges and furrows at their surfaces, commonly aligned perpendicular to the flow direction [French, 2007]. Such ridges are observed at the surface of the fan-shaped deposits (Figure 13f).

[63] The eastern deposits show preserved layered outcrops of the Syu1. This suggests that the mass-wasting has been a very slow process consistent with creeping. Creeping may have been facilitated by the presence of hydrated minerals in the Syu1. However, a landslide origin of the eastern deposits cannot be ruled out.

[64] Rock glaciers form where permafrost is present and where there is an adequate accumulation of coarse clastic debris. Percolating water from snowmelt infiltrates and freezes to form an ice-debris matrix which then deforms [French, 2007]. The melting of snow may have been enhanced on the northern slopes of Aeolis Mons as compared to the southern ones because the former are facing the equator and receive higher average insolation. Gale Crater and the mass-wasting deposits are located along the dichotomy boundary (Figure 2a). The advance of the rock glaciers (or, for that matter, any other mass-wasting deposits) may have been accelerated by seismic activity in the region possibly related to reactivation of $\sim \mathrm{N} 100^{\circ}$ trending faults located along the dichotomy [Watters, 2003]. The occurrence of $\sim \mathrm{E}-\mathrm{W}$ trending fractures, corresponding to possible faults observed on the fan-shaped deposits [Anderson and Bell, 2010], would be consistent with the fact that seismic activity may have affected the materials of Gale Crater.

\subsubsection{Coarse Yardangs Unit}

[65] The Cyu displays a thin subparallel layering, which lies unconformably over the Syul and the mass-wasting deposits, with a dip of $8-9^{\circ} \mathrm{SW}$ for the western Cyu. These relatively high layer dips suggest that the Cyu may correspond to air fall sediments and wind-blown sands like the Syu1, since such high dips would not be expected in the middle of a thick stack of lacustrine deposits. The presence of yardangs shows that the $\mathrm{Cyu}$ is consolidated or semiconsolidated [Goudie, 1983]. It may have been lithified into a cohesive rock by compaction or cementation related to 
water flows at least for the western Cyu. The change in albedo and in erosion patterns between the Cyu and the Syul may indicate that the source of sediment or the grain size is different between the two units.

\subsubsection{Benched Unit}

[66] The thin layers of the Bu located at the top of Aeolis Mons are inclined and dip $4-9^{\circ} \mathrm{NW}$ and exhibit some possible meter-scale cross beds along benches (Figure 15c). Taking into account the high elevation of the $\mathrm{Bu}$ in the crater, these cross beds suggest that the $\mathrm{Bu}$ rather corresponds to lithified aeolian material than fluvial or lacustrine deposits. This aeolian material accumulated at the top of the mound may be primarily sands or other particles that are coarse enough to form dunes. The $\mathrm{Bu}$ layers are the thinnest of the mound (usually $<3 \mathrm{~m}$ ), which may be due to a weak sediment supply (Figure 11). The cliff-bench morphology is indicative of resistant layers alternating with more easily eroded material and may suggest a cyclic deposition possibly influenced by orbital variations as proposed by Lewis et al. [2008]. As mentioned above, several authors suggested that the materials of Aeolis Mons may belong to the MFF [Scott and Chapman, 1995; Thomson et al., 2011; Zimbelman and Griffin, 2010]. Because of the apparent absence of alteration minerals in the $\mathrm{Bu}$, it is the part of Aeolis Mons which is the most similar to the MFF. While the lower part of the mound (Syu1) may have formed in a similar way, they are distinguished from the MFF by the existence of hydrated minerals.

\subsubsection{Caprock Unit}

[67] The Cp drapes the other units of Aeolis Mons and the crater floor and likely corresponds to a late-stage deposition of air fall material. Similar cap units named "thin mesa" have been described in other regions of Mars where layered sedimentary deposits are observed, including the Valles Marineris and its surrounding pits [Malin and Edgett, 2000; Fueten et al., 2011].

\subsection{Crater Floor Units}

\subsubsection{Crater Floor Units 1-4}

[68] The crater floor units likely correspond to detrital deposits of mixed origins including alluvial, colluvial, and aeolian deposits. The source and origin of the deposits may vary according to the location in the crater. The northern Cf1 unit consists of alluvial deposits possibly mixed with colluvial deposits resulting from the gravitational accumulation of the erosion products from the mountainous crater rim. The MSL rover landing site is located in the northwestern Cf1 unit, close to one of the alluvial fan-shaped deposits. The first Navcam images reveal a rock-strewn gravelly surface (Figure 17a), which is consistent with an ancient alluvial plain that has been strongly eroded by winds. The rounded pebbles of the conglomerate observed by Curiosity's Mast Camera at the Link outcrop are also indicative of aqueous sediment transport (Figure 17b) [Williams et al., 2013b]. The cross beds visible at the Shaler outcrop are also indicative of sediment transport in stream flows; the grain sizes being too coarse for having been transported by wind (Figure 17c) [Williams et al., 2013b].

[69] The Cf2 materials are interpreted as colluvial and alluvial deposits accumulated along the slopes of the southeastern crater wall. The materials of the Cf3 unit form an alluvial plain, composed of the erosion products of the highlands surrounding the crater and the crater rim itself. The Cf4 unit, situated topographically mainly below the $\mathrm{Cf} 3$ unit and stratigraphically above the Cf1 unit, may correspond to fine-grained alluvial material deposited distally from the outlet of the wide canyon carved into the Cf3 unit (Figure 5).

\subsubsection{Layered Deposits}

[70] The layered deposits filling the serrated crater on the northwestern part of Gale's floor likely correspond to the erosion product of the rim and upper walls. Other sources from outside the crater may have also contributed to fill the crater. These sources may be aeolian or lacustrine material; the crater thereby acting as a sediment trap.

[71] The layered deposits on the northeastern part of the crater may have been formed by different processes at different times. They may have been deposited after the deposition of the Syu, possibly as air fall deposits possibly reworked by aeolian processes even if no cross beds have been observed. They may also have been deposited in a standing body of water filling the lowest part of Gale Crater after the deposition of the Syu1. Since the layered deposits are located topographically below the Syu1, they may also correspond to materials deposited at the same or a lower stratigraphic level as the Syu1 and be remnants of a former more extensive Aeolis Mons.

\subsubsection{Fan-Shaped Deposits}

[72] One of the scarp-fronted deposits presents a distinct frontal step, which is characteristic of Gilbert-type deltas that form in a standing body of water [Gilbert, 1885] (Figure 18f). Similar deposits have been interpreted as Gilbert-type deltas on Mars, such as in Ismenus Lacus and Xanthe Terra and have been associated to crater lakes [e.g., Ori et al., 2000; Hauber et al., 2009; Dehouck et al. 2010]. The stair-stepped topography observed for two fans and the relative absence of channels at the surface of all fans are consistent with shorttermed fluvial processes [Kraal et al., 2008; Kleinhans et al., 2010].

[73] Some of the thick fan-shaped deposits located at the base of Aeolis Mons share morphologic similarities with retrogressive thaw slumps (RTS; Figures 18e and 18f). RTS result from the thaw of ice-rich permafrost. They are characterized by "a semicircular steep headwall, beneath which there is a gently sloping floor. As the headwall retreats by thaw, sediments are redeposited by falls, slides, debris flows, meltwater, and subslump melt-outs" [French, 2007, p. 194]. RTS are often hundreds of meters in diameter but can be of kilometric scale. RTS are commonly triggered by the removal of the layer of material that thermally protects the excess or massive ground ice [Mackay, 1966]. In the North American Arctic, this process is often initiated by coastal or lateral stream erosion [e.g., French, 2007; Lantuit and Pollard, 2008; Lantz and Kokelj, 2008]. In some cases, RTS are initially developed by simple activelayer slope failure [Bird, 1967]. The headwalls on terrestrial RTS do not typically have such deep reentrants as those observed on Aeolis Mons. This indicates that additional formation processes to RTS would have probably played a role in the formation of these deep reentrants on Aeolis Mons such as groundwater discharge.

[74] Several bowl-like features morphologically similar to RTS on Earth have been observed along the main channel of the outflow channel Athabasca Valles $\left(8.2^{\circ} \mathrm{N}, 154.4^{\circ} \mathrm{E}\right)[$ Van Bun Tseung, 2008]. These RTS would have been formed after the main flooding episodes that carved Athabasca Valles 
hadsaturated the ground with water (ice) during the Late Amazonian Epoch. These flooding episodes may have caused mechanical or thermal erosion of surface material and resulted in the exposure of ground ice and subsequently to the formation of the RTS [Van Bun Tseung, 2008]. This implies that ground ice was present in the recent past to low latitudes.

\section{Proposed Periglacial Environment and Its Hydrological System}

\subsection{Observations Suggestive of a Periglacial Environment}

[75] A periglacial domain includes areas where the mean annual air temperature is less than $+3^{\circ} \mathrm{C}$, which often contain permafrost, and in which frost action occurs or dominates [Dylik, 1964; French, 2007]. As discussed above, several landforms are suggestive of a periglacial environment within Gale Crater. Some of the mass-wasting deposits including the lobate and the fan-shaped features are interpreted to be possible rock glaciers, which form in permafrost regions (Figure 13). The eastern deposits may have been formed by a slow gravity-driven process, possibly by creep deformation of pore ice. The thick fan-shaped features lying on the crater floor and situated at the mouth of steep-headed walls share common morphologic characteristics to thaw slumps (Figures 18e and 18f). Polygonal ridges observed on the layered deposits on the crater floor east of Aeolis Mons may be paleosand wedges, which form in permafrost conditions (Figure 8f). The polygonal pattern on the exhumed and inverted landforms south of Aeolis Mons may also be ancient thermal contraction cracks, although desiccation cracks may seem more likely (Figure $7 \mathrm{~g}$ ). Hallet et al. [2013] investigated the hypotheses that fracture networks close to the MSL landing site may be periglacial in origin. In the same region of the crater, Oehler [2013] identified in orbital data a suite of features including polygonally fractured terrains, sometimes with a circumferential pattern, irregularly shaped and clustered depressions, and a general hummocky topography, that she interpreted as possible periglacial landforms involving permafrost and freeze-thaw cycles in Gale Crater. Many of these landforms may have alternative origins, but collectively, we think that they may indicate that Gale once contained permafrost in a periglacial environment.

[76] The occurrence of a permafrost and an active layer in Gale Crater in the past does not require a climate much warmer than today. Richardson and Mischna [2005] showed that transient liquid water (ice melt) can occur on Mars under current surface pressures and obliquity because of the large range of surface temperatures during the day. Using air temperatures measured by the rover Opportunity in Meridiani Planum and a heat conduction equation, Van Bun Tseung [2008] showed that under current summer conditions, subsurface temperatures above $0^{\circ} \mathrm{C}$ can occur for a few hours at a few decimeters or up to $1 \mathrm{~m}$ depth in the equatorial regions of Mars even under the current very cold climate.

\subsection{Evidence for the Existence of a Paleolake}

\subsubsection{Review}

[77] Several authors suggested the presence of a paleolake within Gale Crater [Cabrol et al., 1999; Malin and Edgett, 2000; Thomson et al., 2011]. From Viking and MOLA data, Cabrol et al. [1999] suggested the existence of an
Amazonian lake because of the occurrence of young floor deposits, streamlined terraces, and layers and channels observed on Aeolis Mons. The water of the lake would have been provided either by the drainage of an aquifer in the Aeolis Mensae region, or by the overspilling of the northern rim by a southern transgression of the Elysium paleolake, supposed to have filled Elysium Planitia during the Amazonian Epoch [Scott and Chapman, 1995]. However, no deep valley breaches the rim of Gale Crater, and the MOLA topographic data show that no enclosed basin which could have hosted a lake occurs in Elysium Planitia [Irwin et al., 2005]. Cabrol et al. [1999] and recently Schwenzer et al. [2012] suggested that a lake may have filled Gale early after its formation, in response to hydrothermal activity. From morphologic and topographic observations, Irwin et al. [2005] concluded that Gale Crater may have contained one or two paleolakes at low elevations $(\leq-3300 \mathrm{~m})$, but they did not find evidence that lakes persisted for millions of years or more. From MOC images, Malin and Edgett [2000] favored a lacustrine origin for Aeolis Mons sediments and other sediments on Mars because of their affinity for closed basins, their thickness, regular layering, and apparent lack of cross beds. Thomson et al. [2011] mentioned that the geomorphologic evidence for fluvial activity may indicate an early lacustrine phase in Gale.

\subsubsection{Observations and Interpretations}

[78] The occurrence of a fan-shaped deposit morphologically similar to a Gilbert-type delta is a strong hint to the existence of paleolake in Gale (Figure 18a). The apex of the delta is situated at $-4200 \mathrm{~m}$ and is roughly at the same elevation as the upper margin of the steep frontal scarp which would correspond to the water level existing at the time of the delta formation. This delta is overlying the Cf4 unit, which shows that the lake existed after the deposition of the Cf4 unit. The thick fan-shaped deposits at the mouth of deep reentrants on the western and southern slopes of Aeolis Mons share morphologic similarities with retrogressive thaw slumps (Figures 18e and 18f). These backwasting thermokarst features [French, 2007] are often initiated by coastal erosion [Lantuit and Pollard, 2008]. The layered deposits observed on the crater floor may have been deposited at least partially in standing waters.

[79] The terraces and possible shorelines observed by Cabrol et al. [1999] have been reassessed in the light of HiRISE and CTX images, and HRSC topographic data. The terraces are observed along the Syul to the west of Aeolis Mons (Figure 20a). The lower ones are horizontal and are situated at $-4450 \mathrm{~m}$ and $-4000 \mathrm{~m}$. The highest terrace is roughly located at $-3700 \mathrm{~m}$ but is not horizontal. It also marks the contact between the Syul and the western Cyu outcrop. These terraces may be stratigraphic contacts highlighted by aeolian erosion due to variations in the strength of the material of the Syu1 [Thomson et al., 2011]. However, no terraces are observed at an elevation higher than $-3700 \mathrm{~m}$ in the Syul even though the unit reaches $-1800 \mathrm{~m}$ in elevation. Differential erosion of the unit by wind would probably be more pervasive as for the Benched unit (Figure 15). Additionally, the lower terraces follow an equipotential surface over long distances of more than $20 \mathrm{~km}$. Consequently, these terraces (the lower ones at least) may result from wave-cut erosion at different lake levels rather than aeolian erosion. To the east of Aeolis Mons, an intriguing scarp cuts the Syu1 and the eastern mass-wasted deposits at 
a

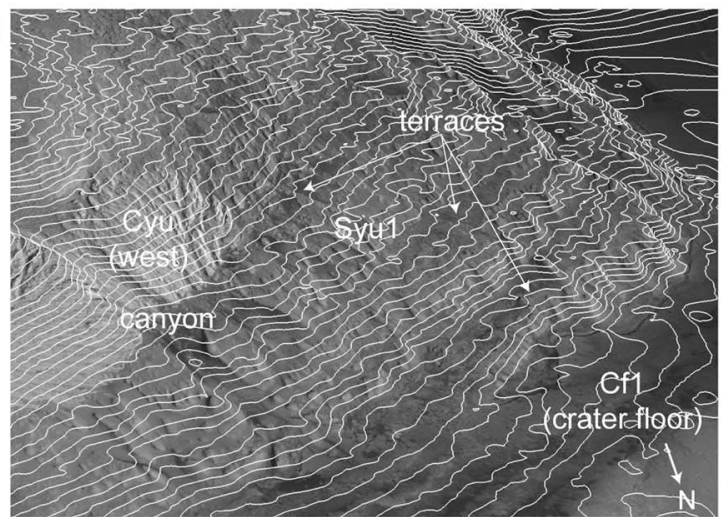

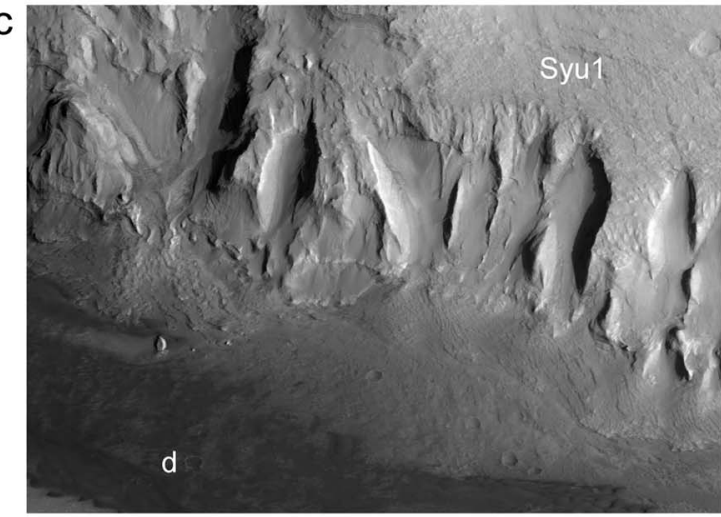

b

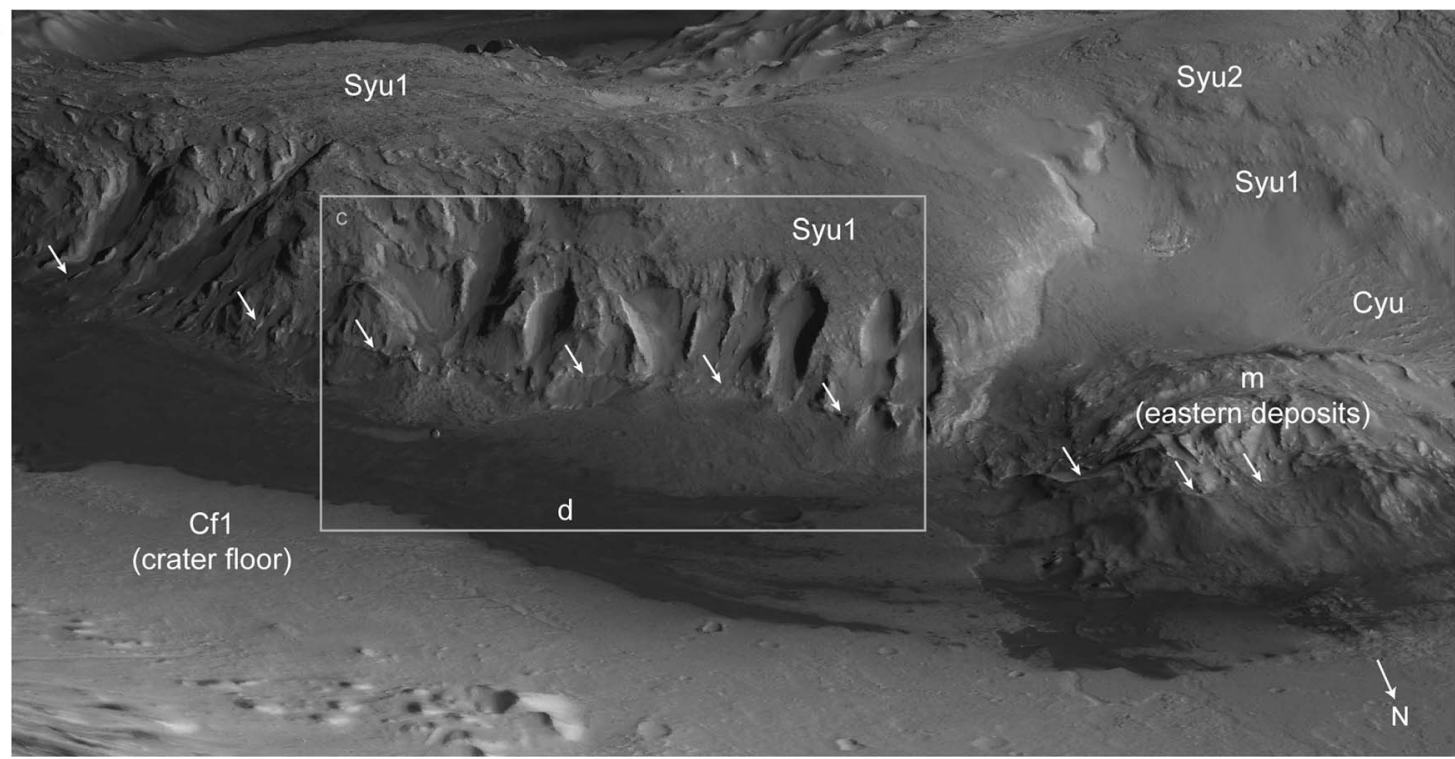

Figure 20. Terraces and other possible shorelines located down Aeolis Mons. Locations of Figures 20a and $20 \mathrm{~b}$ are reported in Figure 1. (a) Oblique view of subhorizontal terraces carved into the Syu1 to the western part of the mound. The three main visible terraces are located at $-3700,-4000$, and $-4450 \mathrm{~m}$ in elevation. Mosaic of CTX images overlain on a HRSC DEM (elevation contours intervals: $50 \mathrm{~m}$, vertical exaggeration: $\mathrm{x} 2$ ). (b) Oblique view of the eastern part of the mound displaying a scarp at $-2300 \mathrm{~m}$ (arrows). The Mosaic of CTX images overlain on a HRSC DEM (vertical exaggeration: x2). (c) Closeup view of Figure 20b showing that the morphology of the slope is different above and below the scarp. Location of Figure 20c is indicated in Figure 20b.

$-4300 \mathrm{~m}$ in elevation over more than $30 \mathrm{~km}$ in length (Figure 20b). The morphology of outcrops is different above and below this scarp (Figure 20c). Above the scarp, slopes of the Syu1 are incised by canyons, which are oriented parallel to the direction of the steepest slope. Below the scarp, no canyons are visible and the slopes are gentler than those above the scarp. These morphologies may be explained by the existence of a paleolake where the scarp would correspond to a past shoreline. Moreover, the canyons or reentrants above the scarp have an appearance (steep sides, abrupt head scar, and low aspect ratio in plan view) that resembles some experimentally formed sapping valleys [e.g., Kochel et al., 1988]. If they are indeed formed by sapping, this could have happened during the slow decrease of the lake level, when liquid water (e.g., from snowmelt [Kite et al., 2012]) would drain toward the lowering base level and induce sapping. Aeolian and current gravity-driven erosion may also have contributed to their current morphology. Consequently, the morphology of the terraces and shorelines are consistent with the presence of a lake, but only after the deposition of the Syul and the mass-wasting deposits.

[80] An obvious observation that is consistent with a paleolake is the presence of valleys, canyons, and sinuous ridges distributed over the crater rims and Aeolis Mons, which imply that water flowed in the crater and may have contributed to feed a lake. Gale is an enclosed basin, which may have hosted a lake in case of a water supply that was higher than the combined effects of evaporation/sublimation and the infiltration of water in the porous ground.

[81] All possible morphologic indicators of the existence of a paleolake, including the Gilbert-type delta fan, possible thaw slumps, terraces, possible shorelines, and layered deposits on the crater floor, are located in the same elevation range, between $-4450 \mathrm{~m}$ and $-3700 \mathrm{~m}$, which would correspond to the ancient lake levels. We estimated the volume of the possible lake at two levels using an HRSC DEM. We 

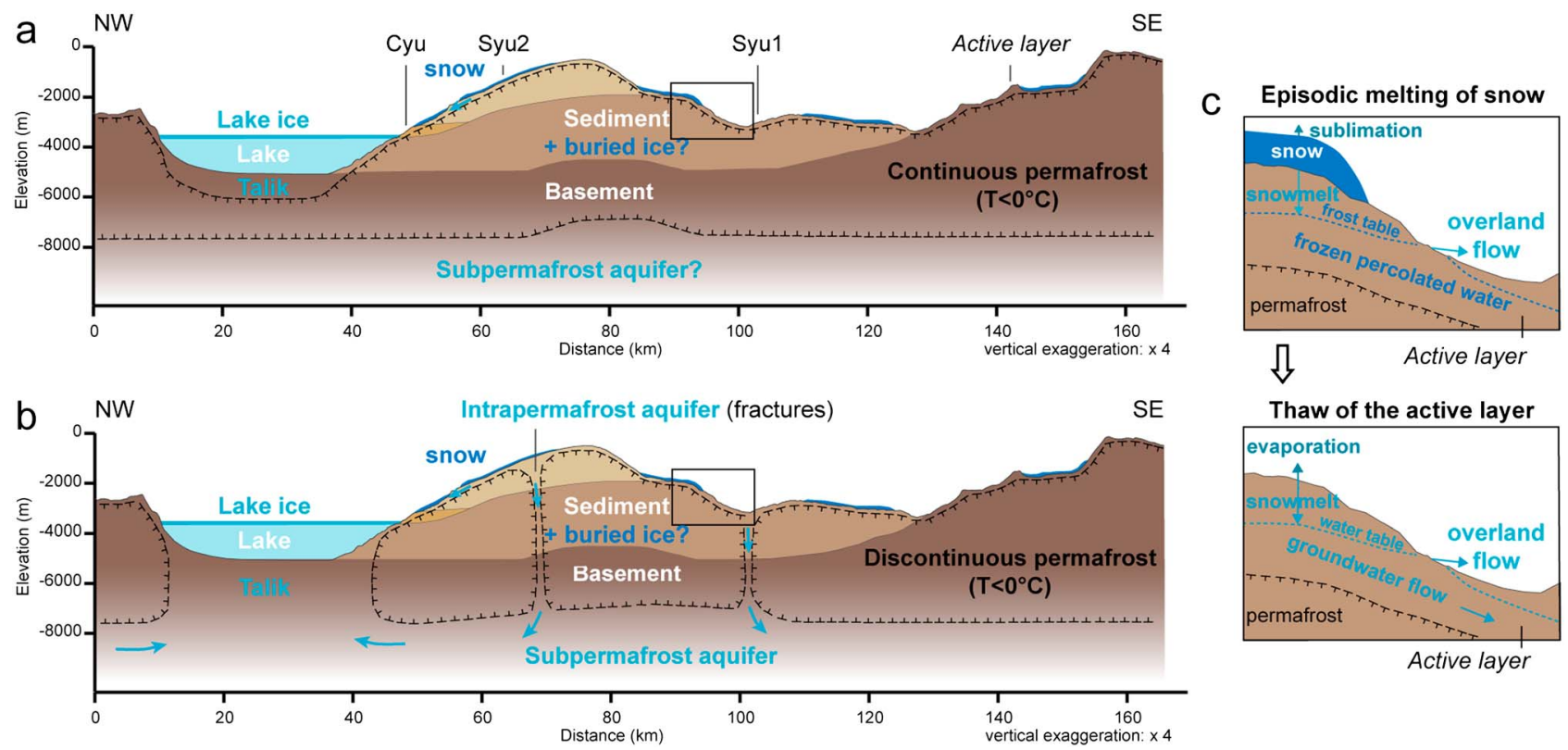

Figure 21. Representation of the proposed periglacial environment of Gale Crater and its possible hydrological systems at high obliquity during the Hesperian Epoch during a melt episode. Cross sections located as "a-a" in Figure 5. The maximum depth of the permafrost is not known. The lake level represented is $-3700 \mathrm{~m}$, considered as the maximum level. The $\mathrm{Bu}$ unit is not represented because it does not show any morphological or mineralogical evidence for the past presence of water. (a) Continuous permafrost hydrology. (b) Discontinuous permafrost hydrology. (c) Close-up view of Aeolis Mons subsurface during a melt episode: from the snow melting at the surface of the mound (top) to the active layer thawing and its ground ice melting (bottom).

assumed that the lake floor elevation corresponds to the current floor elevation. Taking a water level of $-3700 \mathrm{~m}$ (Figure 5), the area of the lake surface would have been $6085 \mathrm{~km}^{2}$, and its volume would have been $3615 \mathrm{~km}^{3}$ with an average water depth of $\sim 590 \mathrm{~m}$. For a water level of $-4200 \mathrm{~m}$ (Figure 5), the lake would have occupied $3514 \mathrm{~km}^{2}$ in area and $1429 \mathrm{~km}^{3}$ in volume with an average water depth of $\sim 400 \mathrm{~m}$. In the latter case, the paleolake of Gale would have had a volume comparable to those of Great Slave Lake $\left(1500 \mathrm{~km}^{3}\right)$ or Lake Ontario $\left(1700 \mathrm{~km}^{3}\right)$ on Earth.

\subsection{A Periglacial Environment With Continuous/ Discontinuous Permafrost}

\subsubsection{Proposed Scenarios}

[82] The occurrence of a paleolake in a periglacial environment in Gale Crater raises several questions including: What are the possible sources of the lake water? How is the presence of sulfates and clays in Aeolis Mons consistent with a periglacial environment and permafrost? Is a periglacial environment considered to be possible by climatic models of Mars at those latitudes in the past? We propose two different scenarios of periglacial conditions which are consistent with our observations and previous models and studies (Figure 21). In the first scenario, we propose that several hundred thousands of years after the impact, the entire region was characterized by continuous permafrost (Figure 21a). This permafrost was overlain by an active layer, which was subject to freeze-thaw cycles. Under suitable obliquity and orbital conditions, ice/snow was stable at the surface. Aeolis Mons was forming by accumulation of air fall and aeolian sediment and possibly snow, resulting in the presence of buried ice within the mound. Episodically, snow at the surface melted. Snowmelt infiltrated into the ground and froze in the active layer (Figure 21c). Rock glaciers formed along the northern slope of the mound. Snowmelt percolating within the sediment caused the precipitation of sulfates and clays, which contributed to indurate the sediment. The shallow frost table inhibited a very deep percolation of snowmelt and facilitated the formation of overland flows, creating the canyons visible along the flanks of Aeolis Mons (Figure 21c). When the melt season continued, ground ice of the active layer melted producing some groundwater flows along the slopes (Figure 21c). A lake was episodically filling the deepest portions of Gale Crater (Figure 21a). The lake was likely partially or totally ice-covered because of the cold air temperature. In this continuous permafrost scenario, the lake may have been primarily recharged by snowmelt and, to a minor degree, by melted ground ice.

[83] In the second scenario, we propose that the region of Gale Crater was characterized by discontinuous permafrost instead (Figure 21b). In that case, the lake may have been connected to a subpermafrost aquifer which may have been recharged by snowmelt percolating through the mound via fractures and by groundwater flow coming from east of Isidis basin as proposed by Andrews-Hanna et al. [2012] in their regional groundwater model (Figure 21b). The possible retrogressive thaw slumps, which are more speculative, may have been formed during a higher peak temperature. Under current conditions, the climate is very dry and ice is not stable at the surface anymore at this low latitude. 


\subsubsection{Was There Ice-Rich Permafrost?}

[84] In our scenarios, ice is stable at the surface. This hypothesis is supported by climatic and thermal models showing that ice (snow) may have accumulated in a few equatorial regions of Mars and may have been stable at the surface under past orbital conditions including a higher obliquity [Madeleine et al., 2009; Kite et al., 2012]. Our scenarios of a periglacial environment with permafrost are consistent with the formation model of sedimentary rocks proposed by Kite et al. [2012], in which liquid water is provided by seasonal melting of snow or ice. The model predicts that the global distribution of snowmelt would have been maximum in Gale Crater as well as in the Valles Marineris and Meridiani Planum when obliquity reached $>\sim 40^{\circ}$, eccentricity $>\sim 0.12$, and perihelion occurred near equinox. In our scenarios, we propose that buried ice corresponding to former snow has been accumulating in Aeolis Mons. This hypothesis is neither strongly supported by our observations nor required in our scenarios but is very plausible. If some of the fan-shaped deposits were indeed thaw slumps, this would require the former presence of ice-rich permafrost. Moreover, assuming that snow was episodically falling in the crater, it is likely that snow accumulated in the crater together with the sediment. Finally, if the sulfates in Aeolis Mons precipitated by freezing of $\mathrm{Mg}$ sulfate brines (see below), it implies the formation of ice. In case of permafrost thawing, this buried ice would have been an additional source of water to snowmelt for altering the sediment, feeding the lake, and carving the canyons in Aeolis Mons.

\subsubsection{Formation of Sulfates and Clays}

[85] Sulfates and clays have been detected at the base of Aeolis Mons (mainly in the Syu1) by Milliken et al. [2010] using remote spectroscopy. Their presence is totally consistent with a periglacial environment with permafrost, which has hydrologic and groundwater characteristics different from those of nonpermafrost terrain [Hopkins et al., 1955]. A high degree of mineralization in subsurface permafrost waters is often characteristic of permafrost terrain, because of the restricted circulation imposed by the permafrost and the concentration of dissolved solids in the taliks (Figure 21) [French, 2007]. Vogt and Larqué [2002] showed that the presence of calcite, clays, and sulfates with peculiar crystalline features in the circum-Baikal region on Earth allows demonstrating that the climate was cold enough for permafrost to form during the Pleistocene, even if cryogenic macroscopic structures are not convincing or lacking. In our scenarios, we propose that sulfates and clays correspond to secondary minerals precipitated in Aeolis Mons in response to percolating snowmelts. By percolating into the active layer, snowmelt dissolved soluble ions from primary minerals in the sediment to form brines. These primary minerals may also have released ions into solutions being weathered by frost action. Then, the brines may have frozen in the active layer where the ground temperature reached the eutectic temperature of the salts. They may have also rose to the surface by capillary action and evaporated where no snow remained, precipitating the salts [Vennum, 1980]. From their ISEEMars model, Kite et al. [2012] showed that snowmelt could have provided the amount of water required to alter and indurate the sedimentary rocks in Gale.

[86] Milliken et al. [2010] interpreted the CRISM spectra of the Syul to be most consistent with $\mathrm{Mg}$ sulfates including monohydrated sulfates, which is likely kieserite $\left(\mathrm{MgSO}_{4} \cdot 1 \mathrm{H}_{2} \mathrm{O}\right)$ and polyhydrated sulfates $\left(\mathrm{MgSO}_{4} \cdot \mathrm{nH}_{2} \mathrm{O}\right)$, which may be epsomite $\left(\mathrm{MgSO}_{4} \cdot 7 \mathrm{H}_{2} \mathrm{O}\right)$, hexahydrite $\left(\mathrm{MgSO}_{4} \cdot 6 \mathrm{H}_{2} \mathrm{O}\right)$, and starkeyite $\left(\mathrm{MgSO}_{4} \cdot 4 \mathrm{H}_{2} \mathrm{O}\right)$. Recently, meridianiite $\left(\mathrm{MgSO}_{4} \cdot 11 \mathrm{H}_{2} \mathrm{O}\right)$ was discovered on the surface of a frozen pond in central British Columbia, Canada [Peterson et al., 2007]. It has also been identified in brine inclusions in the Antarctic ice cap [Ohno et al., 2005]. Meridianiite may be of particular interest in the case of sulfate-rich rocks in Gale Crater because Peterson and Wang [2006] interpreted the plate-shaped voids in the sulfate-rich rocks of Meridiani Planum observed by the rover Opportunity to be characteristic of meridianiite crystals that would have melted into a mixture of epsomite and water. The $\mathrm{MgSO}_{4}-\mathrm{H}_{2} \mathrm{O}$ system has a low eutectic temperature which is $2^{\circ} \mathrm{C}(275 \mathrm{~K})$ [Hogenboom et al., 1995]. Chipera et al., 2007 showed that meridianiite forms quite readily from simple freezing of $\mathrm{Mg}$ sulfate brine solution at a temperature below $2^{\circ} \mathrm{C}$ to form a stable mixture of meridianiite and ice. Considering that the average air and ground temperature is and was likely below $2^{\circ} \mathrm{C}$ in the equatorial regions of Mars, meridianiite may be one of the salts that has precipitated in Aeolis Mons. However, above $2{ }^{\circ} \mathrm{C}$, meridianiite melts incongruently to a slurry of $70 \%$ epsomite and $30 \%$ water by volume. If this mixture is exposed to the current low humidity conditions of equatorial Mars, it will ultimately dehydrate to a fine dust of kieserite [Peterson et al., 2007], which is consistent with the results obtained by Milliken et al. [2010]. Hence, we interpret the Mg sulfates of the Syul to have precipitated from percolating brines saturated in dissolved magnesium sulfate in the subsurface either by capillary action and evaporation and/or by freezing possibly before, during, or after the presence of the lake. An increase of temperature above $2{ }^{\circ} \mathrm{C}$ and a decrease in relative humidity would have induced the melting of meridianiite and the subsequent formation of epsomite and kieserite at the surface of Aeolis Mons. The presence of phyllosilicates inside the Syu1 would be consistent with this scenario. Many authigenic clays were formed in hypersaline settings on Earth [Fisher, 1988]. Baldridge et al. [2009] showed that acidic playa lakes in west Australia have large $\mathrm{pH}$ differences separated vertically and laterally by only a few tens of meters leading to varied chemistry including smectites, Ca sulfates, and $\mathrm{Mg}$ sulfates. Wilson and Bish [2012] used humidity buffer experiments to assess the stability of hydrated $\mathrm{Mg}$ sulfates in the presence of smectites. They showed that hydrated $\mathrm{Mg}$ sulfate phases may persist beyond their expected temperature-relative humidity equilibrium field on longer timescales within smectites- $\mathrm{MgSO}_{4}$ mixtures than in the pure $\mathrm{MgSO}_{4}-\mathrm{H}_{2} \mathrm{O}$ system. For example, dehydration of highly hydrated $\mathrm{Mg}$ sulfates like meridianiite appears to slow in the presence of smectites.

[87] Another hypothesis that cannot be ruled out is that sulfates and clays may correspond to detrital material, at least partially, formed elsewhere on Mars, transported and deposited in Aeolis Mons by aeolian processes.

[88] The formation of sulfates and clays in Aeolis Mons by groundwater upwelling as proposed by Andrews-Hanna et al. [2012] is unlikely in presence of permafrost, which prevents the free circulation of groundwater inside the mound.

[89] Recently, the MSL mission allowed the discovery of clay-bearing mudstones at the "John Klein" outcrop in the Sheepbed unit [Mars Science Laboratory (MSL) Team, 2013]. 


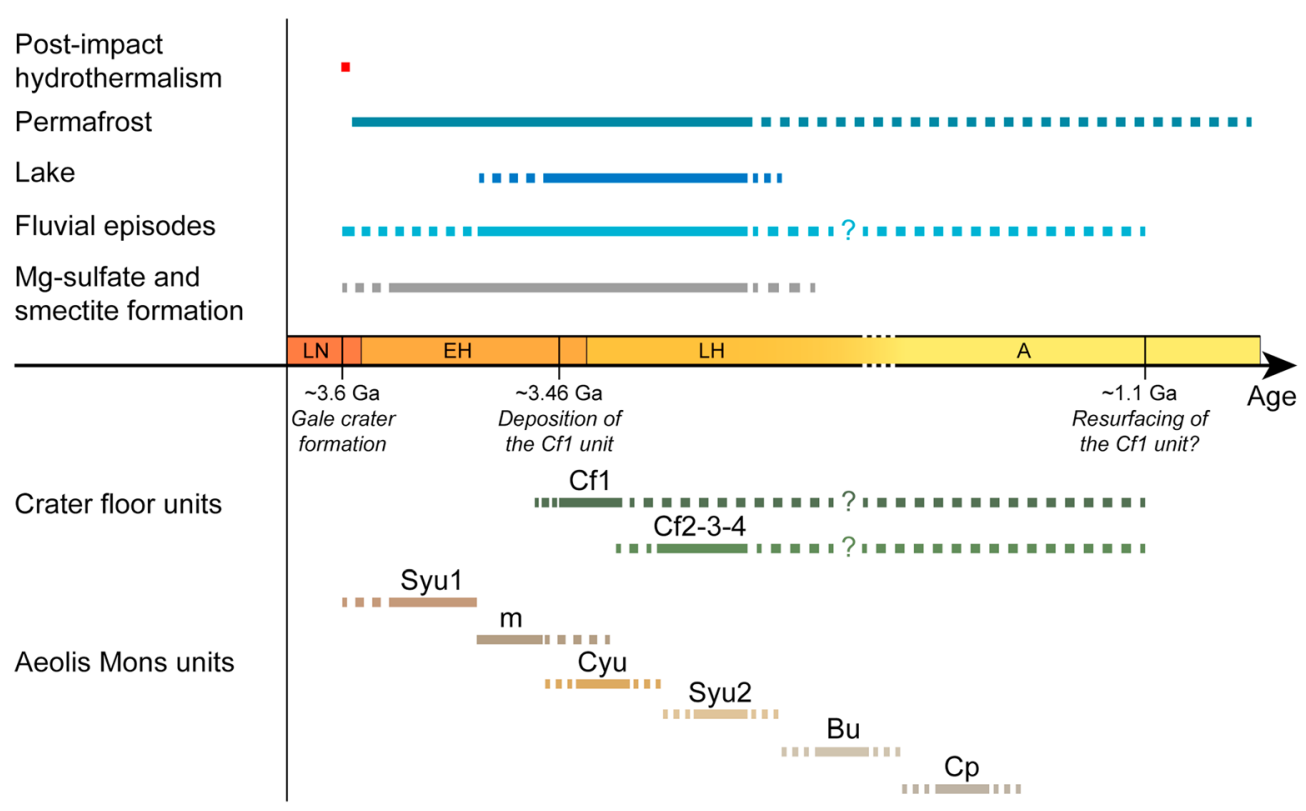

Figure 22. Timing of events deduced from the morphologic, stratigraphic, and crater counting results. The ages of the Martian Epoch (LN: Late Noachian, EH: Early Hesperian, LH: Late Hesperian, A: Amazonian) are derived from Hartmann [2005]. Only the main units are represented.

This unit is included in the Cf1 unit in our study. These mudstones contain smectites, feldspath, pyroxene, magnetite, olivine, anhydrite, bassanite, and $\sim 20 \%$ of amorphous material [MSL Team, 2013]. All instruments onboard Curiosity support the interpretation that this sediment was likely deposited subaqueously, in a habitable environment characterized by neutral $\mathrm{pH}$, chemical gradients that would create energy for microbes, and a distinctly low salinity [MSL Team, 2013]. These clay-bearing mudstones may have been deposited in a lake, which is consistent with our scenario. Clays may be authigenic minerals. Alternatively, they may have formed in Aeolis Mons and have been transported to the crater floor by fluvial processes.

\subsubsection{Sources of Water for the Paleolake}

[90] Several sources of water may have contributed to feed a lake. Water may have been transported into the basin through the valleys incised into the crater rim. However, the poorly hierarchized valley systems and the morphology of the fanshaped deposits suggest a short-term fluvial activity and a limited amount of water supply. Also, the material transported in these valleys and deposited in the northern part of Gale Crater, now exposed in the form of sinuous ridges and thin fans like the Peace Vallis fan (not mapped in this study) close to the MSL landing site, appear to be stratigraphically high within the $\mathrm{Cf1}$ unit and likely postdates the paleolake. In a continuous permafrost scenario, the lake may have been recharged by snowmelt, originating from snowfall onto the lake and from Aeolis Mons by percolating through the active layer on top of the frost table along the slopes. To a minor degree, the lake may have also been recharged by melted ground ice from the active layer (Figure 21a and 21c). In a discontinuous permafrost scenario, an additional possible source of water would have been groundwater upwelling (Figure $21 \mathrm{~b}$ and 21c). Andrews-Hanna et al. [2012] proposed that the groundwater influx in Gale may have been sustained by rain/snow occurring east of the Isidis impact basin.

\subsubsection{Formation Processes of the Canyons in Aeolis Mons}

[91] The presence of canyons carved in Aeolis Mons is consistent with permafrost. The incision of the canyons may have been triggered by surface runoff of snowmelt, the active layer being saturated by water because of the permafrost which inhibits the infiltration of snowmelt in depth. The canyons may have also been carved by sapping or discharge of groundwater corresponding to melted ground ice of the active layer that would have flowed across the top of the permafrost table. An alternative hypothesis is that the canyons would have been incised by active-layer detachment slides, caused by the thawing of the active layer along slopes [Harris and Lewkowicz, 1993]. The permafrost table usually controls the depth of the failure plane, which acts as a lubricated slip plane [French, 2007]. Active-layer detachments on Earth are usually shallow and do not exceed $1 \mathrm{~m}$ in depth. Thus, an active-layer detachment would have exposed the permafrost at the surface allowing the melting of buried ice possibly contained in the Syu, which would have released liquid water and deepened the canyon. Also, the meridianiite possibly contained in the Syu could have reached a temperature above $2^{\circ} \mathrm{C}$ leading to its incongruent melting and the release of liquid water even if this process would only generate a minor amount of water.

\subsubsection{Timing of the Periglacial Activity}

[92] In our scenarios, we propose that the region would have experienced periglacial conditions through most of its history. However, it is not trivial to determine the absolute ages of the possible periglacial landforms. They appear to modify the landscape and could have formed much later than the surfaces that they modify. However, some observations indicate specific times during which periglacial activity occurred in the region. The lobate deposits are located stratigraphically above the Syu1 and below the Cyu. Thus, periglacial activity appears to have occurred at least after the formation of the Syul unit 
and before the deposition of the Cyu unit. Also, the polygonally fractured terrains identified by Oehler [2013] are observed in the Cfl unit and must have formed after $\sim 3.46 \mathrm{Ga}$.

\section{Timing of Events}

[93] From our morphologic, stratigraphic, and crater counting results, we propose the following timing of events in Gale Crater (Figure 22):

[94] 1. The impact crater and its central peak are formed at $\sim 3.61^{+0.04} /{ }_{0.06} \mathrm{Ga}$, during the Late Noachian/Early Hesperian Epoch. The impact likely released enough heat to initiate a hydrothermal system possibly active for several hundred thousand years in the crater [Schwenzer et al., 2012].

[95] 2. After several hundred thousands of years, these postimpact conditions cease to exist. The ground is perennially frozen $\left(\mathrm{T}<0^{\circ} \mathrm{C}\right)$ below a certain depth (Figure 21). The orbital and obliquity configurations induce a subarid climate where ice is stable at the surface in this region. The air fall deposition of fine-grained sediment (dust, volcanic ash, fine-grained impact products, possibly snow) forms the Syul, draping the crater floor. Wind-blown sands may also be a component of this sediment. It is preferentially accumulated in the northern, deeper part of the crater, which acts as a sediment trap.

[96] 3. Episodically, snow melts and percolates into the active layer, alters the sediment and freezes precipitating sulfates and clays. Mass-wasting deposits, interpreted as rock glaciers, form to the north of Aeolis Mons along its slopes. The shallow frost table inhibits the deep infiltration of melt water and facilitates the occurrence of overland flows, carving the canyons along the flanks of Aeolis Mons. These canyons may have also been incised by sapping, fed by melted ground ice of the active layer while it thaws, and by active-layer detachment.

[97] 4. Short-termed fluvial activity (likely driven by snowmelt) and gravity-driven erosion lead to the accumulation of alluvial and colluvial deposits on the crater floor, which form the Cf1 unit at $3.46 \mathrm{Ga}$. The Cf2-4 units are deposited along the crater wall and on the crater floor. On Aeolis Mons, the Cyu material is deposited on top of the Syu1 and the mass-wasting deposits. After a period of hiatus, the Syu2 unit drapes the Cyu unit.

[98] 5. A lake, which may have been partially or totally icecovered, fills the lower portions of the crater, perhaps episodically. Morphological evidence indicates the presence of a lake after the deposition of the Syu1 and mass-wasting units on Aeolis Mons and after the deposition of the Cf4 unit on the crater floor. The lake may have been fed by snowmelt, melted ground ice of the active layer and possibly by groundwater in case of discontinuous permafrost. Layered deposits on the crater floor have possibly been deposited in this lake, as well as the Sheepbed unit identified by Curiosity.

[99] 6. During the Late Hesperian or Amazonian, episodes of fluvial activity occur along the Cf1 unit up to $\sim 1.1 \mathrm{Ga}$. The conglomerates identified by Curiosity probably record this late phase of aqueous activity.

[100] 7. Remobilized deposits such as sands accumulate at the top of Aeolis Mons forming the $\mathrm{Bu}$ unit. Whether it corresponds or not to a part of the lower MFF, the Bu may have been deposited from the Hesperian to the Amazonian. The $\mathrm{Cp}$ material is deposited over the crater.
[101] 8. Under the current orbital and obliquity configurations, ice is not stable at the surface anymore and the active layer is ice-free. Aeolian erosion is still an active process.

\section{Conclusions}

[102] Our crater counting results suggest that Gale Crater was formed at $\sim 3.61^{+0.04} /-0.06 \mathrm{Ga}$, in the Late Noachian/ Early Hesperian. It hosts a wide variety of landforms and sedimentary deposits revealing the occurrence of different paleoenvironments since its formation. We interpret the Aeolis Mons sediment as primarily air fall and aeolian material such as dust, volcanic ash, sands, fine-grained impact products, and possibly snow deposited and cemented in the center of the crater. The geological units of the mound are separated by unconformity surfaces indicating hiatuses in the depositional sequence. A lacustrine deposition of these sediments, including those of the lowermost unit (Syu1) of Aeolis Mons, is unlikely since the highest exposure of this unit exceeds the height of the northern crater rim. The crater floor material deposited around Aeolis Mons and on the crater wall is interpreted to be alluvial deposits related to short-term fluvial events and colluvial deposits. Crater counting on the northern crater floor suggests that fluvial events may have happened as recently as $\sim 1.1 \mathrm{Ga}$. The occurrence of a possible Gilbert-type fan delta, terraces, and possible shorelines suggests that a lake existed in Gale after the formation of the base of Aeolis Mons (the Small yardangs unit 1 and the mass-wasting deposits). We also observe a suite of features suggestive of a periglacial environment with permafrost including mass-wasting deposits (possible rock glaciers and other slope landforms indicative of creep), polygonal ridges (possible paleosand wedges), and fan-shaped deposits (possible thaw slumps). From these observations we propose that Gale Crater has been subject to periglacial conditions within a permafrost environment after the first hundred thousands of years following its formation. Episodic melting of snow in the crater would have caused the formation of sulfates and clays in Aeolis Mons, the formation of rock glaciers and the incision of deep canyons and valleys along its flanks and crater wall and rim, and the formation of a lake in the deepest portions of the crater.

[103] Acknowledgments. We would like to thank the members of the ISSI International Team "Mars Interior Layered Deposits" for their collaboration and very helpful discussions and especially S. van Gasselt for contributing to the data processing. Thank you to Alicia Hore and Nevena Novakovic for their contribution in the measurement of layer attitudes, to Thomas Platz for helpful discussions about crater counting, and to Wouter Marra for discussions on the formation of sapping valleys. We also thank our two anonymous reviewers and the editor for very thoughtful and thorough comments that greatly improved the manuscript. This research has been supported by the Helmholtz Association through the research alliance "Planetary Evolution and Life."

\section{References}

Anderson, R. C., and J. F. Bell III (2010), Geologic mapping and characterization of Gale Crater and implications for its potential as a Mars Science Laboratory landing site, Mars, 5, 76-128, doi:10.1555/mars.2010.0004.

Andrews-Hanna, J. C., and K. W. Lewis (2011), Early Mars hydrology: 2.

Hydrological evolution in the Noachian and Hesperian epochs, J. Geophys. Res., 116, E02007, doi:10.1029/2010JE003709.

Andrews-Hanna, J. C., R. J. Phillips, and M. T. Zuber (2007), Meridiani Planum and the global hydrology of Mars, Nature, 446, 163-166, doi:10.1038/nature05594.

Andrews-Hanna, J. C., M. T. Zuber, R. E. Arvidson, and S. M. Wiseman (2010), Early Mars hydrology: Meridiani playa deposits and the 


\section{LE DEIT ET AL.: SEDIMENTARY INFILLING IN GALE CRATER}

sedimentary record of Arabia Terra, J. Geophys. Res., 115, E06002, doi:10.1029/2009JE003485.

Andrews-Hanna, J. C., A. Soto, and M. I. Richardson (2012), The hydrologic and climatic context of the Gale crater sedimentary mound, Third Conf. on Early Mars, \#7038.

Baldridge, A. M., S. J. Hook, J. K. Crowley, G. M. Marion, J. S. Kargel, J. L. Michalski, B. J. Thomson, C. R. de Souza Filho, N. T. Bridges, and A. J. Brown (2009), Contemporaneous deposition of phyllosilicates and sulfates: Using Australian acidic saline lake deposits to describe geochemical variability on Mars, Geophys. Res. Lett, 36, L19201, doi:10.1029/ 2009GL040069.

Barsch, D. (1996), Rock Glaciers, pp. 331, Springer, Berlin

Berger, G., M. J. Toplis, E. Treguier, C. d'Uston, and P. Pinet (2009), Evidence in favor of small amounts of ephemeral and transient water during alteration at Meridiani Planum, Mars, Am. Mineral., 94, 1279-1282, doi:10.2138/am.2009.3230.

Bibring, J.-P., Y. Langevin, J. F. Mustard, F. Poulet, R. Arvidson, A. Gendrin, B. Gondet, N. Mangold, P. Pinet, and F. Forget (2006), Global mineralogical and aqueous Mars history derived from OMEGA/ Mars Express data, Science, 312, 400-404, doi:10.1126/science.1122659.

Binder, A. B., R. E. Arvidson, E. A. Guinness, K. L. Jones, T. A. Mutch, E. C. Morris, D. C. Pieri, and C. Sagan (1977), The geology of the Viking Lander 1 site, J. Geophys. Res., 82, 4439-4451, doi:10.1029/ JS082i028p04439.

Bird, J. B. (1967), The Physiography of Arctic Canada, pp. 336, John Hopkins Press, Baltimore, MD.

Bourdier, J. L. (1994), Le Volcanisme, Manuels \& Méthodes, BRGM, Orléans

Bradley, B. A., S. E. H. Sakimoto, H. Frey, and J. R. Zimbelman (2002), Medusae Fossae Formation: New perspectives from Mars Global Surveyor, J. Geophys. Res., 107(E8), 5058, doi:10.1029/2001JE001537.

Bristow, T. F., and R. F. Milliken (2011), Terrestrial perspective on authigenic clay mineral production in ancient Martian lakes, Clays Clay Miner., 59, 339-358, doi:10.1346/CCMN.2011.0590401.

Broxton, M. J., and L. J. Edwards (2008), The Ames stereo pipeline: Automated 3D surface reconstruction from orbital imagery, Lunar and Planetary Science Conference 39, \#2419.

Burr, D. M., R. M. E. Williams, K. D. Wendell, M. Chojnacki, and J. P. Emery (2010), Inverted fluvial features in the Aeolis/Zephyria Plana region, Mars: Formation mechanism and initial paleodischarge estimates, J. Geophys. Res., 115, E07011, doi:10.1029/2009JE003496.

Cabrol, N. A., and E. A. Grin (2001), The evolution of lacustrine environments on early Mars: Is Mars only hydrologically dormant?, Icarus, 149, 291-328.

Cabrol, N. A., E. A. Grin, H. E. Newsom, R. Landheim, and C. P. McKay (1999), Hydrogeologic evolution of Gale Crater and its relevance to the exobiological exploration of Mars, Icarus, 139, 235-245, doi:10.1006/icar.1999.6099.

Chevrier, V., and P. E. Mathé (2007), Mineralogy and evolution of the surface of Mars: A review, Planet. Space Sci., 55, 289-314, doi:10.1016/j. pss.2006.05.039

Chipera, S. J., D. T. Vaniman, R. C. Peterson, and M. M. Fitipaldo (2007), Can sulfates besides those of $\mathrm{Mg}$ form low-temperature hyper-hydrates? Lunar and Planetary Science Conference, XXXVIII, \#1408.

Clarke, J. D. A., and C. R. Stoker (2011), Concretions in exhumed and inverted channels near Hanksville, Utah: Implications for Mars, Int. J. Astrobiol., 10, 161-175, doi:10.1017/S1473550411000048.

Dehouck, E., N. Mangold, S. Le Mouélic, V. Ansan, and F. Poulet (2010), Ismenius Cavus, Mars: A deep paleolake with phyllosilicate deposits, Planet. Space Sci., 58, 941-946, doi:10.1016/j.pss.2010.02.005.

Dundas, C. M., L. P. Keszthelyi, V. J. Bray, and A. S. McEwen (2010), Role of material properties in the cratering record of young platy-ridged lava on Mars, Geophys. Res. Lett., 37, L12203, doi:10.1029/2010GL042869.

Dylik, J. (1964), Éléments essentiels de la notion de 'périglaciaire', BiuletynPeryglacjalny, 14, 111-132.

Edgett, K. S. (2005), The sedimentary rocks of Sinus Meridiani: Five key observations from data acquired by the Mars Global Surveyor and Mars Odyssey orbiters, Mars, 1, 5-58.

Fassett, C. I., and J. W. Head (2007), Layered mantling deposits in northeast Arabia Terra, Mars: Noachian-Hesperian sedimentation, erosion, and terrain inversion, J. Geophys. Res., 112, E08002, doi:10.1029/ 2006JE002875.

Fassett, C. I., and J. W. Head (2008), The timing of Martian valley network activity: Constraints from buffered crater counting, Icarus, 195(1), 61-89, doi:10.1016/j.icarus.2007.12.009.

Fergason, R. L., P. R. Christensen, and H. H. Kieffer (2006), High-resolution thermal inertia derived from the Thermal Emission Imaging System (THEMIS): Thermal model and applications, J. Geophys. Res., 111, E12004, doi:10.1029/2006JE002735.

Fisher, R. S. (1988), Clay minerals in evaporite host rocks, Palo Duro Basin, Texas Panhandle, J. Sediment. Res., 58, 836-844, doi:10.1306/212F8E812B24-11D7-8648000102C1865D.
French, H. M. (2007), The Periglacial Environment, 3rd ed., pp. 341, Addison Wesley Longman Ltd., Harlow, United Kingdom.

Fueten, F., R. M. Stesky, and P. MacKinnon (2005a), Structural attitudes of large-scale layering in Valles Marineris Mars, calculated from Mars Orbiter Laser Altimeter data and Mars Orbiter Camera imagery, Icarus, 175, 68-77, doi:10.1016/j.icarus.2004.11.010.

Fueten, F., et al. (2005b), Attitude determination of geological layers using HRSC data and Orion software, Lunar and Planetary Science Conference XXXVI, \#1234.

Fueten, F., J. Flahaut, L. Le Deit, R. Stesky, E. Hauber, and K. Gwinner (2011), Interior layered deposits within a perched basin, southern Coprates Chasma, Mars: Evidence for their formation, alteration, and erosion, J. Geophys. Res., 116, E02003, doi:10.1029/2010JE003695.

Geissler, P. E., et al. (2008), First in situ investigation of a dark wind streak on Mars, J. Geophys. Res., 113, E12S31, doi:10.1029/2008JE003102.

Gendrin, A., et al. (2005), Sulfates in Martian layered terrains: The OMEGA Mars Express view, Science, 307, 1587-1591.

Gilbert, D. K. (1885), The topographic features of lake shores, Annu. Rep. US Geol. Surv., 5, 69-123.

Golombek, M. P., et al. (2012), Selection of the Mars Science Laboratory landing site, Space Sci. Rev., 170, 641-737, doi:10.1007/s11214-012-9916-y.

Goudie, A. S. (1983), Calcrete, in Chemical Sediments and Geomorphology: Precipitates and Residua in the Near Surface Environment, edited by A. S. Goudie and K. Pye, pp. 93-131, Academic Press, New York.

Grant, J. A., S. A. Wilson, B. A. Cohen, M. P. Golombek, P. E. Geissler, R. J. Sullivan, R. L. Kirk, and T. J. Parker (2008), Degradation of Victoria crater, Mars, J. Geophys. Res., 113, E11010, doi:10.1029/2008JE003155.

Grant, J. A., M. P. Golombek, J. P. Grotzinger, S. A. Wilson, M. M. Watkins, A. R. Vasavada, J. L. Griffes, and T. J. Parker (2011), The science process for selecting the landing site for the 2011 Mars Science Laboratory, Planet. Space Sci., 59, 1114-1127.

Greeley, R., and J. E. Guest (1987), Geologic map of the eastern equatorial region of Mars, US Geol. Surv. Misc. Inv. Ser., Map. I-1802-B.

Grotzinger, J. P., et al. (2005), Stratigraphy and sedimentology of a dry to wet eolian depositional system, Burns formation, Meridiani Planum, Mars, Earth Planet. Sci. Lett., 240(1), 11-72, doi:10.1016/j.eps1.2005.09.039.

Grotzinger, J. P., et al. (2012), Mars Science Laboratory mission and science investigation, Space Sci. Rev., 170, 5-56, doi:10.1007/s11214-012-9892-2.

Gutiérrez, M. (2005), Climatic Geomorphology, Developments in Earth Science Processes, pp. 760, Elsevier, New York.

Gwinner, K., J. Oberst, R. Jaumann, and G. Neukum (2010), Regional HRSC multi-orbit Digital Terrain Models for the Mars Science Laboratory candidate landing sites, Lunar Planet. Sci., XLI, Abstract 2727.

Hagedorn, H. (1968), Über äolische Abtragung und Formung in der SüdestSahara, Erkunde, 22, 257-269.

Hallet, B., R. S. Sletten, W. Stewart, R. Williams, N. Mangold, J. Schieber, D. Sumner, G. Kocurek, and MSL Science Team (2013), Lunar and planetary science conference 44, \#3108.

Harris, D. R. (1980), Exhumed paleochannels in the Lower Cretaceous Cedar Mountain Formation near Green River, Utah, Brigham Young Univ. Geol. Stud., 27, 51-66.

Harris, C., and A. G. Lewkowicz (1993), Form and internal structure of active-layer detachment slides, Fosheim Peninsula, Ellesmere Island, Northwest Territories, Canada, Can. J. Earth Sci., 30, 1708-1714.

Hartmann, W. K. (2005), Martian cratering 8: Isochron refinement and the chronology of Mars, Icarus, 174(2), 294-320, doi:10.1016/j.icarus.2004.11.023.

Hartmann, W. K., and G. Neukum (2001), Cratering chronology and the evolution of Mars, Space Sci. Rev., 96, 165-194.

Hauber, E., K. Gwinner, M. Kleinhans, D. Reiss, G. Di Achille, G.-G. Ori, F. Scholten, L. Marinangeli, R. Jaumann, and G. Neukum (2009) Sedimentary deposits in Xanthe Terra: Implications for the ancient climate on Mars, Planet. Space Sci., 57, 944-957, doi:10.1016/j.pss.2008.06.009

Hauber, E., T. Platz, D. Reiss, L. Le Deit, M. G. Kleihans, W. A. Marra T. De Haas, and P. Carbonneau (2013), Asynchronous formation of Hesperian and Amazonian-aged deltas on Mars and implications for climate, J. Geophys. Res. Planets, 118, 1-16, doi:10.1002/jgre.20107.

Hogenboom, D. L., J. S. Kargel, J. P. Ganasan, and L. Lee (1995), Magnesium sulfate-water to $400 \mathrm{MPa}$ using a novel piezometer: Densities, phase equilibria, and planetological implications, Icarus, 115, 258-277, doi:10.1006/icar.1995.1096.

Hopkins, D. M., et al. (1955), Permafrost and ground water in Alaska, U. S. Geol. Surv., professional paper 264-F, 113-146.

Hynek, B. M., R. E. Arvidson, and R. J. Phillips (2002), Geologic setting and origin of Terra Meridiani hematite deposit on Mars, J. Geophys. Res., 107(E10), 5088, doi:10.1029/2002JE001891.

Hynek, B. M., R. J. Phillips, and R. E. Arvidson (2003), Explosive volcanism in the Tharsis region: Global evidence in the Martian geologic record, J. Geophys. Res., 108(E9), 5111, doi:10.1029/2003JE002062.

Irwin, R. P., A. D. Howard, R. A. Craddock, and J. M. Moore (2005), An intense terminal epoch of widespread fluvial activity on early Mars: 2. 


\section{LE DEIT ET AL.: SEDIMENTARY INFILLING IN GALE CRATER}

Increased runoff and paleolake development, J. Geophys. Res., 110, E12S15, doi:10.1029/2005JE002460.

Ivanov, B. A. (2001), Mars/Moon cratering rate ratio estimates, Space Sci. Rev., 96, 87-104.

Jaumann, R., et al. (2007), The high-resolution stereo camera (HRSC) experiment on Mars Express: Instrument aspects and experiment conduct from interplanetary cruise through the nominal mission, Planet. Space Sci., 55 , 928-952, doi:10.1016/j.pss.2006.12.003.

Kerber, L., and J. W. Head (2010), The age of the Medusae Fossae formation: Evidence from crater morphology, stratigraphy, and ancient lava contacts, Icarus, 206, 669-684, doi:10.1016/j.icarus.2009.10.001.

Kite, E. S., I. Halevy, M. A. Kahre, M. J. Wolff, and M. Manga (2012), Seasonal melting and the formation of sedimentary rocks on Mars, with predictions for the Gale Crater mound, Icarus, doi:10.1016/j. icarus.2012.11.034.

Kite, E. S., K. W. Lewis, M. P. Lamb, C. E. Newman, and M. I. Richardson (2013), Growth and form of the mound in Gale Crater Mars: Slope-wind enhanced erosion and transport, Geology, 41, 543-546, doi:10.1130/ G33909.1.

Kleinhans, M. G., H. E. van de Kasteele, and E. Hauber (2010), Palaeoflow reconstruction from fan delta morphology on Mars, Earth Planet. Sci. Lett., 294, 378-392, doi:10.1016/j.epsl.2009.11.025.

Kneissl, T., S. van Gasselt, and G. Neukum (2011), Map-projection-independent crater size-frequency determination in GIS environments-New software tool for ArcGIS, Planet. Space Sci., 59, 1243-1254.

Kochel, R. C., D. W. Simmons, and J. F. Piper (1988), Groundwater sapping experiments in weakly consolidated layered sediments: A qualitative summary, in Sapping Features of the Colorado Plateau-A Comparative Planetary Geology Field Guide, edited by A. D. Howard, R. C. Kochel, and H. E. Holt, pp. 84-93, NASA, Washington, D. C.

Kraal, E. R., M. van Dijk, G. Postma, and M. G. Kleinhans (2008), Martian stepped-delta formation by rapid water release, Nature, 451, 973-976.

Laity, J. E. (1994), Landforms of aeolian erosion, in Geomorphology of Desert Environments, edited by A. D. Abrahams and A. J. Parsons, pp. 506-537, Chapman \& Hall, London.

Laity, J. E., and N. T. Bridges (2009), Ventifacts on Earth and Mars: Analytical, field, and laboratory studies supporting sand abrasion and windward feature development, Geomorphology, 105, 202-217.

Langevin, Y., F. Poulet, J.-P. Bibring, and B. Gondet (2005), Sulfates in the north polar region of Mars detected by OMEGA/Mars Express, Science, 307, 1584-1586.

Lantuit, H., and W. H. Pollard (2008), Fifty years of coastal erosion and retrogressive thaw slump activity on Herschel Island, southern Beaufort Sea Yukon Territory, Canada, Geomorphology, 95, 84-102, doi:10.1016/j. geomorph.2006.07.040.

Lantz, T. C., and S. V. Kokelj (2008), Increasing rates of retrogressive thaw slump activity in the Mackenzie Delta region, N.W.T., Canada, Geophys. Res. Lett., 35, L06502, doi:10.1029/2007GL032433.

Le Deit, L., J. Flahaut, C. Quantin, E. Hauber, D. Mège, O. Bourgeois, J. Gurgurewicz, M. Massé, and R. Jaumann (2012), Extensive surface pedogenic alteration of the Martian Noachian crust suggested by plateau phyllosilicates around Valles Marineris, J. Geophys. Res., 117, E00J05, doi:10.1029/2011JE003983.

Leeder, M. R. (1999), Sedimentology and Sedimentary Basins: From Turbulence to Tectonics, pp. 592, Blackwell Science, Oxford.

Levy, J. S., D. R. Marchant, and J. W. Head (2010), Thermal contraction crack polygons on Mars: A synthesis from HiRISE Phoenix, and terrestrial analog studies, Icarus, 206, 229-252, doi:10.1016/j. icarus.2009.09.005.

Lewis, K. W., O. Aharonson, J. P. Grotzinger, R. L. Kirik, A. S. McEwen, and T.-A. Suer (2008), Quas-periodic bedding in the sedimentary rock record of Mars, Science, 322, 1532, doi:10.1126/science.1161870.

Lucchitta, B. K., A. S. McEwen, G. D. Clow, P. E. Geissler, R. B. Singer, R. A. Schultz, and S. W. Squyres (1992), The Canyon System on Mars, pp. 453-492, Univ. of Arizona, Tucson.

Mackay, J. R. (1966), Segregated epigenetic ice and slumps in permafrost, Mackenzie Delta area, NWT, Geographical Bull., 8, 59-80.

Madeleine, J.-B., F. Forget, J. W. Head, B. Levrard, F. Montmessin, and E. Millour (2009), Amazonian northern mid-latitude glaciation on Mars: A proposed climate scenario, Icarus, 203(2), 390-405.

Maizels, J. K. (1987), Plio-Pleistocene raised channel systems of the western Sharqiya (Wahiba), Oman, in Desert Sediments: Ancient and Modern, Geological Society Special Publication, vol. 35, edited by L. Frostick and I. Reid, pp. 31-50, Blackwell, Oxford.

Malin, M. C., and K. S. Edgett (2000), Sedimentary rocks of Early Mars, Science, 290, 1927-1937, doi:10.1126/science.290.5498.1927.

Malin, M. C., et al. (2007), Context camera investigation on board the Mars Reconnaissance Orbiter, J. Geophys. Res., 112, E05S04, doi:10.1029/ 2006JE002808.
Mandt, K. E., S. L. de Silva, J. R. Zimbelman, and D. A. Crown (2008), The origin of the Medusae Fossae Formation, Mars: Insights from a synoptic approach, J. Geophys. Res., 113, E12011, doi:10.1029/2008JE003076.

Massé, M., O. Bourgeois, S. Le Mouélic, C. Verpoorter, A. Spiga, and L. Le Deit (2012), Wide distribution and glacial origin of polar gypsum on Mars, Earth Planet. Sci. Lett., 317-318, 44 45, doi:10.1016/j.epsl.2011.11.035.

McCauley, J. F., C. S. Breed, F. El-Baz, M. I. Whitney, M. J. Grolier, and A. W. Ward (1979), Pitted and fluted rocks in the Western Desert of Egypt: Viking comparisons, J. Geophys. Res., 84, 8222-8232.

McCollom, T. M., and B. M. Hynek (2005), A volcanic environment for bedrock diagenesis at Meridiani Planum on Mars, Nature, 438, 1129-1131.

McEwen, A. S., B. S. Preblich, E. P. Turtle, N. A. Artemieva, M. P. Golombek, M. Hurst, R. L. Kirk, D. M. Burr, and P. R. Christensen (2005), The rayed crater Zunil and interpretations of small impact craters on Mars, Icarus, 176 , 351-381.

McEwen, A. S., et al. (2007), Mars Reconnaissance Orbiter's High Resolution Imaging Science Experiment (HiRISE), J. Geophys. Res., 112, E05S02, doi:10.1029/2005JE002605.

McEwen, A. S., L. Ojha, C. M. Dundas, S. S. Mattson, S. Byrne, J. J. Wray, S. C. Cull, S. L. Murchie, N. Thomas, and V. C. Gulick (2011), Seasonal flows on warm Martian slopes, Science, 333, 740-743, doi:10.1126/ science. 1204816

McLennan, S. M., et al. (2005), Provenance and diagenesis of the evaporitebearing Burns formation, Meridiani Planum Mars, Earth Planet. Sci. Lett. 240, 95-121.

McNally, H. H., and I. R. Wilson (1995), Silcretes of the Mirackina paleochannel, Arckaringa, South Australia, AGSO J. Austr. Geol. Geophys., 16, 295-301.

Mellon, M. T., B. M. Jakosky, H. H. Kieffer, and P. R. Christensen (2000), High-resolution thermal inertia mapping from the Mars Global Surveyor thermal emission spectrometer, Icarus, 148(2), 437-455, doi:10.1006/ icar.2000.6503

Michael, G. G., and G. Neukum (2010), Planetary surface dating from crater size-frequency distribution measurements: Partial resurfacing events and statistical age uncertainty, Earth Planet. Sci. Lett., 294, 223-229.

Milazzo, M. P., L. P. Keszthelyi, W. L. Jaeger, M. Rosiek, S. Mattson, C. Verba, R. A. Beyer, P. E. Geissler, A. S. McEwen, and the HiRISE Team (2009), Discovery of columnar jointing on Mars, Geology, 37, 171-174, doi:10.1130/G25187A.1.

Milliken, R. E., J. P. Grotzinger, and B. J. Thomson (2010), Paleoclimate of Mars as captured by the stratigraphic record in Gale Crater, Geophys. Res. Lett., 37, L04201, doi:10.1029/2009GL041870.

Mills, H. H. (1981), Boulder deposits and the retreat of mountain slopes, or 'gully gravure' revisited, J. Geol., 89, 649-660.

Moratto, Z. M., M. J. Broxton, R. A. Beyer, M. Lundy, and K. Husmann (2010), Ames Stereo Pipeline, NASA's Open Source Automated Stereogrammetry Software, Lunar and Planetary Science Conference 41, \#2364.

Mars Science Laboratory (MSL) Team (2013), press releases from NASA JPL-Caltech/MSSS/LANL/CNES/IRAP/LPGN on the NASA website (http://www.nasa.gov/mission pages/msl/news/msl-latest-news-archive.html) Murton, J. B., J.-P. Coutard, J.-P. Lautridou, J.-C. Ozouf, D. A. Robinson, and R. B. G. Williams (2001), Physical modelling of bedrock brecciation by ice segregation in permafrost, Permafrost Periglac. Process., 12, 255-266.

Nash, D. J., and S. J. McLaren (2007), Geochemical Sediments and Landscapes, pp. 465, Blackwell, Oxford

Niles, P. B., and J. Michalski (2009), Meridiani Planum sediments on Mars formed through weathering in massive ice deposits, Nat. Geosci., 2 215-220, doi:10.1038/ngeo438.

Oehler, D. Z. (2013), A periglacial analog for landforms in Gale crater, Mars, Lunar and Planetary Science Conference 44, \#1322.

Ohno, H., M. Igarashi, and T. Honoh (2005), Salt inclusions in polar ice core: Location and chemical form of water soluble impurities, Earth Planet. Sci. Lett., 232, 171-178.

Okubo, C. H., and A. S. McEwen (2007), Fracture-controlled paleo-fluid flow in Candor Chasma Mars, Science, 315, 983-985, doi:10.1126/science.1136855.

Ori, G. G., L. Marinangeli, and A. Baliva (2000), Terraces and Gilbert-type deltas in crater lakes in Ismenius Lacus and Memnonia (Mars), J. Geophys. Res., 105, 17,629-17,641.

Osterloo, M. M., F. S. Anderson, V. E. Hamilton, and B. M. Hynek (2010), Geologic context of proposed chloride-bearing materials on Mars, J. Geophys. Res., 115, E10012, doi:10.1029/2010JE003613.

Pain, C. F., and C. D. Ollier (1995), Inversion of relief-A component of landscape evolution, Geomorphology, 12, 151-165.

Pain, C. F., J. D. A. Clarke, and M. Thomas (2007), Inversion of relief on Mars, Icarus, 190, 478-491, doi:10.1016/j.icarus.2007.03.017.

Peterson, R. C., and R. Wang (2006), Crystal molds on Mars: Melting of a possible new mineral species to create Martian chaotic terrain, Geology, 34, 957-960.

Peterson, R. C., W. Nelson, B. Madu, and H. F. Shurvell (2007), Meridianiite: A new mineral species observed on Earth and predicted to exist on Mars, Am. Mineral., 92, 1756-1759. 


\section{LE DEIT ET AL.: SEDIMENTARY INFILLING IN GALE CRATER}

Péwé, T. L. (1959), Sand-wedge polygons (tesselations) in the McMurdo Sound region, Antarctica-A progress report, Am. J. Sci., 257, 545-552.

Pondrelli, M., A. P. Rossi, L. Marinangeli, E. Hauber, K. Gwinner, A. Baliva, and S. Di Lorenzo (2008), Evolution and depositional environments of the Eberswalde fan delta, Mars, Icarus, 197, 429-451, doi:10.1016/j. icarus.2008.05.018.

Poulet, F., J.-P. Bibring, J. F. Mustard, A. Gendrin, N. Mangold, Y. Langevin, R. E. Arvidson, B. Gondet, C. Gomez, and the OMEGA Team (2005), Phyllosilicates on Mars and implications for early Martian climate, Nature, 438, 623-627, doi:10.1038/nature04274.

Richardson, M. I., and M. A. Mischna (2005), Long-term evolution of transient liquid water on Mars, J. Geophys. Res., 110, E03003, doi:10.1029/ 2004JE002367.

Rossi, A. P., G. Neukum, M. Pondrelli, S. van Gasselt, T. Zegers, E. Hauber, and C. B. Foing (2008), Large-scale spring deposits on Mars?, J. Geophys. Res., 113, E08016, doi:10.1029/2007JE003062.

Schultz, P. H., and A. B. Lutz (1988), Polar wandering of Mars, Icarus, 73, 91-141.

Schwenzer, S. P., et al. (2012), Gale crater: Formation and post-impact hydrous environments, Planet. Space Sci., doi:10.1016/j.pss.2012.05.014.

Scott, D. H., and M. H. Carr (1978), Geologic Map of Mars, USGS Map, I1083, scale $1: 25,000,000$.

Scott, D. H., and K. L. Tanaka (1982), Ignimbrites of Amazonis Planitia region of Mars, J. Geophys. Res., 87, 1179-1190.

Scott, D. H., and M. G. Chapman (1995), Geologic and topographic maps of the Elysium paleolake basin, Mars, U. S. Geol. Survey Geol. Series Map I2397, scale 1: 5,000,000.

Scott, D. H., and K. L. Tanaka (1986), Geologic Map of the western equatorial region of Mars, U.S. Geol. Surv. Misc. Geol. Invest. Map, I-1802-A, $1: 15 \mathrm{M}$ scale.

Squyres, S. W., and the M.E.R. team (2004), In situ evidence for an ancient aqueous environment at Meridiani Planum, Mars, Science, 306, 1709-1714

Squyres, S. W., O. Aharonson, R. E. Arvidson, and the M.E.R. Team (2006), Planetary science: Bedrock formation at Meridiani Planum, Nature, 443, E1-E2, doi:10.1038/nature05212.

Thomson, B. J., B. T. Bridges, R. Milliken, A. Baldridge, S. J. Hook, J. K. Crowley, G. M. Marion, C. R. de Souza Filho, A. J. Brown, and C. M. Weitz (2011), Constraints on the origin and evolution of the layered mound in Gale Crater, Mars using Mars Reconnaissance Orbiter data, Icarus, 214, 413-432, doi:10.1016/j.icarus.2011.05.002.

Twidale, C. R., and J. A. Bourne (1998), The use of duricrusts and topographic relationships in geomorphological correlation: Conclusions based in Australian experience, Catena, 33, 105-122, doi:10.1016/S0341-8162 (98)00065-4.

Van Bun Tseung, J.-M. (2008), Retrogressive thaw slumps on Mars: Constraints on potential formation mechanisms, M. Sc. Dissertation, University of Calgary (Canada), 137 pages, AAT MR38308.

Vennum, W. R. (1980), Evaporite incrustations and sulphide oxidation products from the southern Antarctic Peninsula, N. Z. J. Geol. Geophys., 23, 499-505.
Vogt, T., and P. Larqué (2002), Clays and secondary minerals as permafrost indicators: Examples from the circum-Baikal region, Quat. Int., 95-96, 175-187.

Wahrhaftig, C., and A. Cox (1959), Rock glaciers in the Alaska range, GSA Bull., 70, 383-436, doi:10.1130/0016-7606(1959)70[383:RGITAR]2.0.CO;2.

Watters, T. R. (2003), Thrust faults along the dichotomy boundary in the eastern hemisphere of Mars, J. Geophys. Res., 108(E6), 5054, doi:10.1029/ 2002JE001934.

Watters, T. R., et al. (2007), Radar sounding of the Medusae Fossae Formation Mars: Equatorial ice or dry, low-density deposits?, Science, 318, 1125-1128, doi:10.1126/science.1148112.

Werner, S. C., and K. L. Tanaka (2011), Redefinition of the crater-density and absolute-age boundaries for the chronostratigraphic system of Mars, Icarus, 215, 603-607, doi:10.1016/j.icarus.2011.07.024.

Williams, R. M. E., T. C. Chidsey, and D. E. Eby (2007), Exhumed paleochannels in Central Utah-Analogs for raised curvilinear features on Mars, in Central Utah-Diverse Geology of a Dynamic Landscape, edited by G. C. Willis, M. D. Hylland, D. L. Clark, and T. C. Chidsey, pp. 221-235, Utah Geological Association Publication 36, Salt Lake City, Utah.

Williams, R. M. E., R. P. Irwin, J. R. Zimbelman, T. C. Chidsey, and D. E. Eby (2011), Field guide to exhumed paleochannels near Green River, Utah: Terrestrial analogs for sinuous ridges on Mars, in Analogs for Planetary Exploration, vol. 483, edited by W. B. Garry and J. E. Bleacher, Geol. Soc. Amer. Special Paper, Boulder, Colorado, U.S.A., pp. 483-505, doi:10.1130/2011.2483(29).

Williams, R. M. E., R. P. Irwin, D. M. Burr, T. Harrison, and P. McClelland (2013a), Variability in martian sinuous ridge form: Case study of Aeolis Serpens in the Aeolis Dorsa, Mars, and insight from the Mirackina paleoriver, South Australia, Icarus, 225, 308-324, doi:10.1016/j.icarus.2013.03.016.

Williams, R. M. E., et al. (2013b), Martian fluvial conglomerates at Gale crater, Science, 340(6136), 1068-1072, doi:10.1126/science.1237317.

Wilson, S. A., and D. L. Bish (2012), Stability of Mg-sulfate minerals in the presence of smectites: Possible mineralogical controls on $\mathrm{H}_{2} \mathrm{O}$ cycling and biomarker preservation on Mars, Geochim. Cosmochim. Acta, 96 , 120-133, doi:10.1016/j.gca.2012.08.008.

Wray, J. J. (2012), Gale crater: The Mars Science Laboratory/Curiosity Rover Landing Site, Int. J. Astrobiol., doi:10.1017/S1473550412000328.

Zabrusky, K., J. C. Andrews-Hanna, and S. M. Wiseman (2012), Reconstructing the distribution and depositional history of the sedimentary deposits of Arabia Terra, Mars, Icarus, 220, 311-330, doi:10.1016/j.icarus.2012.05.007.

Zimbelman, J. R. (2008), Geologic mapping of the MC-23 NW quadrangle on Mars. U.S. Geol. Surv. Open File Report, 2008 Planetary Geologic Mapping meeting, Flagstaff, AZ.

Zimbelman, J. R., and L. J. Griffin (2010), HiRISE images of yardangs and sinuous ridges in the lower member of the Medusae Fossae Formation, Mars, Icarus, 205, 198-210, doi:10.1016/j.icarus.2009.04.003.

Zimbelman, J. R., and S. P. Scheidt (2012), Hesperian Age for Western Medusae Fossae Formation, Mars, Science, 336, 1683, doi:10.1126/ science. 1221094 